\title{
Comparison of noise reduction results for fit-testing and continuous observations during coal mining for selected earplug and earmuff
}

Mingyu Wu

West Virginia University

Follow this and additional works at: https://researchrepository.wvu.edu/etd

\section{Recommended Citation}

Wu, Mingyu, "Comparison of noise reduction results for fit-testing and continuous observations during coal mining for selected earplug and earmuff" (2010). Graduate Theses, Dissertations, and Problem Reports. 4676.

https://researchrepository.wvu.edu/etd/4676

This Dissertation is protected by copyright and/or related rights. It has been brought to you by the The Research Repository @ WVU with permission from the rights-holder(s). You are free to use this Dissertation in any way that is permitted by the copyright and related rights legislation that applies to your use. For other uses you must obtain permission from the rights-holder(s) directly, unless additional rights are indicated by a Creative Commons license in the record and/ or on the work itself. This Dissertation has been accepted for inclusion in WVU Graduate Theses, Dissertations, and Problem Reports collection by an authorized administrator of The Research Repository @ WVU.

For more information, please contact researchrepository@mail.wvu.edu. 


\author{
By \\ Mingyu Wu \\ Dissertation submitted to the College of Engineering and Mineral Resources \\ at West Virginia University \\ in partial fulfillment of the requirements \\ for the degree of \\ Doctor of Philosophy \\ In \\ Occupational Safety and Health \\ Approved by \\ Steve E. Guffey, PhD, Committee Chairperson \\ Warren R. Myers, PhD \\ Michael Klishis, Ph.D \\ Gerry Hobbs, Ph.D \\ Kevin Michael, Ph.D. \\ Department of Industrial and Management Systems Engineering \\ Morgantown, West Virginia \\ 2010
}

Keywords: Noise reduction, fit testing, coal mining, hearing protector 


\title{
ABSTRACT \\ COMPARISON OF NOISE REDUCTION RESULTS FOR FIT- TESTING AND CONTINUOUS OBSERVATIONS DURING COAL MINING FOR SELECTED EAR PLUG AND EAR MUFF
}

\begin{abstract}
Mingyu Wu
It is not clear how effective hearing protective devices are during actual use, including during coal mining. A proposed solution is individual fit-testing, which is usually done in an office environment. However, it is not clear that fit-testing accurately represents protection while actually working. This research investigates both issues for coal miners for two hearing protectors (E-A-R earplug and Peltor earmuff). It consists of two related studies: lab studies of fit-testing and field studies relating fit-testing at coal mine offices to the actual noise reductions provided for the same coal miners during work.

The effects of several variables on fit-testing results were investigated in the lab studies. First, the necessity of using a reverberatory chamber for fit-testing was investigated by testing the same individuals in both a chamber and an ordinary university laboratory room. The overall A-weighted noise reduction $\left(\mathrm{NRA}_{\mathrm{A}}\right)$ difference was found to be about $1 \mathrm{dBA}$, a modest difference of little practical importance, indicating that an ordinary room can be used as a substitute for a reverberatory chamber for fit- testing. As part of this study, each subject was tested while oriented at 0,180 , and 90 degrees to the noise source. The fit-testing results showed modest effects of orientation to the source on NRA values. Likewise, having each subject do various body movements during testing produced only modest differences from results found while sitting still. Finally, the effect of re-fitting was tested by having each of five subjects remove and then re-don his or her Peltor ${ }^{\mathrm{TM}}$ ear muff or E-A-R ${ }^{\mathrm{TM}}$ earplugs twelve times. The twelve refittings produced NRA variations of 10 to $34 \mathrm{dBA}$, suggesting that the average of multiple fittests may be required to determine a representative value for each individual. Finally, by comparing noise levels measured concurrently the study demonstrated that there were negligible differences due to the use of the dosimeters.
\end{abstract}

For the field study, the investigator fit tested seventeen coal miners in ordinary coal mine offices while they wore either their own cap-mounted muffs or investigatorsupplied E-A-R ear plugs, depending on whether they normally used cap-mounted muffs or earplugs while working prior to the study. The fit-test setup and apparatus was identical to the fit-testing done in the university lab room, with the exceptions that an analyzer and two dosimeters were employed. The fit-testing results showed that the coal 
miners' NRA was highly variable among the twelve different fitting measurements. Most subjects' NRA values varied over a range of more than $10 \mathrm{dBA}$, suggesting that the average of many fit-testings are necessary to adequately represent the NRA for each miner, agreeing with the results of the lab study.

Either earlier or later the same day for the same fit-tested miners, NRA values were determined continuously during full shifts of work using two dosimeters, one measuring at the shoulder and the other measuring proximal to the ear plug or muff. The field study also showed that the minute-by-minute NRA values of the tested coal miners fluctuated widely (ranges $=-15.9$ to $44.6 \mathrm{dBA}$ ) during their tested work shifts. Using observations of HPD use and non-use during each miner's work shift, investigators developed an algorithm to determine whether an HPD was worn during unobserved periods. These determinations made it possible to estimate the total fraction of the work shift and of exposure dose for each worker that were attributable to failure to wear the HPD. The results showed that the percentage of the noise dose measured in the ear attributable to failure to wear the HPD ranged from 0 to $98 \%$ with an average across subjects of $58 \%$. The fraction of minutes in which the HPD were not worn ranged from $0 \%$ to $78 \%$, with an average of $26 \%$ minutes across all subjects. Broken down by HPD type, the comparable figures for dose and time were $60 \%$ and $29 \%$ for the earmuff, and $57 \%$ and $24 \%$ for the earplug.

The correlation between fit-testing and work NRA average values for these miners differed between earplugs and ear muffs. For the earplug, there was a modest linear relationship $\left(\mathrm{R}^{2}=0.53\right)$ between fit-testing and work experience. For the earmuff, a linear relationship was not found when all subject results were included.

In conclusion, failure to wear the HPD was a main cause of the low mean NRA values during work for these subjects. The relationship between the average of twelve fit-tests and the same worker's work NRA would be moderately strong only if a pair of invalid results were arbitrarily omitted and did not show prediction relationship for earmuff. 


\section{ACKNOWLEDGEMENTS}

This research was supported by a National Institute for Occupational Safety and Health (NIOSH) grant (IR010005). I would like to express my sincere appreciation and gratitude to Dr. Steve Guffey for of his enormous talent and great patience. I would like to extend my thanks to Dr. Kevin Michael and Dr. Gerry Hobbs for generously sharing their time and professional knowledge. I also would like to take this opportunity to extend thanks to Dr. Warren Myers and Dr. Michael Klishis for their supportive actions for me and for sharing their technical expertise with me and for serving on my committee. I present my many thanks to Dr. William Dodrill, Raphael Dodrill, Braxton Lewis, and John Engel for their kind assistance and help of establishment of the experiment equipment and facilities, which greatly contributed to the progress of the dissertation work. Tom Stockdale and Brandon Takacs coordinated and escorted me on mine visits and shared mining and safety knowledge, which was also highly appreciated. Lastly and especially, I would express my gratitude to my wife $\mathrm{Yu}$ Tu for her understanding and support of the many long hours that I had spent away from her and our son, Andrew, so that I could achieve my goal. 


\section{TABLE OF CONTENTS}

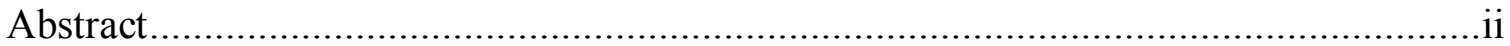

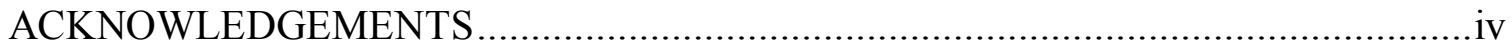

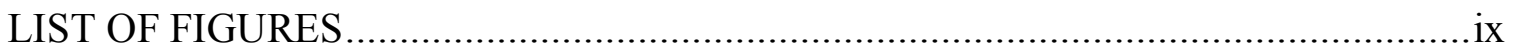

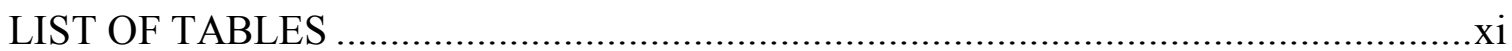

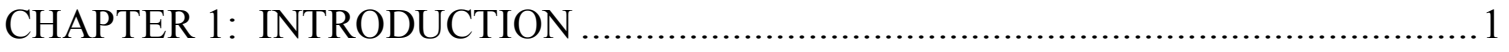

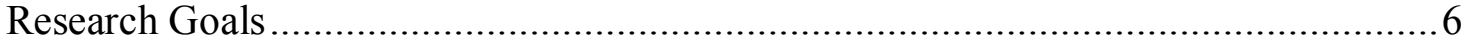

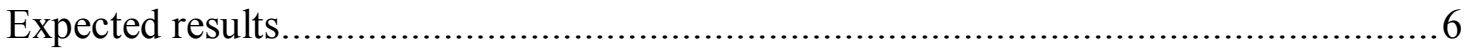

CHAPTER 2: LITERATURE REVIEW ............................................................... 7

2.1. Comparing HPD NRA for fit-testing to NRA for on-job-performance at

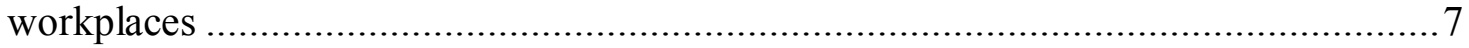

2.2. Determining causes of low NRA during coal miners' work ..............................9

2.3. Can HPD be fit tested in a common office with MIRE? ....................................... 9

2.4. Does refitting affect the HPD NRA? ........................................................... 10

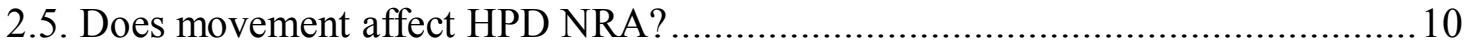

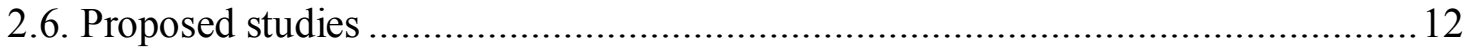

CHAPTER 3: FIRST LAB STUDY: METHOD TO MEASURE NOISE

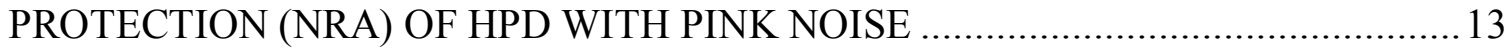

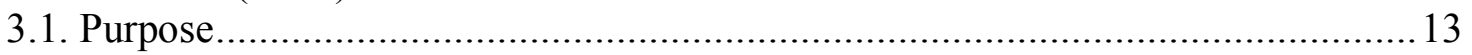

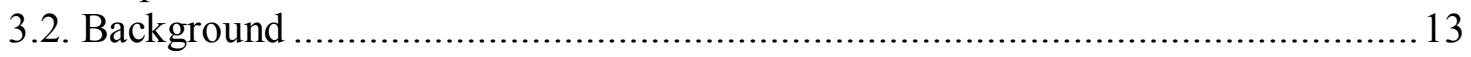

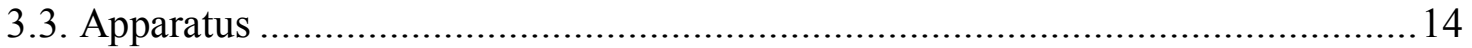

3.3.1. Apparatus for the noise signal generation .............................................. 15

3.3.2. Apparatus: the tested earmuffs and earplugs ........................................... 15

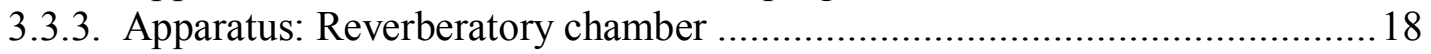

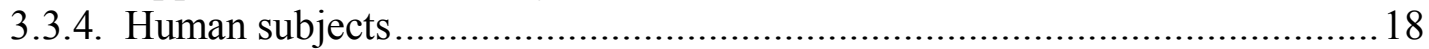

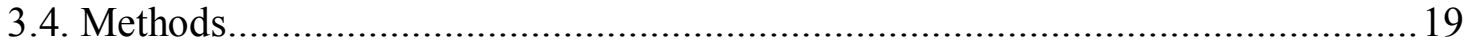

3.4.1 Method for noise level (SPL) sampling ............................................... 19

3.4.2. Methods for achieving NRA and comparing the NRA between pink noise and

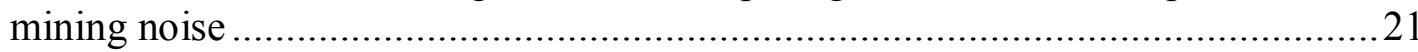

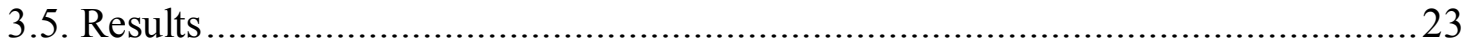

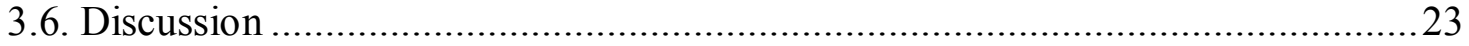

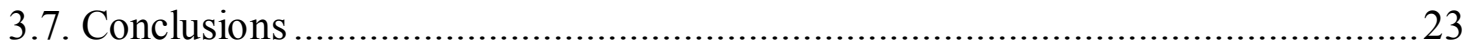

CHAPTER 4: SECOND LAB STUDY: DEVELOP AND VALIDATE A FIT-TESTING

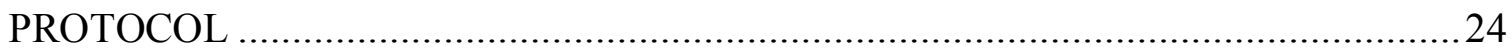

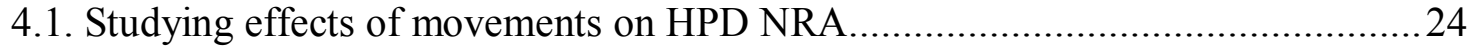

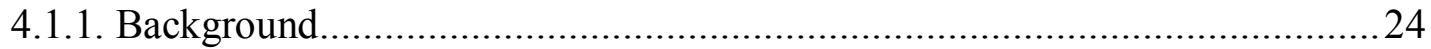

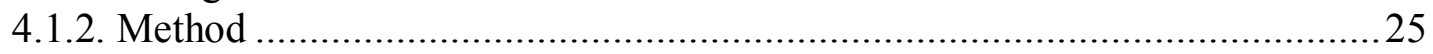

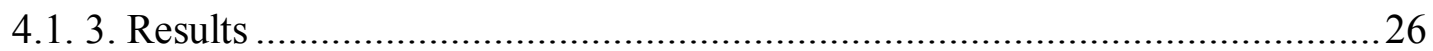

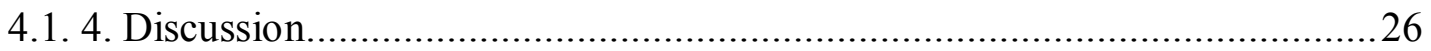

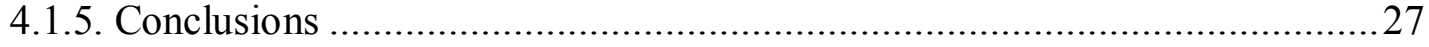

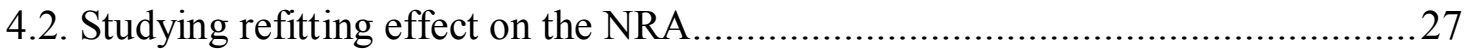

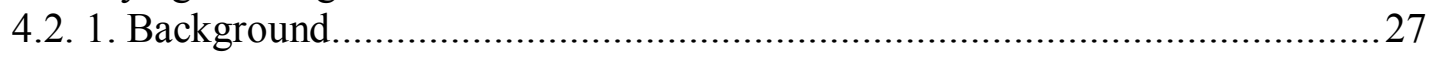

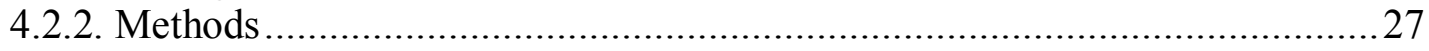




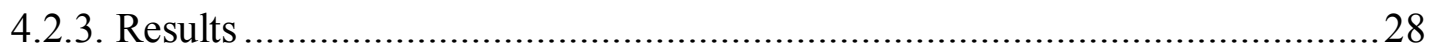

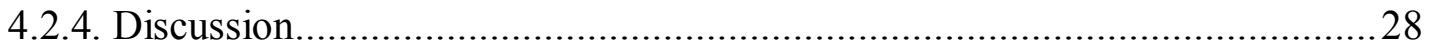

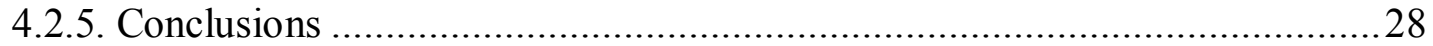

4.3. Studying whether a common office environment can adequately replace

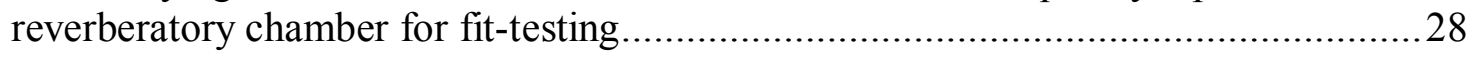

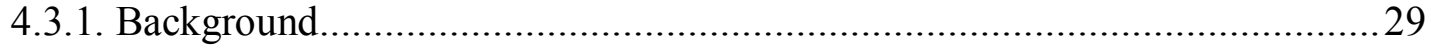

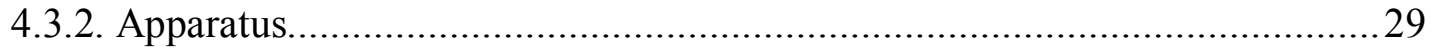

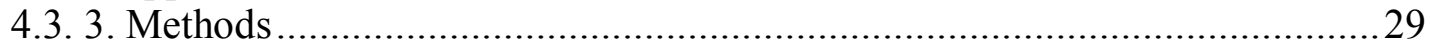

Justifying the 18 " distance for fit-testing in a common office.................................30

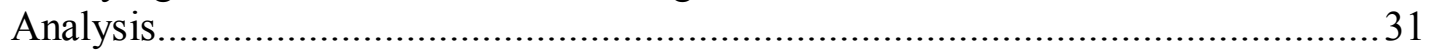

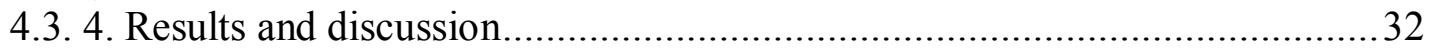

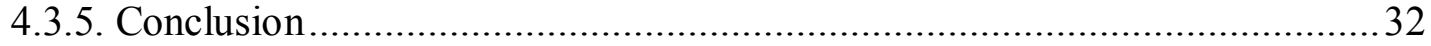

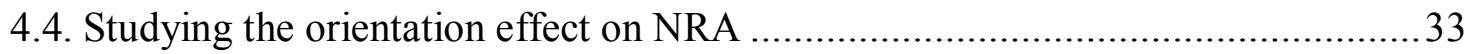

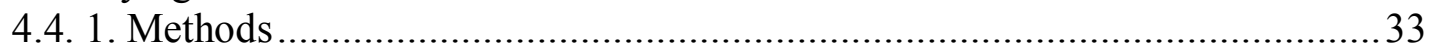

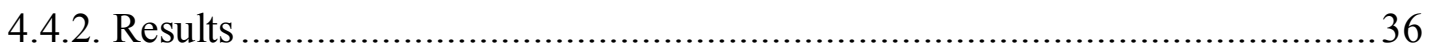

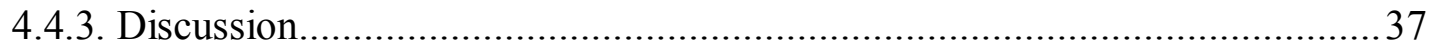

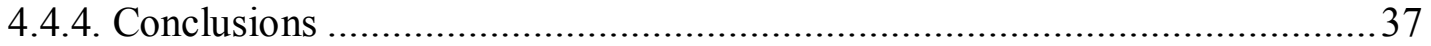

CHAPTER 5: FIT TESTING COAL MINERS IN COAL MINE OFFICES ..................38

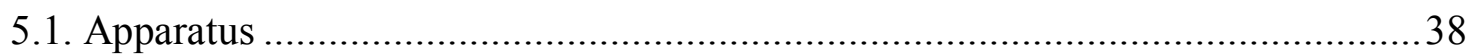

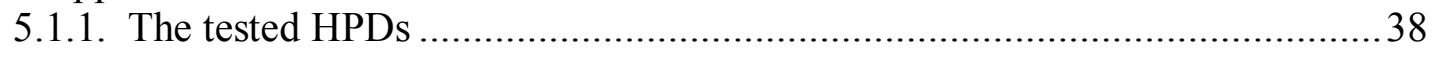

5.1.2 Instrument to generate fit-testing noise signal..................................................

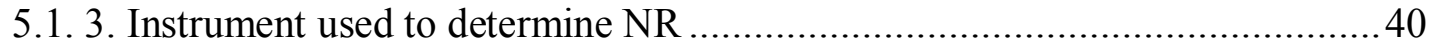

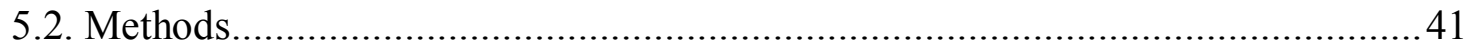

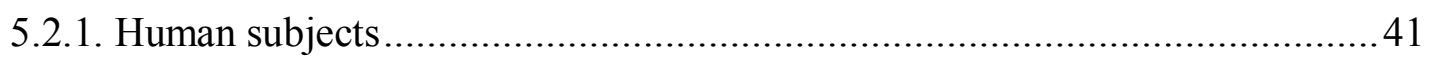

5.2.2. Noise signal chosen for fit-testing ..........................................................4

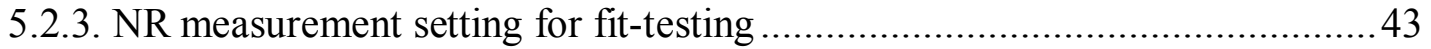

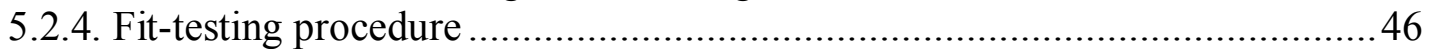

5.3. Noise protection ability of the HPDs and the refitting effect...............................4 47

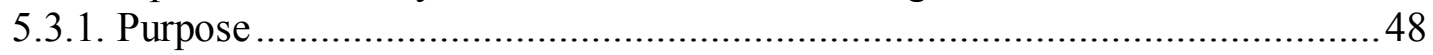

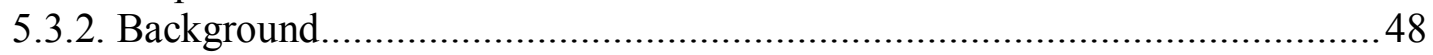

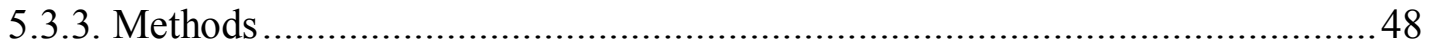

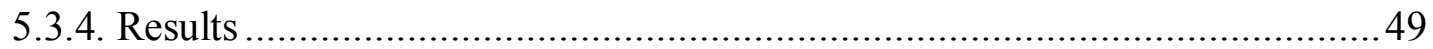

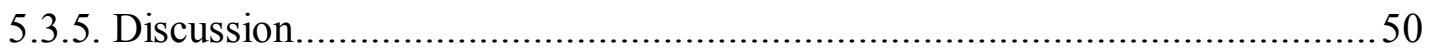

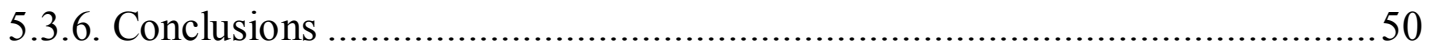

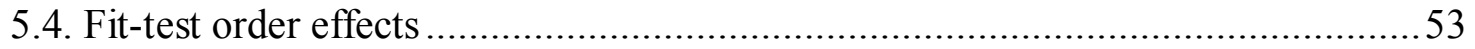

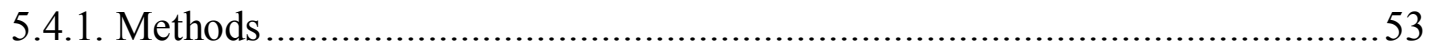

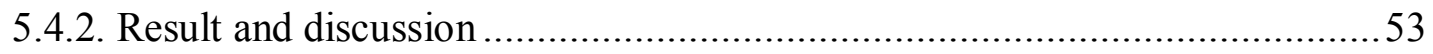

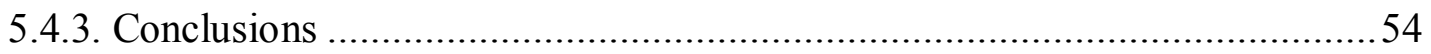

5.5. Orientation effect on the NRA of coal miners' HPDs ..........................................55

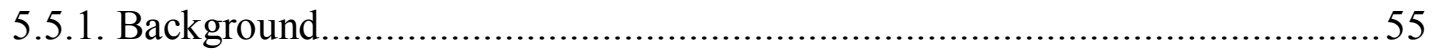

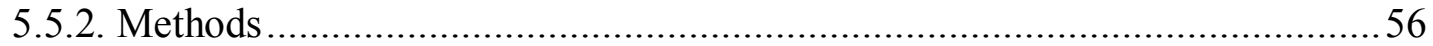

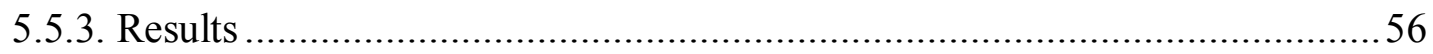

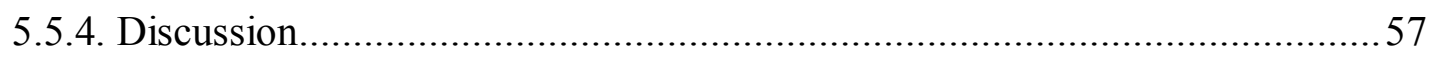

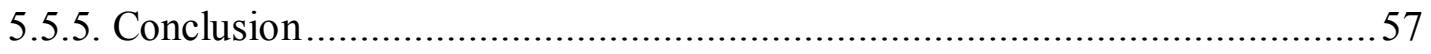

5.6. Frequency-specific NR values....................................................................5

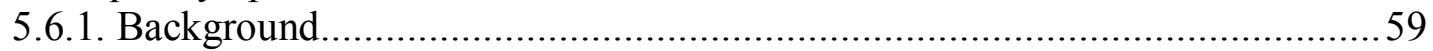




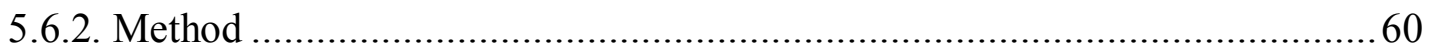

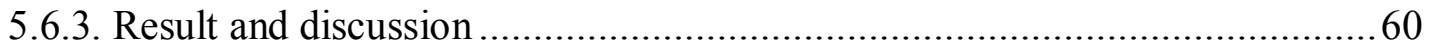

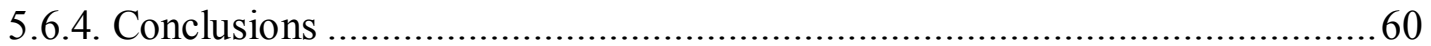

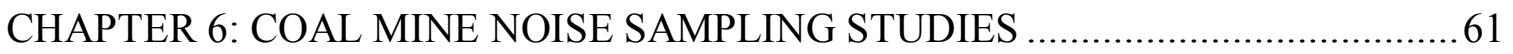

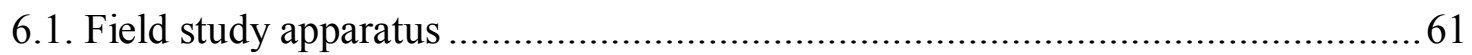

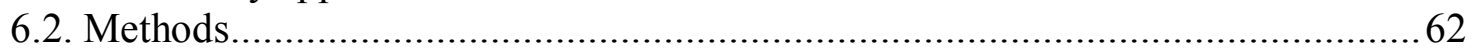

6.3. Comparing observed HPD use and tasks with body movements to observed NRA

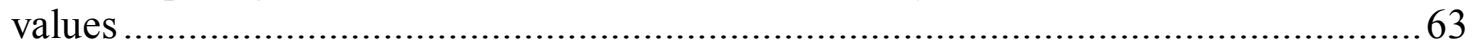

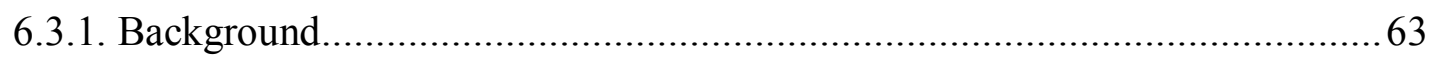

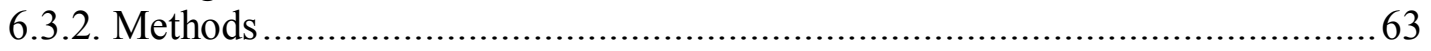

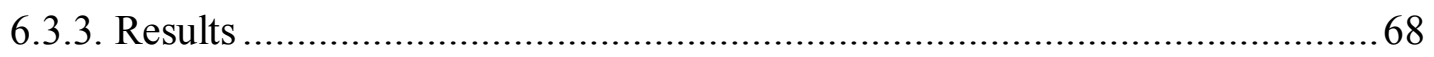

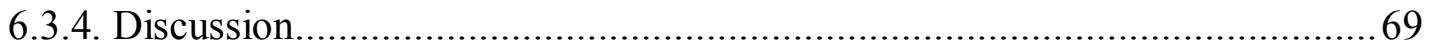

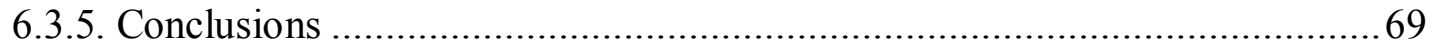

6.4. Estimating HPD use (i.e., wearing or non-wearing) during non-observed periods

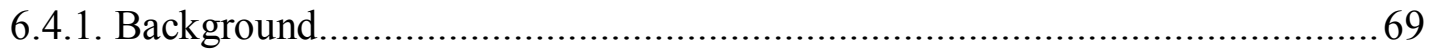

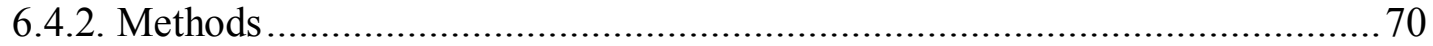

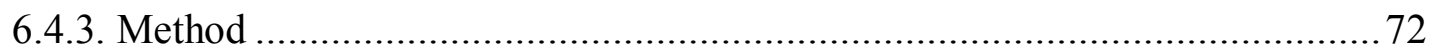

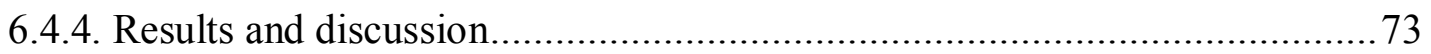

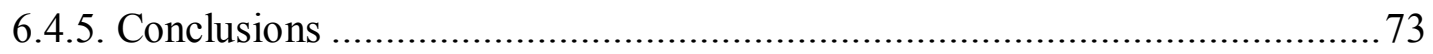

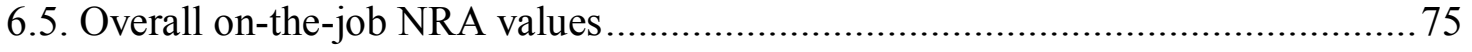

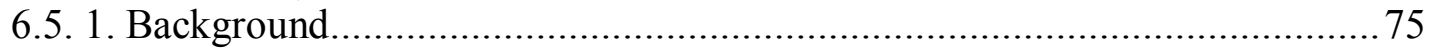

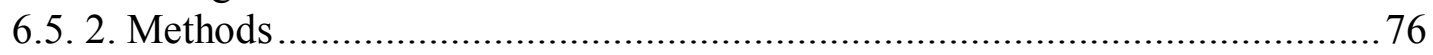

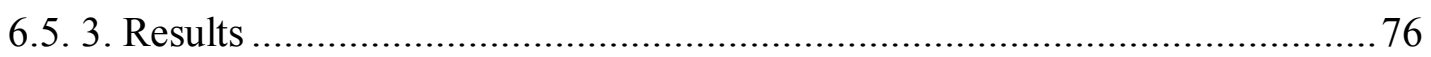

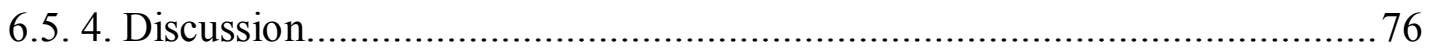

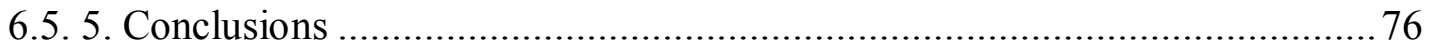

6.6. Determining relationships between the ambient noise level and the miner's HPD use and determining the difference of fraction of time not worn between the earplugs

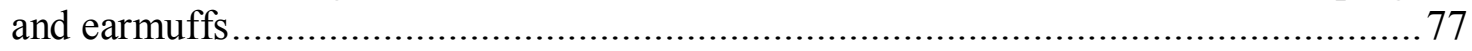

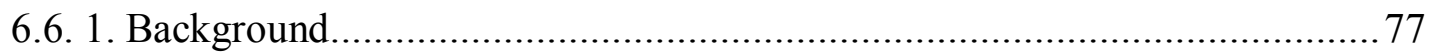

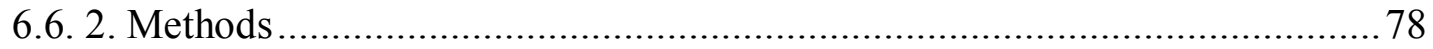

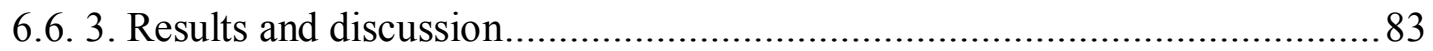

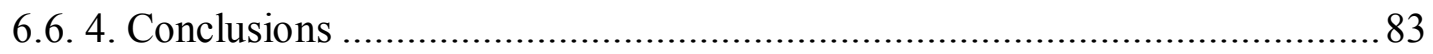

6.7. Coal miners' ambient (unprotected) noise dose and ear (protected) noise dose ....83

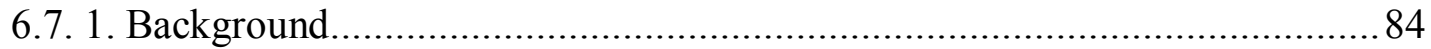

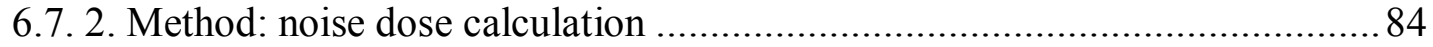

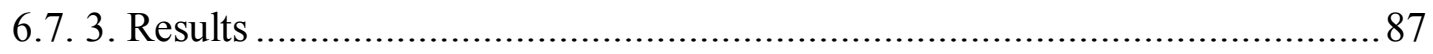

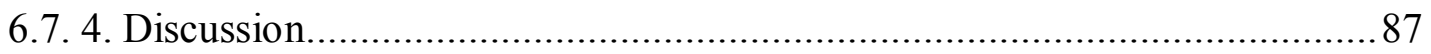

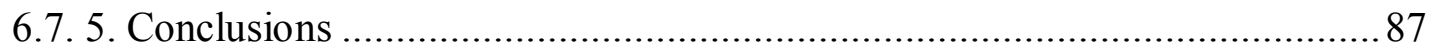

CHAPTER 7: COMPARING HPD NRA FOR FIT-TEST TO COAL MINING WORK88

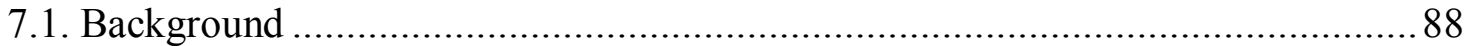

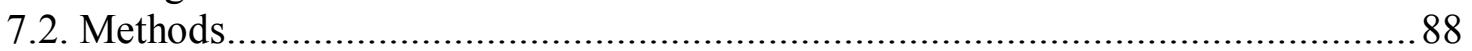

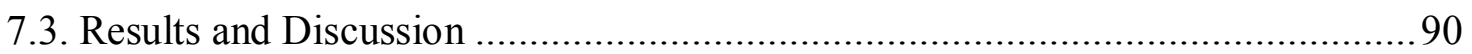

7.3.1. Earmuff prediction relationship between average of multiple fit-tests and work NRA average 
7.3.2. Earplug predictive relationship between NRA for the average of multiple fittests and work

7.3.3. Result and discussion: HPD (earplug and earmuff combined) prediction relationship between the average of multiple fit-tests and work NRA.

7.3.4. Result and discussion: comparing NRA variability for multiple fit-tests to work .92

7.3.5. Result and discussion: HPD (i.e., earplugs and earmuffs) prediction relationship between $1^{\text {st }}$ fit-test and work conditions ......

7.4. Conclusions

BIBLIOGRAPHY .94 


\section{LIST OF FIGURES}

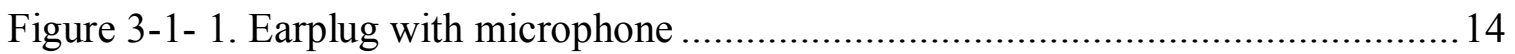

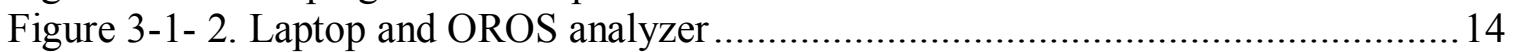

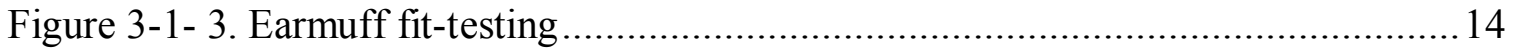

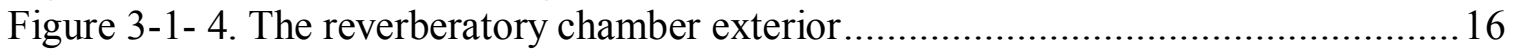

Figure 3-1 - 5. The reverberatory chamber interior .................................................... 16

Figure 3-1-6. NRA value calculation when underground noise spectrum was applied

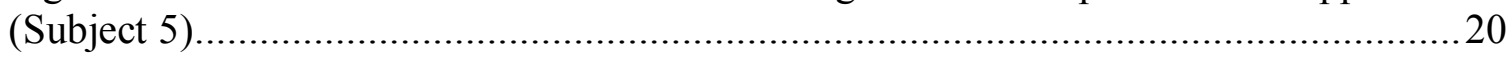

Figure 3-1- 7. NRA value calculation when drilling noise spectrum was applied (Subject

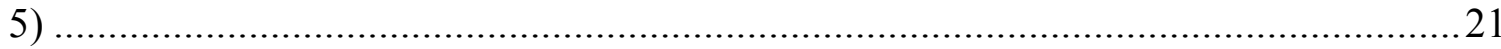

Figure 4-2- 1. Refitting effect on the HPD NRA …............................27

Figure 4-3- 1. Earplug NRA comparison for the chamber and the Lab $246 \ldots \ldots \ldots \ldots \ldots \ldots . . . .31$

Figure 4-3- 2. NRA comparison of earmuff for the chamber and ................................. 32

Figure 4-4- 1. Earmuff mean NR (dB) comparison at every frequency between chamber

Figure 4-4- 2. Earplug NR (dB) mean comparison at every frequency between chamber

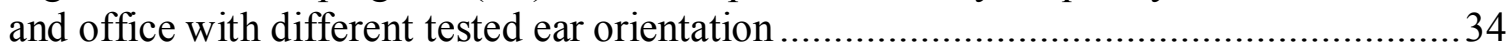

Figure 5-1- 1. Laptop, amplifier and speaker.................................... 38

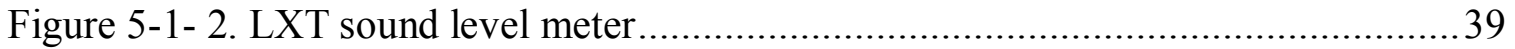

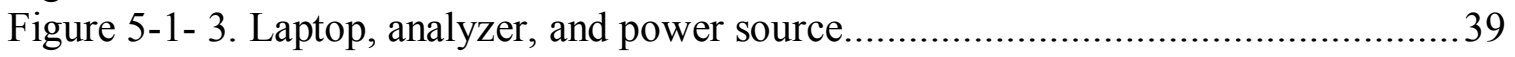

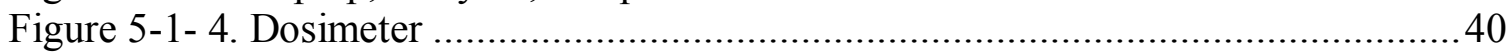

Figure $5-2-1$. Earmuff fit-testing ............................................... 41

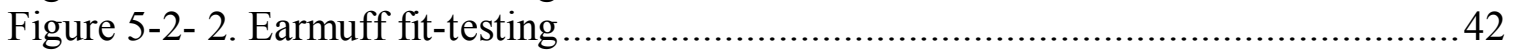

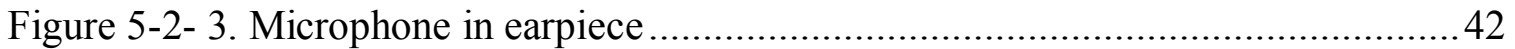

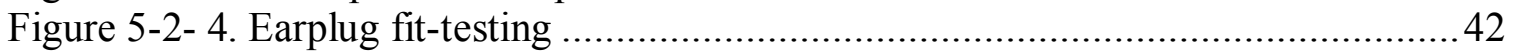

Figure 5-2- 5. Dosimeter stability testing: sampling time duration vs. NRA and SPLA

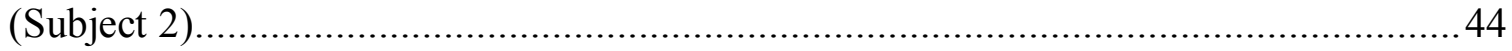

Figure 5-3- 1. The HPD NRA for each individual with all measurements and orientations

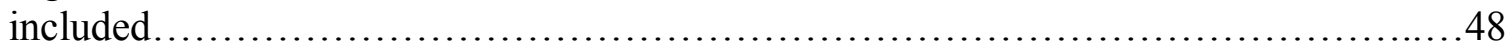

Figure 5-4- 1. a-k individual subject results for $90^{\circ}$ orientation for E-A-R earplug fit-

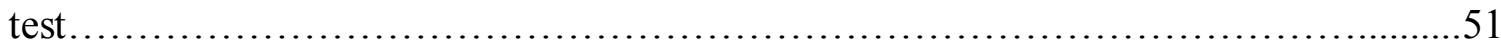

Figure 5-4- 2. 1-q individual subject results for 90 orientation for Peltor earmuff fit-test..

Figure 5-5-1. NRA comparison of earplug among different orientations................5

Figure 5-5- 2. NRA comparison of earmuff among different orientations .....................54

Figure 5-6- 1. Frequency-specific NR of the earmuff averaged over all orientations in the

fit-testing at the coal mine office...............................................57

Figure 5-6- 2. Frequency-specific NR of the earplug averaged over all orientations in the

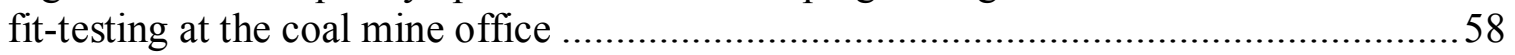

Figure 6-1- 1. Noise sampling with two dosimeters............................. 62

Figure 6-3-1. Observed NRA vs. time for Subject 1 with HPD off during normal

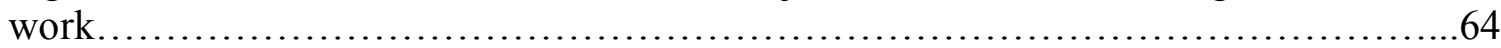

Figure 6-3-2. Observed NRA vs. time for Subject 13 with HPD on during normal work 
Figure 6-4- 1. HPD wearing status for observed periods for Subject $15 \ldots \ldots \ldots \ldots \ldots \ldots . . \ldots 70$

Figure 6-4- 2. Compare "judged" with observed use of HPD during work...............73

Figure 6-5- 1. On-the-job NRA (dBA) mean for each subject throughout sampling time during work excluding data when $\mathrm{SPL}_{\text {ambient }}<80 \mathrm{dBA}$ or subject judged not wearing HPD

Figure 6-6- 1. HPD usage results for Subject 6: ambient noise SPL vs. HPD...............77

Figure 6-6- 2. a-f. Individual miner's earmuff usage results: ambient noise SPL vs. HPD

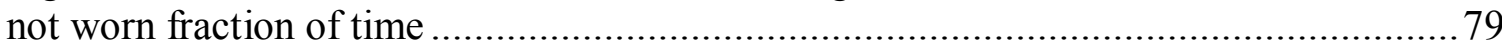

Figure 6-6- 3. g-q. Individual miner's earplug usage results: ambient noise SPL vs. HPD

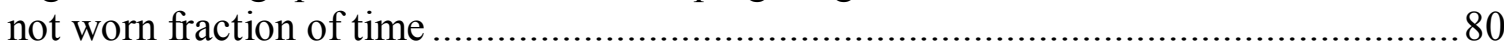

Figure 6-7- 1. Projected ( 8 Hrs) ambient noise \% dose and in-ear noise \% dose for each

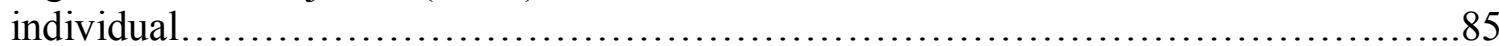

Figure 7-1 - 1. Compare earmuff NRA for multiple fit-tests and work .................89

Figure 7-1- 2. Compare earplug NRA for multiple fit-tests and work ..................89

Figure 7-1- 3. Compare HPD (earmuff and earplug combined) NRA for multiple fit-tests

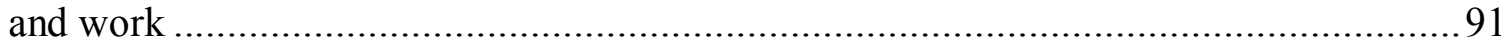

Figure 7-1- 4. Compare earmuff NRA for $1^{\text {st }}$ fit-test and work ..........................93

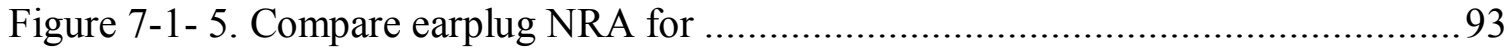




\section{LIST OF TABLES}

Table 3-1- 1. Sound field directionality, maximum differences ( $\Delta \mathrm{Max})$, data are in $\mathrm{dB}$,

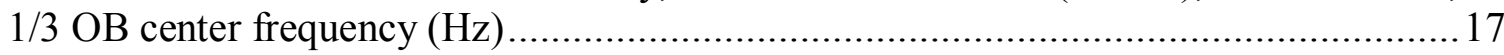

Table 3-1-2. Sound field uniformity, maximum differences ( $\Delta$ Max). Data are in $\mathrm{dB}, 1 / 3$

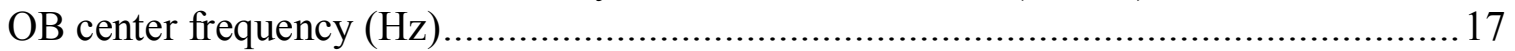

Table 4-1-1. Assigned movement activity list....................................24

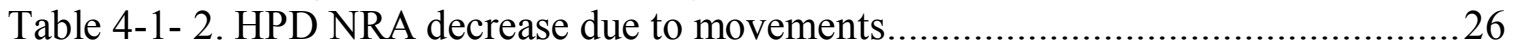

Table 4-2-1. HPD NRA mean and SD for refitting effect study........................28

Table 4-3-1. NRA comparison of the HPDs for reverberatory chamber and the Lab 246 with different tested ear orientation................................................. 32

Table 4-4- 1. ANOVA of orientation and subject effect on NRA of the E-A-R earplug..........................................................................

Table 4-4- 2. ANOVA of orientation and subject effect on NRA of the Peltor earmuff ..33 Table 4-4- 3. Earplugs NR (dB) mean comparison at every frequency between chamber and office with different tested ear orientation

Table 4-4- 4. Earmuff NR (dB) mean comparison at every frequency between chamber and office with different tested ear orientation ....................................................... 36

Table 5-2-1. Dosimeter stability testing (Subject 2 )............................44

Table 5-2-2. Dosimeter stability testing: sampling time duration vs. NRA and SPLA (Subject 2)

Table 5-2- 3. Fit-testing measurement order for the analyzer ................................... 45

Table 5-2- 4. Fit-testing measurement order when using the two dosimeters .................46

Table 5-3-1. The HPD NRA for each individual averaged across all measurements and orientations from fit-testing...................................................49

Table 5-3-2. HPD NRA averaged across all measurements and orientations from fittesting

Table 5-5- 1. NRA value for both HPDs among all three orientations with the same fitting

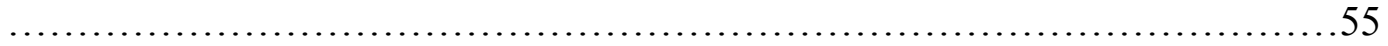

Table 5-5-2. ANOVA of orientation and subject effect on NRA of the E-A-R earplug ...55

Table 5-5- 3. ANOVA of orientation and subject effect on NRA of the Peltor earmuff .. 55 Table 5-6- 1. Frequency-specific NR of the HPDs averaged by all orientations in the fit-

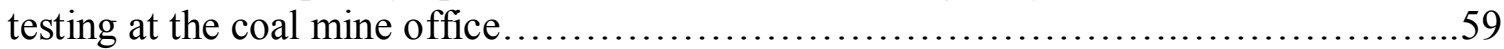
Table 6-3-1. Observed NRA vs. time for Subject 1 with HPD off during normal work..65 Table 6-3-2. Observed NRA vs. time for Subject 13 with HPD on during normal work .................................................................65

Table 6-3 - 3. The effect of task with movements (tramming vs. drilling \& bolting) on the

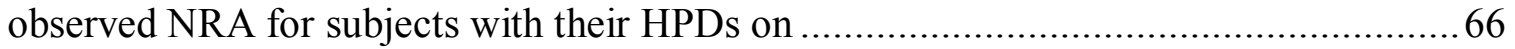

Table 6-3- 4. Observed individual coal miner's task(s) vs. the observed NRA ..............67

Table 6-4- 1. Judgment method example of the HPD wearing status for................71

Table 6-5- 1. On-the-job NRA (dBA) mean for each subject throughout sampling time during work excluding data when $\mathrm{SPL}_{\text {ambient }}<80 \mathrm{dBA}$ or subject judged not wearing HPD....................................................................... 75 
Table 6-6- 1. Individual miner's HPD usage results: ambient noise SPL vs. HPD not

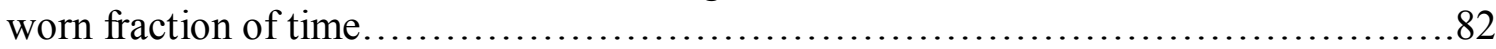

Table 6-7- 1. Noise dose sampling from each individual miner........................86

Table 7-1 - 1. Compare HPD NRA for fit-test and work on each subject.................89

Table 7-1-2. HPD regression analysis between multiple fit-tests and work................90 


\section{CHAPTER 1: INTRODUCTION}

High noise levels are very common in coal mines. Long-term exposure to high noise levels can induce hearing loss (NIHL). According to Franks and Stephenson (1996a), NIHL is an irreversible occupational injury and is the most common occupational disease in the United States today. Despite decades of Mine Safety and Health Administration (MSHA) enforcement of noise reductions and hearing conservation, miners are still losing hearing. The problem is severe in all areas of mining, including surface, preparation plants and underground. Seventy percent to ninety percent of all miners have NIHL great enough to be classified as a hearing disability. By the age of 50, approximately $90 \%$ of the miners had a hearing impairment due to the noise exposure (Franks, 1996b).

Great emphasis has been placed on miner noise exposure protection (Durkt, 1993). To protect people from excessive noise exposure, MSHA (1999) requires that the permissible noise exposure not exceed $90 \mathrm{dBA}$ time-weighted average ( $8 \mathrm{hr}$-TWA) for an 8 -hour period with a $5 \mathrm{~dB}$ exchange rate, and an action limit (AL) of $85 \mathrm{dBA} 8 \mathrm{hr}$-TWA. Exceeding the latter requires hearing tests, training, and in many cases, hearing protection.

Engineering control (EC) and hearing protector devices (HPD) are the two main solutions employed in protecting coal miners from NIHL. Engineering controls are permanent measures to control noise (Berger, 1993b). MSHA requires that engineering control be implemented, if feasible, when noise levels are above $90 \mathrm{dBA}$. However, EC is expensive and reductions in noise levels have been slow in coming. It is not always feasible to reduce the noise below $90 \mathrm{dBA}$. HPD is obviously easier to implement and less expensive than EC in many circumstances (Berger, 1993b). Consequently, in many cases coal mine operators largely rely on HPD to protect miners from noise exposures.

There are two types of HPDs. One type is earplugs, which are either inserted in the ear canal or placed against the entrance to the ear canal to block noise. Earplugs are made from materials, such as slow-recovery closed-cell foam, vinyl, silicone, or spun fiberglass. Earplugs also may be constructed from foam. They may be pre-molded, formable, custom molded, or semi-insert. The other common types of HPD are earmuffs, which fit over the ear to provide an acoustic seal against the head, or encase the entire head (Berger, $2000 \mathrm{c}$ ). Earmuffs can be a separate device in which the muffs are clamped against the ears by spring-like bands worn over the head. For workers, like miners, who must wear hard hats, muffs typically are mounted to each side of the helmet. In coal mines the low profile Peltor earmuffs are often used. Earplugs, such as E-A-R, are also commonly used in coal mines. 
The coal mining industry is heavily reliant on HPD to prevent and reduce NIHL (Frank, Bise, \& Michael, 2003). HPD, if worn correctly, may be able to provide adequate noise exposure protection and are assumed to be an effective way to protect coal miners against NIHL. Nevertheless, hearing loss is still severe in coal mining industry despite MSHA's mandates that miners' hearing be protected when 8-hr TWA exposure exceeds $85 \mathrm{dBA}$. Many speculate that HPDs fail to adequately protect because miners fail to wear them often enough when noise levels are excessive. However, this theory has not been demonstrated experimentally.

Basically, there are two approaches to describing the effectiveness of a HPD: noise insertion loss (IL) and noise reduction (NR). IL is the difference between the sound pressure levels (SPLs) measured proximate to the HPD with and without the HPD, as given by the formula:

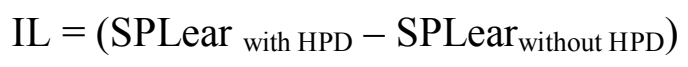

$\mathrm{NR}$ is the difference between the ambient noise level and the noise level proximate to the HPD when the protector is worn, as given by the formula:

$$
\mathrm{NR}=\left(\mathrm{SPL}_{\mathrm{ambient}}-\mathrm{SPLear}_{\mathrm{with} \mathrm{HPD}}\right)
$$

As Berger (2005) stated, IL is a more direct measure of HPD effectiveness, but NR has the advantage that it can be used to measure attenuation for time-varying signals by recording SPLs from two microphones simultaneously. IL is not practical for field work because the noise level may not be constant before and after the HPD attenuation. IL method is more likely to be employed in a laboratory where the acoustic environment can be well-controlled. NR can be performed both in a laboratory and in an industrial environment.

As Berger (1986c) stated, the relationship between IL and NR is:

$$
\mathrm{IL}=\mathrm{NR}+\mathrm{TFOE}
$$

Where TFOE is the transfer function of the open ear (i.e., the amplification relative to the undisturbed sound field caused by ear canal and pinna resonances), which depends on the frequency, ear, and subject (Casali, Mauney, \& Burks, 1995). For these reasons, Neitzel, Somers, and Seixas (2006) indicated that people usually determine the NR of HPD to predict noise protection in the field, although it provides lower values than IL.

There are two primary techniques available for measuring the HPD noise attenuation (e.g., IL and NR) in the field for individual workers: Real-Ear-at-Threshold (REAT) and 
Microphone-in-Real-Ear (MIRE) (Casali et al., 1995; Berger, Franks, \& Lindgren, 1996). REAT has been recognized as a "gold standard" when measuring the noise attenuation of a HPD, against which other HPD measurement methods are compared to determine their accuracy. In REAT one measure subject's hearing threshold without wearing a HPD, and then re-measure the subject's hearing threshold level while wearing HPD. The difference between these two thresholds is the noise attenuation ability of the HPD, which is actually an insertion loss measurement (Berger, 1986c). Berger \& Kerivan (1983) proved that REAT measurements tend to over-predict attenuation of HPD at low frequencies due to physiological masking. Nevertheless, it is still the most accurate way to measure noise attenuation of HPD because it considers all the pathways by which sound can reach inner ear (Berger, 2005; Berger, 1986c).

However, REAT is mainly used in laboratories due to its high cost in individual fittesting. When doing REAT measurement, the subject needs to sit in a very quiet environment to track her/his threshold. Industrial environments are often noisy, making it very hard to meet REAT test requirements without using an expensive audiometric test booth. As the American National Standards Institute (ANSI, 1974) requires, MIRE should be carried out in a reverberation chamber. Furthermore, REAT is time-consuming. Usually it takes about 20 minutes to finish measuring HPD for one subject (Mauney, 1993), which is a high requirement for a test performed for many workers.

MIRE is considered to be quick and economical yet accurate enough to replace REAT in measurement of noise attenuation of HPD in the field. It is an objective and physical measurement on a human subject. A microphone is placed either on the entrance of ear canal (for earmuff measurement) or in the ear canal (for earplug). Hearing conservation professionals and researchers can employ either IL (using one microphone) or NR (using two microphones) measurement method to determine the noise attenuation of HPDs (Neitzel. et al., 2006; Berger, 2005). Casali et al. (1995) showed that MIRE can predict noise attenuation at low frequencies better than REAT because there is no occluded effect from the hearing protector. However, MIRE does not measure all of the sound pathways to the ear in the same way as does REAT, because it misses the boneconduction pathways that bypass the HPD. The response of ears to an incoming sound may be through vibration of the eardrum or by direct excitation of the inner ear through bone conduction. Consequently, MIRE exaggerates noise attenuations above $1000 \mathrm{~Hz}$. (Casali et al., 1995; Berger, 2005; Berger, 2000 c). Despite the disadvantages, MIRE is a still an acceptably accurate method and has equal or less variability than REAT (Casali et al., 1995; Berger et al., 1983; Berger et al., 1996). MIRE also is straightforward and much easier for people to learn. The sound pressure level (SPL) of every frequency is obtained at one time with microphone(s) for noise IL and NR calculation. In addition, the measurement can be completed within a very short period of time. Furthermore, MIRE does not require a quiet environment like the sound proof chamber needed for REAT, 
which makes it economical and easy to be performed in an industrial environment. In summary, MIRE is a fast, economic and accurate enough way to measure the noise protection of a HPD in the field.

It is necessary to determine HPD effectiveness because they can fail to adequately protect. Even when HPD is worn sound still can enter the ear. Berger (1980 c) stated that there are four distinct pathways for sound transmission to the occluded ear. They include air leaks, vibration of the HPD, transmission, and bone conduction. To obtain adequate protection the wearer must make a nearly air tight seal with the canal (earplug) or the side of the head (earmuff). Otherwise, the sound can leak into the ear. Due to the flexibility of the ear canal flesh, earplugs can move or vibrate in a piston-like manner within the ear canal. Likewise an earmuff cannot be attached to the head in a totally rigid manner. Its cup will vibrate against the head as a mass/spring system. Vibration limits the low frequency attenuation of HPD. Sound transmission through the cup material and the earmuff cushion can be significant in some earmuffs, but usually it is not important to earplugs. However, for both muffs and plugs bone conduction can be a significant factor at extremely high noise levels.

All HPDs sold in the United States are required by law (EPA, 1979) to have their packages labeled with a noise reduction rating (NRR) value, which is the estimated noise attenuation in dBA provided to the person wearing it by the HPD. Enforcing the Hearing Conservation Amendment to the Occupational Noise Standard (OSHA, 1983) requires OSHA inspectors to evaluate the effectiveness of hearing protectors supplied to exposed employees by their employers. OSHA inspectors assume that the protector supplies only one-half of the NRR value.

There is no method prescribed in the MSHA noise regulations to evaluate whether a HPD can provide a coal miner sufficient protection from noise exposure. However, it is a common practice to employ NRR with the OSHA "derating" to determine whether a miner's noise exposure level will be sufficiently reduced by the HPD. This practice arises from the perception that the NRR value overestimates the real world performance of HPDs. The over-estimation may arise from the methodology used when experimentally determining NRR values. The experimenter ensures a good fit for each subject's ear. Furthermore, the test period is very short. In short, the noise attenuation of a HPD is thus achieved in an unrealistic, “optimized manner" (Berger, 1993b).

As the last one of defense line reducing noise hazards, HPDs may fit some coal miners well and provide adequate noise protection, but they may provide inadequate protection to others. Attenuation is highly dependent on individual-specific HPD fit (Berger, 1980c). It is impossible to predict individual coal miner's performance in the field from group data measured in the laboratory (e.g. NRR method) due to the variability in the fit and performance users achieve in the field (Berger, 2007a). 
Many of the issues in testing the effectiveness of ear protectors have been important to fit-testing respiratory protectors. Respirator fit-tests are required by OSHA before workers are allowed to wear their respirators in contaminated environments. The intent is to ensure that the respirator provides at least a sufficient degree of protection and that the wearer has the opportunity to learn how it feels when the respirator fits well enough to provide good protection (Weber and Mullins 2000).

Likewise, an individual fit-testing should be conducted for a HPD when it is initially dispensed and before a worker is allowed to use it in noisy work environments. If it is unwise to rely on the published NRR value (Berger, 2007; Neitzel and Seixas, 2005; Neitzel et al., 2006), a more effective test is needed. As a result, much research explored potentially valid fit-testing methods suitable for use in the field.

Currently, there are two main commercial devices available that are capable of testing personal HPD fitting. One employees the field microphone in real ear (F-MIRE) approach developed by Voix and Laville (2004). It contains a single small two-element microphone and associated proprietary technology. One of the microphones is coupled through the earplug to measure the sound pressure levels in the ear canal, and the other microphone measures the ambient sound pressure level. The noise reduction obtained from the two microphones is corrected to estimate the IL of a HPD for the particular individual. F-MIRE is intended to be tested in a common office, and it allegedly provides an accurate measurement of both earmuffs and earplugs.

FitCheck (Michael and Associates, State College, PA) is another device available for fit-testing. The FitCheck system makes computer-controlled measurements of subjects' hearing thresholds in up to eight 1/3-octave noise bands. It uses loudspeakers mounted in circumaural ear-cups to send out test signal, under both occluded (earplug inserted) and unoccluded (no earplug inserted) conditions, and determines attenuation by calculating the difference between the two thresholds. FitCheck system actually utilizes the RealEar-Attenuation-Threshold (REAT) measurement method. Thresholds are tested at the following 1/3-octave center frequencies: $125 \mathrm{~Hz}, 250 \mathrm{~Hz}, 500 \mathrm{~Hz}, 1000 \mathrm{~Hz}, 2000 \mathrm{~Hz}$, $4000 \mathrm{~Hz}$, and $6300 \mathrm{~Hz}, 8000 \mathrm{~Hz}$ (Neitzel et al., 2006). Fit-Check is portable and can be used to do the fit-testing in field, but only for earplugs.

However, there is no published study available to prove whether an individual fittesting is able to accurately predict a worker's HPD effectiveness during his/her actual work. In addition, it is often speculated that many workers (including coal miners) do not wear HPD even when they are required to do so. Failing to wear HPDs in coal mines is commonly considered to be one of the main reasons why miners are losing their hearing (McBride, 2004). However, this "common knowledge" is not yet proved by any experimental data from any field study. 


\section{Research Goals}

This dissertation research consists of two primary parts: lab studies and field studies. Firstly, a fit-testing protocol was developed and validated in the lab studies. Secondly, the investigator fit tested some coal miners' HPD using the protocol developed from the lab studies in coal mine offices, and compared the NRA for the fit-testing to continuously recorded NRA values during normal coal mining work. Specifically, the goals of the research were to:

(1) Determine whether a reverberatory chamber is necessary for accurate fittests.

(2) Develop a fit-testing protocol for use in a common office environment including determining the conditions in the lab that produced reduced NRA values.

(3) Fit test coal miners' HPD in a common coal mine office with the fittesting protocol developed.

(4) Determine on-the-job NRA values for coal miners during normal work

(5) Determine whether the fit-testing NRA was able to predict actual NRA during normal work of coal miners

(6) Determine the fraction of noise dose that is due to failure of the miner the protector.

\section{Expected results}

It was assumed that in the lab study that the NRA of each fit-tested HPD will be approximately the same whether done in a common office or the reverberatory chamber. In addition, it was expected that the NRA values of HPD would be affected by the subjects' movement activities, fitting, etc.

In the field studies at coal mines, it was expected that $\mathrm{NR}_{A}$ of coal miners from fittesting will be approximately the same as that measured during periods when the same HPD is worn properly during work. 


\section{CHAPTER 2: LITERATURE REVIEW}

The literature reviewed for this study included articles comparing HPD NRA for fittesting to NRA for on-job-performance at workplaces, studies that determined causes of low NRA during coal miners' work, and studies investigating the adequacy to fit test HPD in a common office with MIRE, refitting effect, and movement effect on HPD NRA.

\subsection{Comparing HPD NRA for fit-testing to $\mathrm{NR}_{A}$ for on-job-performance at workplaces}

Chung, Hardie, and Gannon (1983b) studied the performance of earmuffs in actual working environments using two modified dosimeters (Quest M-8). Each was connected to a 0.25 -inch microphone, with one microphone inside and the other outside the earmuff. Jobs varied from stationary to very mobile. Subjects fitted themselves with their own earmuffs, regardless of the condition of the earmuffs. A total of 101 worker-subjects from various industries, including lumber, canning, printing, steel fabrication, and wire rope industries, participated in this study. Seventeen types of earmuffs, including cap-mounted and over-the-head, were tested. Depending on the level of noise, the sampling period varied from 5 to 10 minutes. The average attenuation of the 101 earmuffs was $20.3 \mathrm{dBA}$, ranging from 2.5 to $37.3 \mathrm{dBA}$ with a standard deviation (SD) of $6.5 \mathrm{dBA}$. The author concluded that earmuffs are a potentially adequate method of protection against NIHL.

Using alike methods, Durkt (1993) evaluated the effectiveness of ten types of overthe-head and one type of behind-the-head earmuffs. Mine employees performed normal work duties for approximately 40 minutes, mainly in surface mines. The NRA of the earmuffs was determined using two FM-wireless transmitting and receiving systems. One system measured the ambient noise level; the second system measured the noise level inside a muff. The noise level data for both systems was transmitted back to the corresponding receivers and was recorded onto a two-channel tape recorder. All tape recordings were analyzed by two one-channel real-time-analyzers (RTA) for $1 / 3^{\text {rd }}$ octave band frequency analysis as well as the overall $\mathrm{dBA}$. A total of 107 individual tests were conducted to obtain the NRA across frequencies and the difference between inside and outside dBA levels. The overall A-weighted difference was the measured NRA value. The results indicated that the observed averaged NRAs varied from 12.3 to $18.1 \mathrm{dBA}$ among these earmuffs, with a SD varying from 5.4 to $9.2 \mathrm{dBA}$ within each earmuff. The average noise protection of all the earmuffs was $14.7 \mathrm{dBA}$, with a high variability $(\mathrm{SD}=$ 7.3 dBA) between muffs.

Giardino and Durkt (1996) performed studies evaluating muff-type HPDs in similar mining environments with similar instrumentation and analysis techniques. A total of 23 different models of HPDs and 54 different noise sources (20 different machine types) 
were evaluated in the study for a total of 1265 separate HPD evaluations. Their results were similar to that of Durkt (1993). Across all noise sources and all HPD models they found that $50 \%$ of the workers had an observed NRA of $16 \mathrm{dBA}$ or less, about $20 \%$ of the workers had an observed NRA of $10 \mathrm{dBA}$ or less, and $5 \%$ of the workers had an observed NRA of $5 \mathrm{dBA}$ or less.

The Exposure Smart Protector (ESP) TM (ESP) was developed by doseBusters USA (College Park, Pennsylvania) for monitoring ear noise level proximate to HPD in workers' normal work activities. The apparatus integrate a personal noise dosimeter with traditional hearing protection. The method includes two microphones monitoring protected (under HPD) and unprotected wearing positions (ambient) for the ESP. When worn, the ESP measures and documents a worker's actual noise exposure, both protected and unprotected. According to Burks and Michael (2003), some field studies in coal mines, steel mills, etc. have been conducted by doseBusters USA to demonstrate the efficacy and application of the ESP to the earmuffs. These workplace evaluations ranged in duration from 2 days to 3 months and involved 10 to 35 workers in each of test. The only intervention took place at the beginning of each study when the workers were instructed to wear the ESP's when it's noisy and remove them when it was quiet. In the full-shift or partial-shift noise sampling with the ESP, the protected noise exposure data were compared with the unprotected noise exposure levels, as measured with standard personal noise dosimeter near the top of each worker's shoulder. The main purpose of the studies was to prove that when a worker receives individual, quantitative feedback every day on his/her noise exposure, the worker is capable of balancing protection and communication and thus effectively managing his/her own exposure at a safe level. The results showed that few workers experienced a noise exposure above the Action Level (AL) of $50 \%$, or a Time Weighted Average (TWA) of $85 \mathrm{dBA}$, when wearing the ESPs, indicating that the study purpose was accomplished by using the ESPs.

From a literature review of studies in which the results of individual respirator fit tests were compared to actual on the job respirator work performance, it was found that the vast majority of studies have found no predictive relationship between respirator fittesting and actual work performance. As Janssen and Bidwell (2007) indicated, the actual work situation is complicated by the fact that many unknown variables may affect a respirator's performance during work, such as environmental humidity, temperature, the worker's movements, refitting, and so on. That makes it difficult to find a solid prediction relationship for a respirator user. Researcher (Berger, 2007; Neitzel and Seixas, 2005; Neitzel et al., 2006) of hearing protection believe that an individual fit-testing of a HPD can predict its actual work performance on work. However, examining the respirator fittesting prediction, one may doubt whether there is any prediction relationship between fit-testing of a HPD and its actual use in work. The investigators found that no study that 
directly compared the HPD NRA for fit-testing in a common office with full-shift on-jobperformance in a coal mine.

\subsection{Determining causes of low NRA during coal miners' work}

There are numerous factors in coal mines that may lower the NRA of a coal miner's HPD. During normal work a coal miner typically moves his body often during the long periods of wearing time. Consequently, his HPD may loosen and be compromised. However, a review of the literature found no study that quantitatively demonstrated the main causes of low NRA values. Nevertheless, some researchers (Berger, 1980c \& 1986c, Chung et al., 1983b) suggested that improper fit/wearing, failure to wear, and movements seem to be the main factors to affect NRA in field.

\subsection{Can HPD be fit tested in a common office with MIRE?}

The American National Standards Institute (ANSI, 1995) specifies that MIRE be carried out in a reverberatory chamber for the IL measurement of an earmuff. Actually, researchers usually make MIRE noise attenuation measurement (e.g., IL and NR) of both earmuffs and earplugs in a reverberatory chamber, as indicated in the studies from Mauney (1993), Durkt (1993), Giardino et al. (1996), Casali et al. (1995), etc. However, it is not practical for most companies to obtain a reverberatory chamber for MIRE fittesting, reducing the likelihood of widespread adoption of fit-testing. If it can be proved that MIRE NRA measurement can be performed in a common office without using a reverberatory chamber, fit-testing would be feasible for more worksites.

Using the MIRE method, Toivonen, Paakkonen, Savolainen, and Lehtomaki (2002) measured the IL of earplugs (Bilsom and Sweden) in a common office. A miniature microphone was fixed to the end of the earplug and inserted into the ear canal. The microphone was situated between the eardrum and the earplug for occluded noise level measurement. The same microphone was inserted into the ear canal at the same distance from the eardrum employed earlier for open ear measurements to obtain IL. The subject was also checked with the REAT method, but only measured at $1000 \mathrm{~Hz}$ to compare with MIRE at $1000 \mathrm{~Hz}$. Their study showed that average individual's IL from the office MIRE was $4 \mathrm{~dB}$ higher than REAT at $1000 \mathrm{~Hz}$. There was no overall A-weighted IL comparison for the common office and the REAT measurement in the study.

Neitzel et al. (2006) compared the IL of a foam earplug (E-A-R Classic, NRR 29) and a custom-molded silicone earplug (dB Blocker Vented) measured with MIRE to values obtained with a Fit-Check using $1 / 3^{\text {rd }}$ octave-bands on 79 construction workers in a common office. Large disparities were found. The measured MIRE noise protection at each frequency was lower than REAT values determined with Fit-Check, and the relationship between them was highly variable, suggesting that it was difficult to find the 
precise attenuation of HPD with either the MIRE method or the Fit-Check. Moreover, up to 5-dBA and 10-dBA differences in overall noise attenuations were found, respectively, on the two earplugs. Neitzel et al. speculated that the test office background noise affected the Fit-Check REAT measurements. They also suggested that the deviation between MIRE and REAT measurement may have been mostly due to subjects refitting their earplugs.

Compared to noise attenuation with REAT or MIRE in a reverberatory chamber, the common-office MIRE could produce deviations at some high frequencies. However, when we consider the actual noise protection ability of a HPD, the OVERALL dBA noise attenuation is far more important than the results at specific frequencies. Whether the overall dBA noise attenuation measured with MIRE in a common office is comparable with that obtained with MIRE in a reverberatory chamber is unclear based on currently published studies. If the overall $\mathrm{dBA}$ noise attenuation is actually comparable, it could be concluded that the MIRE can be used directly to perform useful HPD fit-testing in common offices. Moreover, a common office is usually a semi-reverberatory acoustic environment (K. Michael, personal communication, 2006). Since NRA measurement may be taken at various tested ear orientations from the noise source, it would be useful to determine how the NRA of HPD varies as a function of tested ear orientation from the noise signal. A review of the literature failed to find any studies that addressed this issue.

\subsection{Does refitting affect the HPD NRA?}

Evaluation of the effect of refitting on the noise attenuation of HPDs in MIRE fittesting does not appear to have been done in any published study of hearing protection, except for Neitzel et al. (2006). They studied the variability due to refitting on earplug NRA value (E-A-R Classic \& dB Blocker Vented) with MIRE done in a common office for 79 construction workers. Each worker had a total of four tests (four different fittings) for each earplug, with two tests on each of two consecutive days for each earplug. Their results showed that the standard deviation (95\% confidence interval) of these two earplugs was 5.4 (3.7 - 7.9) dBA and 2.9 (1.6-5.0) dBA on the overall dBA noise attenuation, indicating that refitting affects the variability of noise attenuation values determined during fit-testing.

\subsection{Does movement affect HPD NRA?}

It is very common for HPD fit-testing to be completed within short periods of time while the subject sits without any movements, conditions required by REAT (1974), ANSI (1995), F-MIRE and FitCheck, etc. However, during work it is unlikely that many workers sits still at all times. Workers including coal miners, usually have to make various movements in order to do their tasks. These movements may loosen a HPD and thus reduce its protection capability (Casali \& Park, 1990; Berger, 1980c \& 1986a). 
Hence, a worker may risk NIHL even when his stationary fit-testing has indicated sufficient noise protection from his HPD.

Casali and Grenell (1989) studied the decrease in noise attenuation of earmuffs (Willson 665) due to moderate physical movements (e.g., jaw movement, walking, etc.). Noise attenuation (essentially IL) measurements were taken on 24 subjects with the standard REAT protocol (ANSI S3.19-1974) before and after 1.25 hours of movements, during which subjects did not refit the earmuff at any time. Statistical analyses indicated that the movement significantly decreased low-frequency attenuation but by only a small amounts $(1.5 \mathrm{~dB}$ at $125 \mathrm{~Hz})$ little practical importance.

Krutt and Mazor (1980), Abel and Rokas (1986), Berger (1981b), Kasden and D'Aniello (1978), and Cluff (1989) studied a variety of earplugs, such as pre-molded, custom-molded, mineral down, and slow-recovery foam earplugs. They tested the noise attenuation with REAT immediately after the initial fitting. The subjects then made some head and jaw movements (e.g., eating and talking) for one hour or longer, after which the HPD's noise attenuation was re-checked. Attenuations produced by earplugs other than foam earplugs were reduced substantially (up to $8 \mathrm{~dB}$ ) at some frequencies. The studies showed consistently that a foam earplug, such as E-A-R, had NR values that were resistant to the effects of wearing time and to head and jaw movements.

Savich (1982) attempted to determine the noise attenuation of earmuffs due to head movements. The investigator stated that neck movement did not cause significant reductions in the observed attenuations. However, he reported no detailed experimental protocols of results.

Using the REAT method, Casali et al. (1990) studied the effects of movements on four hearing protectors: Bilsom UF-1, user-molded E-A-R foam plug, pre-molded, tripleflanged UltraFit plug. They also studied the combination of an earmuff with each of two earplugs. Noise attenuations were obtained prior to use, following 1-hour of use, and following 2-hour of use that included either highly kinematic work activity or vigorous jaw movement. Casali et al. found that the movement activities within extended wearing times induced up to a 6-dB and 3-dB decreases in frequency-specific attenuations over time for the pre-molded plug and muff-plug combination, respectively. The muff NR values were only slightly affected by the activity. Their reduction of noise attenuation was small (only $2 \mathrm{~dB}$ ) at $500 \mathrm{~Hz}$ and below. At other frequencies, the reduction for the earmuff was about $1 \mathrm{~dB}$ or less. The E-A-R foam plug's NRA values were largely resistant to movements, and did not show any significant reduction of noise attenuation. The Bilsom muff was the only HPD that demonstrated an attenuation difference between activities, and this was found at only $6300 \mathrm{~Hz}$.

Based on all the studies reviewed above, it can be concluded that the attenuation of certain HPDs may decrease at some specific frequencies after one hour or longer of 
movement activities, but the movement effect on foam earplugs (i.e., the E-A-R earplug) and earmuffs were not practically important. However, it remained unclear how much the instantaneous movement affected the instantaneous noise attenuation of HPD, since NR values were always measured at the end of the wearing time, not during it.

\subsection{Proposed studies}

This dissertation research consists of lab studies and of field studies at coal mines. The main purpose of the lab studies was to develop and validate a fit-testing protocol with the MIRE method to be used in a common coal mine office. The effects of important factors, including movement activity, ear orientation from the noise source, refitting, and the sound field on the NRA of the selected HPDs were tested. NRA was the dependent variable since it is a feasible measurement of attenuations for field studies. Its advantages are that it does not matter if the ambient noise level is varying and that the background noise does not have to be particularly low.

Specifically, the research objectives were to:

Lab studies:

1. Determine if there is a significant difference in $\mathrm{NR}_{\mathrm{A}}$ between a common office environment and a reverberatory chamber in the lab studies.

2. Determine if there are significant differences in $\mathrm{NR}_{\mathrm{A}}$ among three angles of orientation $\left(0^{\circ}, 90^{\circ}\right.$, and $\left.180^{\circ}\right)$ of the tested ear to the noise source.

3. Determine if there are significant changes in $\mathrm{NR}_{\mathrm{A}}$ with repeated HPD fittings.

4. Determine if specific movements have substantial instantaneous effects on $\mathrm{NR}_{\mathrm{A}}$ for any tested HPD.

Field studies:

5. Determine on-the-job $\mathrm{NR}_{\mathrm{A}}$ values for coal miners during normal work.

6. Determine how well the $\mathrm{NR}_{\mathrm{A}}$ from fit-testing of each coal miner's HPD predicts the $\mathrm{NR}_{\mathrm{A}}$ determined during his normal coal mining work.

7. Determine causes of low $\mathrm{NR}_{\mathrm{A}}$ values while miners work.

8. Determine coal miners' ambient (unprotected) noise dose and ear (protected) noise dose during their normal work

9. Determine the amount of noise dose due to failure to wear HPD. 


\section{CHAPTER 3: FIRST LAB STUDY: METHOD TO MEASURE NOISE PROTECTION (NRA) OF HPD WITH PINK NOISE}

This study investigated the appropriate method to measure the noise protection ability of the selected HPDs and the validation of pink noise for fit-testing HPDs.

\subsection{Purpose}

The main purpose of this study was to investigate where NRA values determined using pink noise differ substantially from results determined using pre-recorded mine noise.

\subsection{Background}

In assessing workplace noise exposures, the overall A-weighted NR (NRA) is the relevant metric of exposure. Therefore, the focus here is to determine $\mathrm{NR}_{\mathrm{A}}$, the deviation in A-weighted noise level due to the presence of the HPD. $\mathrm{NR}_{\mathrm{A}}$ was computed as follows:

$$
\mathrm{NR}=\mathrm{SPL}_{\text {ambient }}-\mathrm{SPL} \text { ear with HPD. }
$$

Where:

The SPL ambient was overall A-weighted ambient noise level measured

The SPLear with нрD was the overall A-weighted noise level in ear measured

Pink noise is often used as the noise signal for the assessment of NRA (Berger 2000c). However, mining noise does not have the flat spectra of pink noise. Since it is well known the HPD have different values of NR for different frequencies, it is possible that the NRA value determined with pink noise will differ from NRA vales determined with coal mining noise. 


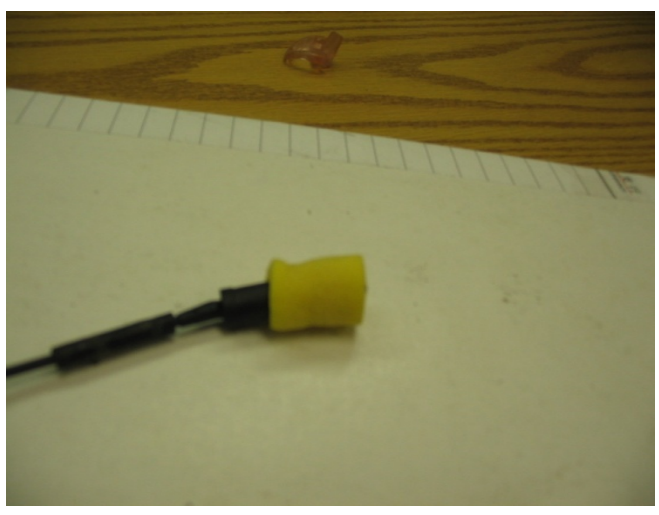

Figure 3-1- 1. Earplug with microphone

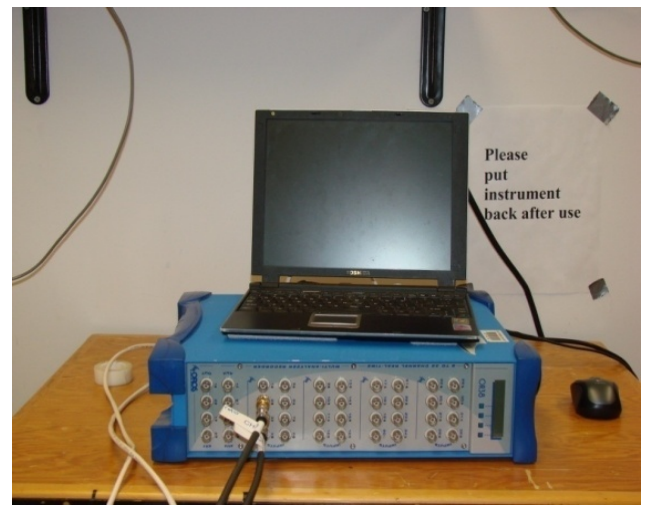

Figure 3-1-2. Laptop and OROS analyzer

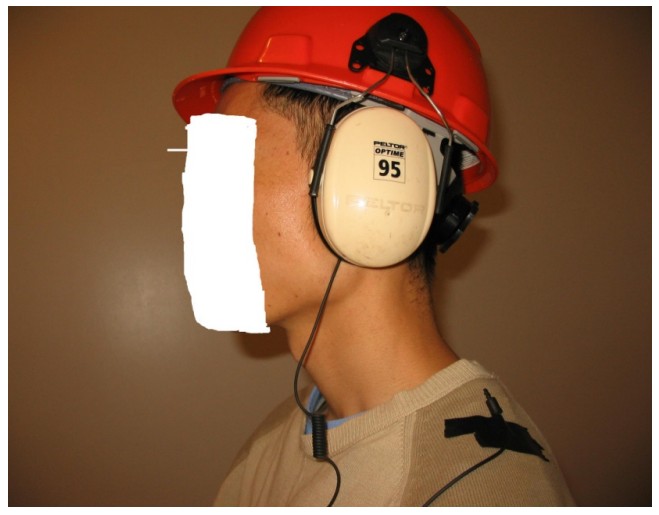

Figure 3-1- 3. Earmuff fit-testing

\subsection{Apparatus}


The apparatus use for the noise generation and measurements are described in this section.

\subsubsection{Apparatus for the noise signal generation}

A multi-channel Real Time Analyzer OROS 38 (OROS, Falls Church, VA) was used to generate the pink noise signal $(80 \mathrm{~Hz}-12500 \mathrm{~Hz}$ ) (ANSI, 1995). It also was used to measure and record the noise level at each center frequency of the $1 / 3^{\text {rd }}$ octave band as well as the overall A-weighted noise level (SPLA). The analyzer was driven by NVGate software (software version: nvgate 4.22) installed on a laptop (Toshiba Portege R100, Irvine, CA). The analyzer and the laptop are shown in the Figure 3-1-2. The pink noise signal was amplified by two amplifiers (Behringer Europower EP1500) that drove the speaker (Infinity Primus P162) for the signal presentation.

The $1 / 4$ " microphone (doseBuster, USA) sensed the sound level signal, which was amplified by a power source (Michael Associate, USA) and then sent to the OROS 38 analyzer for signal processing. Finally, the noise level information was presented on the laptop. Just before and after the experiment, the microphones were calibrated against a standard pure tone noise signal of $114 \mathrm{~dB}$ at $1000 \mathrm{~Hz}$ generated by a calibrator (Norsonic AS, Norway, type 1251 IEC).

\subsubsection{Apparatus: the tested earmuffs and earplugs}

The earplug used throughout these studies was a disposable PVC foam plug (regular E-A-R, NRR 29). Personnel of doseBuster, Inc. drilled or punched a hole through the center of the plug along its long axis so that a $1 / 4^{\prime \prime}$ diameter plastic tube that passed through the center of the foam plug. The doseBuster microphone was screwed into this plastic tube, allowing it to receive noise signals through the plug and to sample noise inside ear canal. A study from doseBuster showed that the acoustic attenuation characteristics of the remolded E-A-R earplug were not changed from its original value (Burks et al., 2003). The E-A-R earplug was selected because it is the most widely used earplug in American industries (Berger, 2000c) and is also commonly used in coal mines. The earplug with a microphone is shown in the Figure 3-1-1. In addition, the lab studies used a low profile hardhat earmuff (Peltor, NRR 23), which is also commonly used by coal miners (Takacs and Stockdale, personal communication, 2008). The earmuff equipped for testing is shown in Figure 3-1-3. 


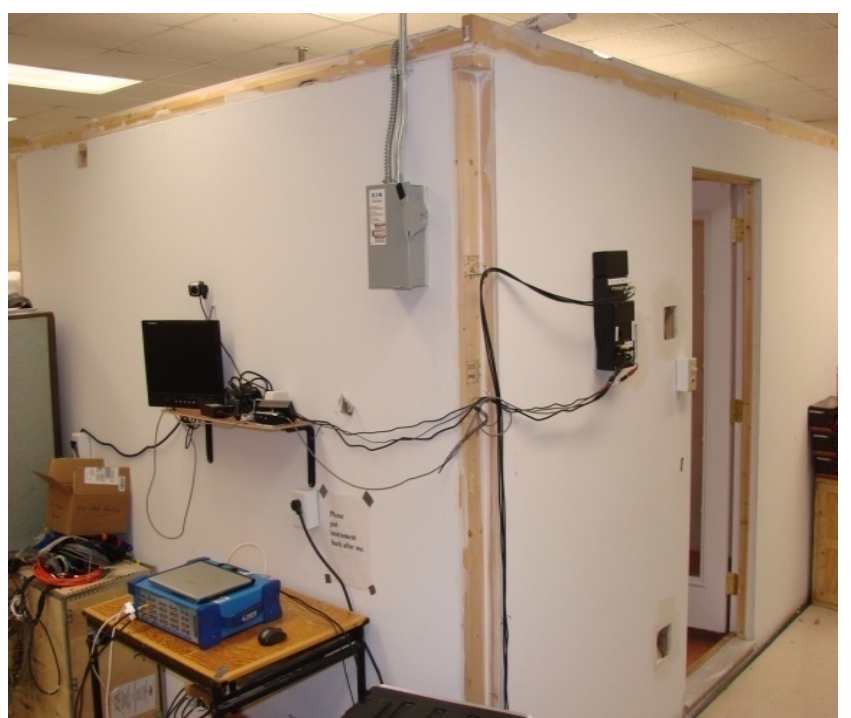

Figure 3-1-4. The reverberatory chamber exterior

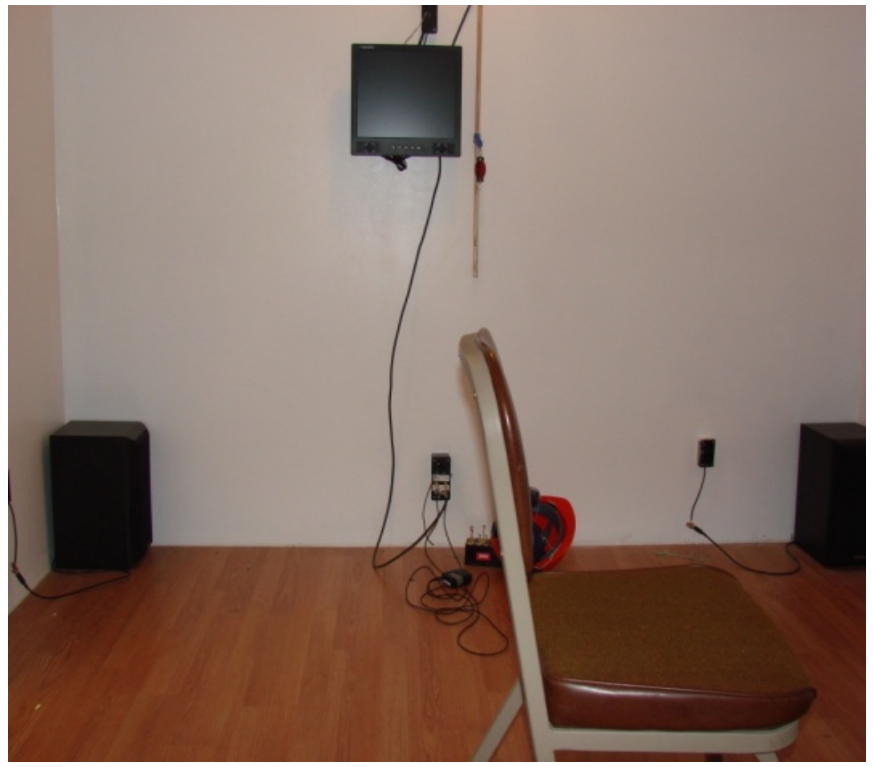

Figure 3-1-5. The reverberatory chamber interior 
Table 3-1- 1. Sound field directionality, maximum differences ( $\Delta$ Max), data are in $\mathrm{dB}, 1 / 3$ OB center frequency $(\mathrm{Hz})$

\begin{tabular}{|l|r|r|r|r|r|r|r|r|r|r|r|r|r|r|r|r|r|r|r|}
\hline & 125 & 160 & 200 & 250 & 315 & 400 & 500 & 630 & 800 & $1 \mathrm{k}$ & $\begin{array}{c}1.25 \\
\mathrm{k}\end{array}$ & $\begin{array}{c}1.6 \\
\mathrm{k}\end{array}$ & $2 \mathrm{k}$ & $\begin{array}{c}2.5 \\
\mathrm{k}\end{array}$ & $\begin{array}{c}3.15 \\
\mathrm{k}\end{array}$ & $4 \mathrm{k}$ & $5 \mathrm{k}$ & $\begin{array}{c}6.3 \\
\mathrm{k}\end{array}$ & $8 \mathrm{k}$ \\
\hline $\begin{array}{l}\text { up-down } \\
(\Delta \text { Max })\end{array}$ & 1.3 & 0.9 & 1.1 & 1 & 1.5 & 1 & 0.7 & 0.1 & 0 & 0.8 & 1.8 & 0.3 & 1.1 & 0 & 0.2 & 0.3 & 0.6 & 0.4 & 0.3 \\
\hline $\begin{array}{l}\text { front- } \\
\text { back }(\Delta \\
\text { Max })\end{array}$ & & & & & & & & & & & & & & & & & & \\
\hline $\begin{array}{l}\text { left-right } \\
(\Delta \text { Max })\end{array}$ & 0.2 & 0.2 & 0.2 & 1.5 & 1.5 & 2.1 & 1.6 & 0.8 & 1 & 1.4 & 0.6 & 0.2 & 0.5 & 0 & 0.6 & 0.1 & 0.8 & 0.3 & 0.3 \\
\hline
\end{tabular}

Table 3-1- 2. Sound field uniformity, maximum differences ( $\Delta$ Max). Data are in dB, 1/3 OB center frequency $(\mathrm{Hz})$

\begin{tabular}{|c|c|c|c|c|c|c|c|c|c|c|c|c|c|}
\hline Frequency & 500 & 630 & 800 & $1 \mathrm{k}$ & $1.25 \mathrm{k}$ & $1.6 \mathrm{k}$ & $2 \mathrm{k}$ & $2.5 \mathrm{k}$ & $\begin{array}{c}3.15 \\
\mathrm{k} \\
\end{array}$ & $4 \mathrm{k}$ & $5 \mathrm{k}$ & $6.3 \mathrm{k}$ & $8 \mathrm{k}$ \\
\hline$(\Delta \operatorname{Max})$ & 4.9 & 2.6 & 1.7 & 2.1 & 1.9 & 3 & 2.5 & 1.4 & 1.4 & 1.4 & 1.6 & 1.8 & 2.4 \\
\hline
\end{tabular}




\subsubsection{Apparatus: Reverberatory chamber}

A reverberatory chamber was used in some laboratory studies for the assessment of NRA. Reverberatory chambers are intended to produce a diffuse sound field. According to ANSI 12.24-1995, achieving a diffuse sound field includes two main requirements: uniformity and directionality. Uniformity requires that the sound SPL measured at six positions $\pm 15 \mathrm{~cm}$ from the center of the subject's head (without the subject present) in the front-back, up-down, left-right should be within $6 \mathrm{~dB}$ for all test bands at $125 \mathrm{~Hz}$ through $8000 \mathrm{~Hz}$. The difference between left and right should not exceed $2 \mathrm{~dB}$ for any $1 / 3^{\text {rd }}$ octave frequency band. Sound non-directionality requires that the SPL values are within $3 \mathrm{~dB}$ at and above $500 \mathrm{~Hz}$ of $1 / 3^{\text {rd }}$ of octave band with a free- field rejection value of $10 \mathrm{~dB}$ between front to side and front to back, as measured with the directional microphone (Neumann, KM 185) without the head present.

The reverberatory chamber is located at the Mineral Resource Building at West Virginia University. Its interior and exterior are shown as Figures 3-1-4 and 3-1-5, respectively. Fiber glass filled the 5-inch gap between the outer wall and inner wall, which were 1-inch plywood. All the inner chamber walls were covered with gypsum. The chamber was floored with wooden parquet tiles. The entire chamber rested on a large

piece of 1 " thick rubber mat to reduce low-frequency vibrations caused by the ventilation fans in the building. A glass door allowed people to enter and exit the chamber. Video monitors were inside and outside the chamber walls, allowing the investigator and human subjects to see each other. Microphone controlled by the investigator allowed verbal communication.

The uniformity of the reverberatory chamber sound level met the requirements listed in the ANSI 12.24-1995 standard. As shown Table 3-1-1, none of the SPL differences between the front-back, up-down and left-right exceeded $2 \mathrm{~dB}$ at the headcenter-location at any frequency of $1 / 3^{\text {rd }}$ octave band. Table 3-1-2 shows that the SPL difference at each $1 / 3^{\text {rd }}$ octave band frequency was within $3 \mathrm{~dB}$, except for the $500 \mathrm{~Hz}$, where the maximum difference was $4.9 \mathrm{~dB}$. Therefore, the reverberatory chamber was able to generate diffuse sound field at the head-center-location which met ANSI 199512.24, except for $500 \mathrm{~Hz}$ for the sound directionality characteristic, where it exceeded the requirement by about $2 \mathrm{~dB}$.

\subsubsection{Human subjects}

Five students from West Virginia University served as paid volunteer human participants. Subjects were at the age of 20 to 30 year old, including two females and three males. Their ethnicity includes both Asian and Caucasian. The subjects signed a consent form before the experiment began. 


\subsection{Methods}

The method for noise level sampling and NRA comparison between pink noise and mining noise are described in the following sections.

\subsubsection{Method for noise level (SPL) sampling}

Only subjects' left ears were tested. While testing an earplug, one microphone was screwed to the end of the earplug (see Figure 3-1-1). It was then inserted into the ear canal by the subject without any instructions or help from the investigators. The microphone was thus situated between the eardrum and the earplug when measuring SPLear, the noise level near the eardrum. The only plug tested was the modified E-A-R plug. The other microphone was placed on the middle of the shoulder crest to measure the ambient noise level (SPLambient). The two microphones simultaneously measured SPL at the center frequency of each $1 / 3^{\text {rd }}$ octave band across the range from $125 \mathrm{~Hz}$ to 8000 $\mathrm{Hz}$ (ANSI, 1995) as well as the overall SPLA. The pink noise signal was approximately $80 \mathrm{~dB}$ at each $1 / 3^{\text {rd }}$ octave band frequency. The noise floor of the microphone was at most $30 \mathrm{~dB}$ at each frequency of the $1 / 3^{\text {rd }}$ octave band. Therefore, the $80-\mathrm{dB}$ noise signal allowed the microphone to have up to a $50-\mathrm{dB}$ dynamic range.

The investigator allowed 30 seconds for the E-A-R earplug to fully expand in the subject's ear canal before measurements started. OROS noise analyzer was set at linear function. An integrated 15 -second sampling time was used reduce variability. The noise reduction was computed as:

$\mathrm{NR}=\mathrm{SPL}_{\text {ambient }} \mathrm{SPL}$

Where:

The SPL ambient was ambient noise level measured

The SPLear with HPD was the noise level in ear measured

The only earmuff tested was the low profile hardhat earmuff (Peltor, NRR 23). A hole with a $1 / 10$ " diameter was made on the side of the earmuff cup. The microphone was set through the earmuff hole and stick out of the inside earmuff foam, with the microphone tip close to the entrance to ear canal to measure the noise level at the ear opening. A small rubber ring wrapped around the microphone wire to fill in the gap between the earmuff cup hole and the wire to reduce noise leakage. The other microphone was set at the middle point of the shoulder crest to measure ambient noise levels. The NR was computed with the Equation 2, as with the plugs. 
The subject read the fitting instructions from the manufacturer package of the HPD and then donned the HPD without any help or instruction from the experimenter. Subject was allowed to adjust the hardhat or earmuff for his own comfort before any measurement started.

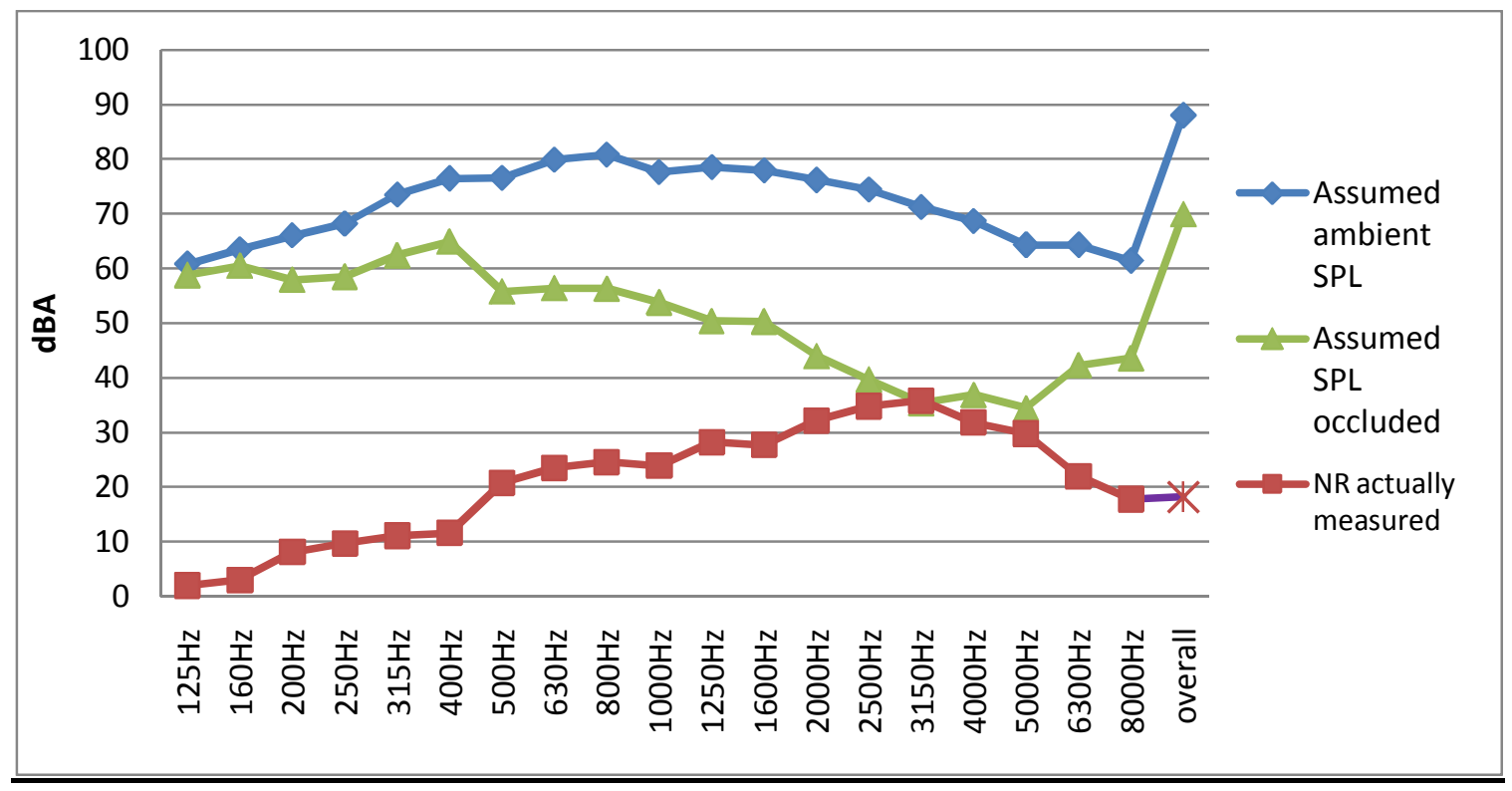

Figure 3-1- 6. NRA value calculation when underground noise spectrum was applied (Subject 5)

\section{NOTE: “*” is calculated NRA in above figure}

The NRA of underground noise $=88.1 \mathrm{dBA}-69.9 \mathrm{dBA}=18.2 \mathrm{dBA}$

The NRA of pink noise $=91.5 \mathrm{dBA}-71.6 \mathrm{dBA}=19.9 \mathrm{dBA}$. Note that the readings of 91.5 and $71.6 \mathrm{dBA}$ were directly taken from the analyzer, respectively.

The NRA value difference for pink and underground noise is: $19.9 \mathrm{dBA}-18.2 \mathrm{dBA}=1.7 \mathrm{dBA}$ 


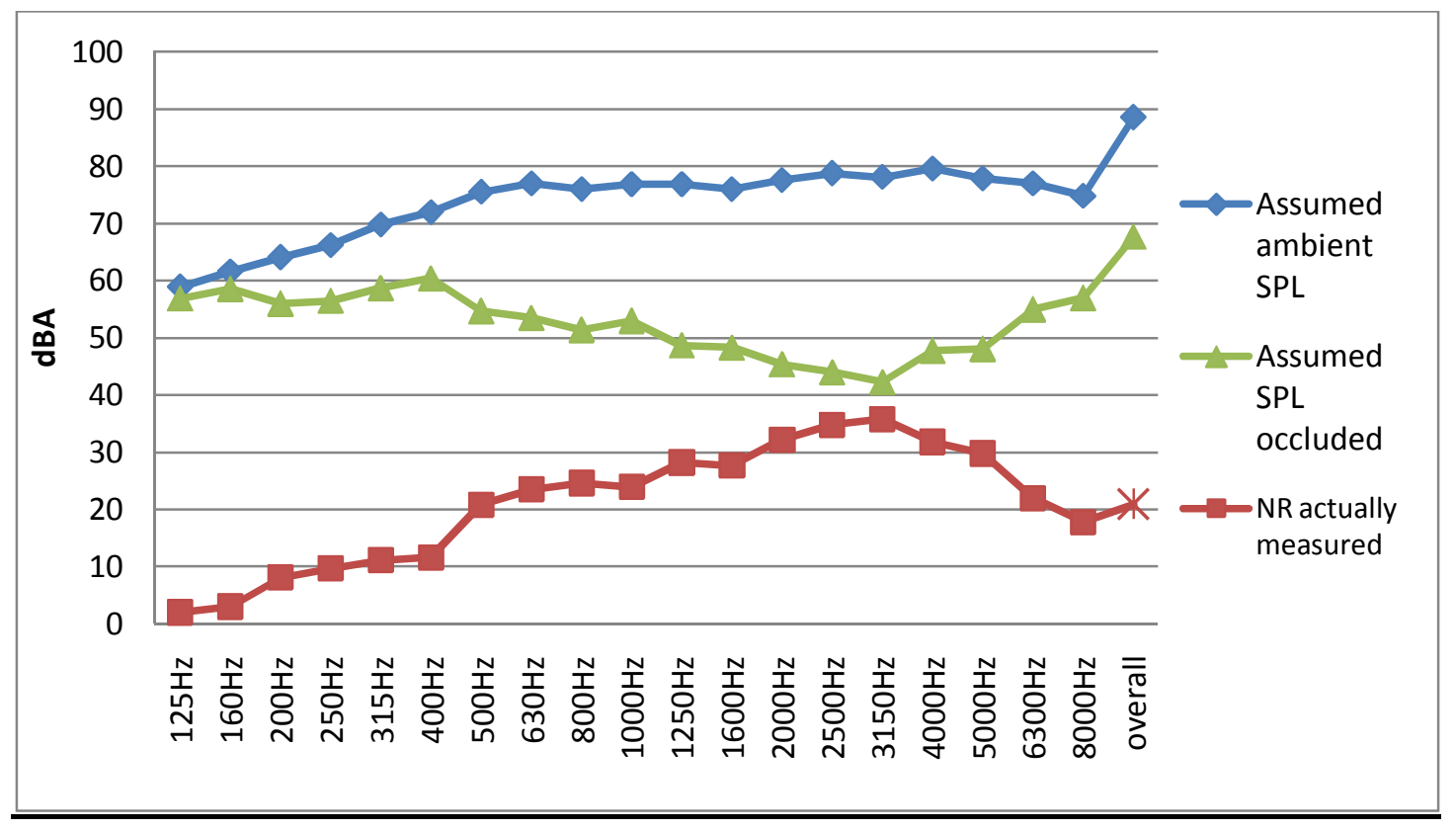

Figure 3-1- 7. NRA value calculation when drilling noise spectrum was applied (Subject 5)

NOTE: “*” is calculated NRA in above figure

The NRA of drilling noise $=88.6 \mathrm{dBA}-67.7 \mathrm{dBA}=20.9 \mathrm{dBA}$

The NRA of pink noise $=91.5 \mathrm{dBA}-71.6 \mathrm{dBA}=19.9 \mathrm{dBA}$. Note that the readings of 91.5 and $71.6 \mathrm{dBA}$ were directly taken from the analyzer, respectively.

The NRA value difference for pink and drilling noise is: $19.9 \mathrm{dBA}-20.9 \mathrm{dBA}=-1.0 \mathrm{dBA}$

\subsubsection{Methods for achieving NRA and comparing the $N_{A}$ between pink noise and mining noise}

National Institute for Occupational Safety and Health (NIOSH) created two coal mining noise spectra: drilling and underground. These were averages of diverse sounds from a range of mining machines, encompassing most types of noise generated by mining equipment from predominantly low frequency to predominantly high frequency (Durkt, 1993). These two noise spectra were also used later in coal mine fit-testing.

As a check, all the frequency-specific NRs measured in the reverberatory chamber were applied to the NIOSH underground noise and drilling noise spectrum, respectively, to calculate the $\mathrm{NR}_{\mathrm{A}} \mathrm{s}$, which were compared with the $\mathrm{NR}_{\mathrm{A}}$ of the pink noise spectrum. As described, pink noise was the real noise signal used to measure the NRA as well as the frequency-specific NRs of the selected HPDs.

To calculate the NRA if we assumed the underground noise was used to take the measurement, the A-weighted noise level at each frequency of $1 / 3^{\text {rd }}$ octave band of the 
underground noise spectrum was used to calculate the overall A-weighted noise signal (see Figure 3-1-6), using the following formula:

$$
\text { Overall SPLA }=10 * \sum_{i=1}^{n=19} \log \left(10^{S P L i} / 10\right)
$$

Where:

Overall SPLA is the overall A-weighted ambient noise level of the underground noise spectrum

SPL1 is A-weighted noise level at the frequency of $125 \mathrm{~Hz}$ of the underground noise spectrum

SPL2 is A-weighted noise level at the frequency of $160 \mathrm{~Hz}$ of the underground noise spectrum

SPL19 is A-weighted noise level at the frequency of $8000 \mathrm{~Hz}$ of the underground noise spectrum

In addition, the protected noise level under the HPD at each frequency of the underground noise spectrum was calculated based on the noise level using the following formula:

$\mathrm{SPL}$ under $\mathrm{HPD}=\mathrm{SPL}$ ambient $-\mathrm{NR}$

Where:

SPL under HPD is the A-weighted protected noise level under a HPD at a specific frequency of the underground noise spectrum

SPL ambient is the A-weighted ambient noise level at a specific frequency of the underground noise spectrum

$\mathrm{NR}$ is the noise reduction actually measured at each $1 / 3^{\text {rd }}$ octave frequency range by the OROS analyzer

The overall A-weighted noise level (overall SPLA under HPD) under the HPD protection was also calculated with above Equation 3. As a result, the $\mathrm{NRA}_{\mathrm{A}}$ in assumed underground noise exposure was calculated using the following formula:

$$
\mathrm{NR}_{\mathrm{A}}=\text { overall SPLA }- \text { overall SPLA under HPD }
$$


Where:

NRA is the overall A-weighted noise reduction by the HPD in the assumed underground noise spectrum

SPLA is overall A-weighted ambient noise level in the assumed underground noise spectrum

SPL under HPD is overall A-weighted noise level under HPD protection in the assumed underground noise spectrum

Likewise, the NRA of the HPD was also calculated out when the drilling noise spectrum was applied (see Figure 3-1-7).

\subsection{Results}

It was found that there was only about 1 or $2 \mathrm{~dB}$ differences of NRA between using pink noise and using the mining noise spectra (i.e., underground noise or drilling noise spectrum).

\subsection{Discussion}

The difference of 1-2 dBA is not important. Therefore, it is accurate enough to use pink noise as the signal source to measure the noise protection of the HPD in place of the mining noise spectra.

\subsection{Conclusions}

Pink noise can be used as the signal source to measure the noise protection of the HPD in placement of the mining noise spectra. 


\section{CHAPTER 4: SECOND LAB STUDY: DEVELOP AND VALIDATE A FIT- TESTING PROTOCOL}

The purpose of this lab study was to develop a MIRE fit-testing protocol that can be used in a common office environment, thus justifying fit-testing in coal mine offices and other rooms.

The lab study consisted of three main parts: (1) determine if some typical movements similar to those down in coal mining had important effects on HPD $\mathrm{NR}_{\mathrm{A}} ;(2)$ determine the refitting effect on HPD NRA; (3) compare the measured HPD NR $\mathrm{A}_{\mathrm{A}}$ for the Lab 246 (a common office environment) to value determined in a reverberatory chamber located in the adjacent lab; and (4) determine the effect of ear orientation to the noise source on HPD NR $\mathrm{A}_{\mathrm{A}}$ in the Lab 246.

The noise generation and noise level measurement device, HPD selection, reverberatory chamber, and the methods for human subject selection, method for noise level sampling, and NRA determination were the same as described in Chapter 3.

Table 4-1- 1. Assigned movement activity list

* Move head from side to side

* Walk

* Bend over to pick a 3-pound bucket

* Push

* Squat and lift 3-pound bucket from side and put forward

* Talk

\subsection{Studying effects of movements on HPD NRA}

The purpose of this study was to determine if there are instantaneous effects on $\mathrm{NR}_{\mathrm{A}}$ when a subject wearing the HPD makes movements that are similar to those made by a coal miner during his work (see Table 4-1-1).

\subsubsection{Background}

The movement effect was not expected to be important to the NRA. Therefore, this study sampled a few human subjects to confirm the lack of movement effects. 


\subsubsection{Method}

The experiment was conducted in the reverberatory chamber. The subject randomly selected one of movements from the movement list (see Table 4-1-1). He then sat still with his or her HPD on while exposed to a fixed noise level. Without having re-fitted the HPD, he then made the selected movement for 15 seconds while exposed to the same pink noise in the chamber as in the stationary test condition. The mean $\mathrm{NR}_{\mathrm{A}}$ before and during the movements were computed and compared. The instantaneous effect of the movement on the HPD performance was the $\mathrm{NR}_{\mathrm{A}}$ difference between the stationary and moving conditions.

Specific steps of the study were as follows:

1. The experimenter described the experiment to the human subject.

2. The subject entered the reverberatory chamber and sat at the middle of chamber.

3. Without any suggestion or hints, the experimenter let the subject chose a HPD (earmuff or earplug).

4. Without any suggestion or hints, the experimenter let the subject chose a movement from the list (see Table 4-1-1).

5. The experimenter placed a microphone on the middle point of the subject's shoulder crest. If the earplug was tested, the subject inserted it into his/her ear canal, without any instruction from the experimenter. If the earmuff was tested the subject donned the hardhat and earmuff without any instruction from the experimenter.

6. The experimenter left the chamber, shut its door and sat at the monitoring station.

7. If the earplug was tested no measurements were taken until at least 30 seconds, allowing the earplug in subject's ear to fully expand

8. The experimenter signaled the subject through the two-way radio monitor to sit still, then turned the pink noise on and sampled the noise from both of the two microphones for 15 seconds.

9. The experimenter signaled the subject through the monitor to do the movement he had selected, then turned on the pink noise, sampled the noise from the two microphones for 15 seconds while the subject was doing the movement.

10. Kept repeating above Steps 4 through 9 until all the assigned movements from the list were finished (different movement was chose in Step 4 until all assigned movements were completed). 
11. The subject was tested for another type of HPD using Step 4 through 10.

12. Repeated the Step 1 through 13 to do the second replication of the experiment.

Table 4-1-2. HPD NRA decrease due to movements

\begin{tabular}{|c|c|c|c|c|}
\hline \multirow{2}{*}{ Movement } & \multicolumn{2}{|c|}{$\begin{array}{c}\text { Earplug NRA } \\
\text { decrease, dBA }\end{array}$} & \multicolumn{2}{c|}{$\begin{array}{c}\text { Earmuff NRA } \\
\text { decrease, dBA }\end{array}$} \\
\cline { 2 - 5 } & mean & CI & mean & CI \\
\hline move head from side to side & 1 & $(0.4,1.5)$ & 0.6 & 0.6 \\
\hline walk & 0.9 & $(0.7,1.2)$ & 0.5 & $(0.3,1)$ \\
\hline $\begin{array}{c}\text { bend over to pick a 3-pound } \\
\text { bucket }\end{array}$ & 1.5 & $(0.7,2.2)$ & 0.8 & $(0.7,0.8)$ \\
\hline push & 1.6 & $(1.5,1.8)$ & 1.5 & $(1.3,1.6)$ \\
\hline $\begin{array}{c}\text { squat and lift 3-pound bucket } \\
\text { from side and put forward }\end{array}$ & 2 & $(1.7,2.2)$ & 1.6 & $(0.6,2.7)$ \\
\hline talk & 3.9 & $(3.0,4.7)$ & 1.2 & $(0.8,1.6)$ \\
\hline
\end{tabular}

* $95 \%$ confidence interval

\subsection{Results}

The results of the study are shown in the Table 4-1-2. Except while talking, the mean value of NRA decreased by $2 \mathrm{dBA}$ or less for each movement. Two dBA is not important for noise protection.

The mean value of NRA decreased by $4 \mathrm{dBA}$ due to the talking when the subjects wore earplugs, indicating that the talk produced sort of important effect on the earplug.

\subsection{Discussion}

It is likely that the effect of talking on the earplug was due to bone conduction (K. Michael, personal communication, 2009). Because the microphone in the earmuff measurement was mounted at the ear canal entrance, it picked up less voice level than the earplug microphone inside the ear canal, which explained why the talk had much less effect on the NR of earmuff than the earplug.

Nevertheless, talking should not affect the overall $\mathrm{SPL}_{\text {ear }}$ values in the workplace. The investigator found the coal miners did not talk often with their HPD on when noise levels were high. If they wanted to talk, they usually took their HPD off. Therefore, the talk activity should not be considered an important factor in the fit-testing protocol. Furthermore, the total time talking in noisy environments was low. 


\subsubsection{Conclusions}

Neither movements nor talking are likely to have important effect on NRA in the workplace. For that reason, fit-testing in these studies was done while the subject was sitting and stationary.

\subsection{Studying refitting effect on the $\mathrm{NRA}_{A}$}

This study was to determine if there was important refitting effect on the NRA during fit-testing of the selected HPDs.

\subsection{Background}

Neitzel et al. (2006) studied the variability due to refitting on the same type of earplug NRA value (e.g., E-A-R Classic) for construction workers. They found that the refitting effect is important ( $\mathrm{SD}=5.4 \mathrm{dBA}$ among different refittings of the same earplug).

Therefore, the investigator expected the refitting would substantially affect $\mathrm{NR}_{\mathrm{A}}$ values, but there would be no clear pattern in current study.

\subsubsection{Methods}

In the movement study, the subject removed and re-fitted each HPD 12 times under the stationary conditions. The fit-testing was done using the apparatus and methods of the previous study. The mean and standard deviation (SD) of the NRA across all 12 fittings was calculated to determine whether the refitting effect was important.

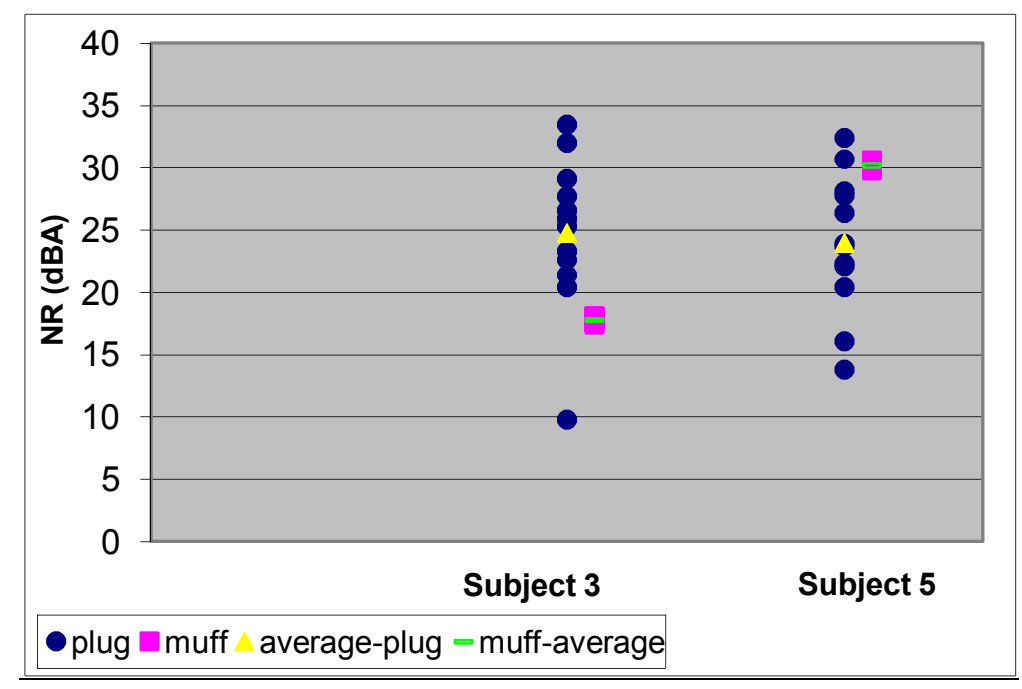

Figure 4-2- 1. Refitting effect on the HPD NRA 
Table 4-2- 1. HPD NRA mean and SD for refitting effect study

\begin{tabular}{|c|c|c|c|c|}
\hline \multirow{2}{*}{ HPD } & $\begin{array}{c}\text { Subject } \\
\text { ID }\end{array}$ & $\mathrm{n}$ & $\begin{array}{c}\text { Mean } \\
(\mathrm{dBA})\end{array}$ & SD (dBA) \\
\hline \multirow{3}{*}{ plug } & $\# 3$ & 12 & 24.8 & 6.2 \\
\cline { 2 - 5 } & $\# 5$ & 12 & 24.0 & 5.5 \\
\hline \multirow{2}{*}{ muff } & $\# 3$ & 12 & 17.8 & 0.2 \\
\cline { 2 - 5 } & $\# 5$ & 12 & 30.2 & 0.3 \\
\hline
\end{tabular}

\subsubsection{Results}

The results of the study are shown in Figure 4-2-1 and Table 4-2-2. Two human subjects refitted themselves for each of the HPDs and were tested for the NRA. In total, there were 12 fittings for the earplug and 12 fittings for the earmuff for each subject. The results for the earmuff showed a Stdev $=0.3 \mathrm{dBA}$, a negligible value.

However, the results of the earplug refitting showed much more variability. Each of the two subjects had a NRA range of more than $17 \mathrm{dBA}$ across the 12 different refitting, with a SD of 6.6 and 5.5, respectively.

\subsubsection{Discussion}

Neitzel et al. (2006) studied the refitting effect on the same type of earplugs (i.e. E-AR) with the MIRE technique in a common office on 79 construction workers. Each worker had a total of four tests (four refittings). The results showed a standard deviation of 5.4, which is similar to the results of this study. The variability for each earplug test may be attributable to different earplug insertion depths in the ear canal for each refitting.

\subsubsection{Conclusions}

For these two subjects and this E-A-R earplug, multiple tests would be necessary to represent their average NRA values. The refitting had an important effect on the NRA for the earplug. For the earmuff, one-time fit-testing NRA was adequate to represent the fittesting result of these two subjects. The earmuff refitting effect was trivial.

\subsection{Studying whether a common office environment can adequately replace reverberatory chamber for fit-testing}

This study was intended to prove that MIRE NRA measurement can be performed in a common office without using a reverberatory chamber. Specifically, the study determined if there was a significant difference in $\mathrm{NR}_{\mathrm{A}}$ between a common office environment and a reverberatory chamber. 


\subsubsection{Background}

ANSI (1995) and researchers (Mauney,1993; Durkt, 1993; Giardino et al., 1996; Casali et al.,1995) specify that MIRE be carried out in a reverberatory chamber in order to achieve an accurate noise attenuation of a wear's HPD. However, it is not practical for most companies to obtain a reverberatory chamber for MIRE fit-testing due to the complication of acoustic construction technique and accompanying high cost.

\subsubsection{Apparatus}

A standard laboratory (Lab 246) at Mineral Resource Building of West Virginia University was used in this study. It was adjacent to the room housing the reverboratory chamber. In the Lab 246 there were tables, chairs, lab hoods, and counters, etc. Hence, its acoustical environment should be similar to a common office, which is usually semireverberatory.

\subsection{Methods}

The experiment used common apparatus and common method to obtain $\mathrm{NR}_{\mathrm{A}}$ as described in 4.1. The unique apparatus is described in Section 4.3.2. Each subject selected either an earmuff or earplug. The subject was then tested for $\mathrm{NR}_{\mathrm{A}}$ in the reverberatory chamber. When that test was completed, the subject walked to adjacent Lab 246 while wearing the same microphone and HPD. The subject then sat on a chair with his or her tested ear $18^{\prime}$ ' from a speaker. The subject rotated in the orientation of $0^{\circ}, 90^{\circ}$, and $180^{\circ}$ from the speaker for different $\mathrm{NR}_{\mathrm{A}}$ determinations without refitting the HPD. After the measurement for the first HPD (i.e., earplug or earmuff) was completed, the subject took the tested HPD off and donned the other HPD for repeated NRA determinations at each of the three orientations with that HPD fitting. When the second HPD measurements were completed in the Lab 246, the subject walked to the reverboratory chamber for NRA while keeping the same HPD fitting and was fit-tested in the chamber.

Specifically, the experimental steps were as follows:

1. The subject read the manufacturer's fitting instructions for the HPD (earplug \& earmuff).

2. The subject entered the reverberatory chamber, and sat on a chair at the middle of chamber.

3. The subject randomly selected either the earmuff or the earplug to test first.

4. The experimenter set a microphone on the middle point of the subject's shoulder crest. If the earplug was tested, the subject inserted it into his/her ear canal, 
without any instruction or help from the experimenter; if the earmuff was tested, the subject donned the earmuff without any instruction or help from the experimenter.

5. If the earplug was tested the experimenter waited outside the chamber 30 seconds for the earplug in subject's ear to fully expand.

6. The experimenter signaled the subject through the monitor to sit still, and then turned the pink noise on. The OROS analyzer sampled the noise from the two microphones for 15 seconds.

7. Keeping the same microphone setting and the same HPD fitting, subject carefully walked to Lab 246, and sat on a chair with his or her tested ear 18" from the speaker.

8. The subject was instructed to rotate the stool until his or her ear was orientated at $0^{\circ}, 90^{\circ}$, or $180^{\circ}$ from the speaker, with the angle randomly chosen by the subject.

9. The experimenter signaled the subject to sit still and then turned the pink noise on. The OROS analyzer sampled the noise from the two microphones for 15 seconds.

10. The subject was instructed to rotate the stool to each of the other two orientations in turn and 15 second samplings were taken for each.

11. The subject took the HPD off and donned the other type of HPD, and the procedure was repeated for it.

12. Keeping the same HPD fitting and the same microphones in place, the subject walked to enter the reverberatory chamber. He or she sat on the chair in the middle of the reverberatory chamber.

13. Step 6 was repeated for the NR measurement.

\section{Justifying the 18" distance for fit-testing in a common office}

The very short distance (18') from the speaker made the subject so close to the noise source so that he/she was in the direct sound field. Hence, the sound should be very directional. This is probably a far more directional environment than in coal mines. The investigator found that the coal miners typically were in the far field of the sound (more than 4 feet) while they were working. In addition, the coal mine work environment is somewhat more absorptive than typical workplace due to the large surface area of fractured coal. 


\section{Analysis}

The HPD NRA averaged from the three orientations in the Lab 246 was compared to the NRA measured in the reverberatory chamber. A correction factor based on the $\mathrm{NR}_{\mathrm{A}}$ measured in the reverberatory chamber was applied to the NRA measured in the Lab 246 if there was a substantial difference found between them. Moreover, the effect of tested ear orientation to the noise source on the HPD NRA and on frequency-specific NR was also examined, with the procedure described in the study.

- Dependent variable: $\mathrm{NR}_{\mathrm{A}}=\left(\mathrm{SPL}_{\mathrm{ambient}}-\mathrm{SPLear}_{\mathrm{with}} \mathrm{HPD}\right)$

- Independent variable: test location (reverberatory chamber or within another lab)

- Student t-test

- H0: no effect of the test location;

- H1: significant effect of the test location

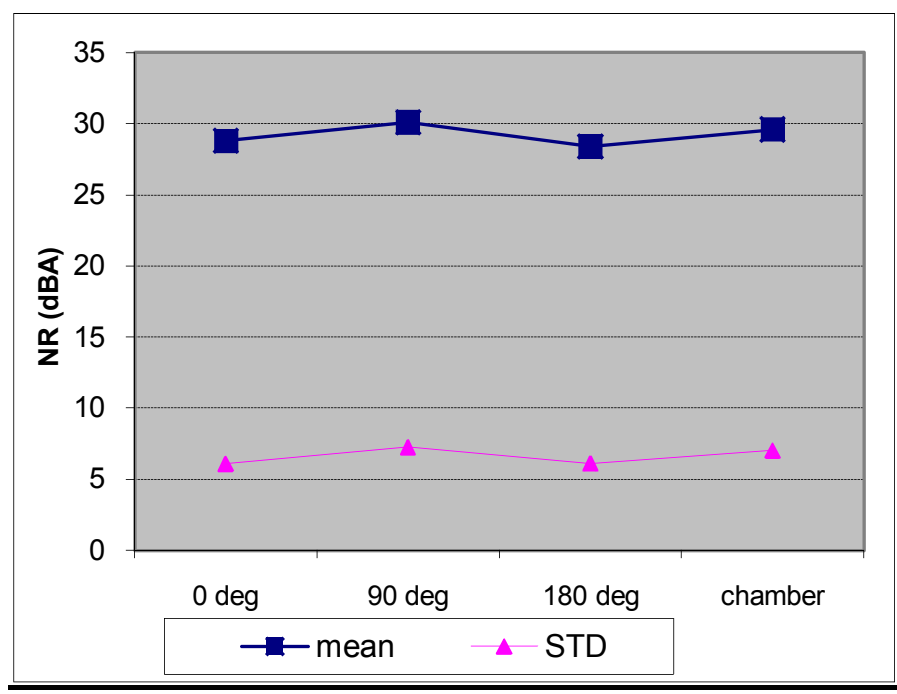

Figure 4-3- 1. Earplug NRA comparison for the chamber and the Lab 246 for each source orientation (each point is the average of five subjects) 


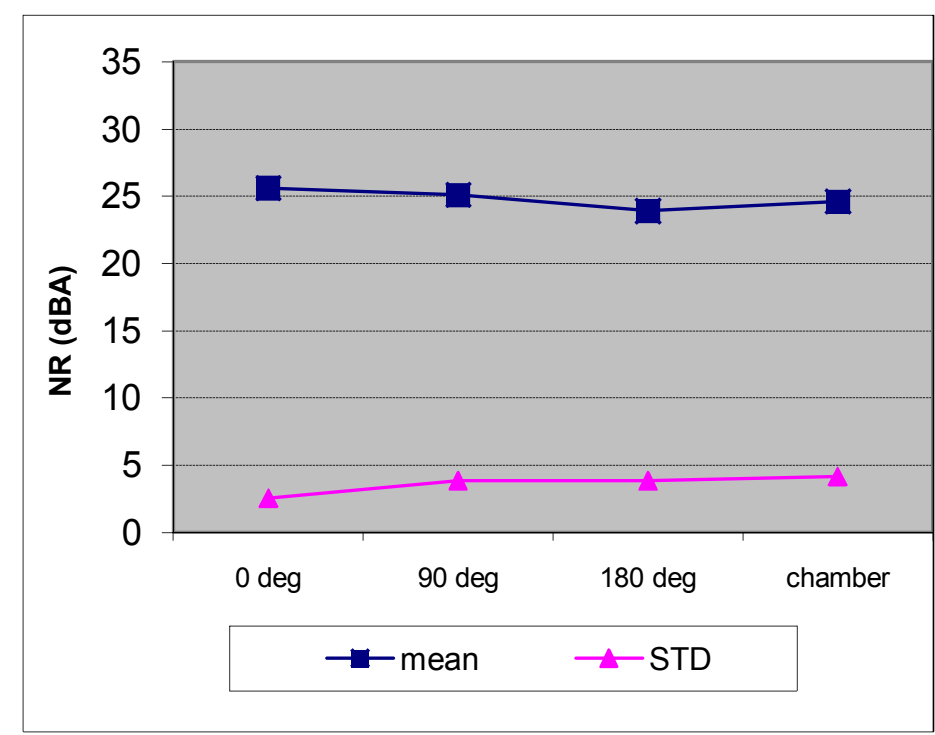

Figure 4-3-2. NRA comparison of earmuff for the chamber and the Lab 246 with different orientation (each point is the average of five subjects)

Table 4-3- 1. NRA comparison of the HPDs for reverberatory chamber and the Lab 246 with different tested ear orientation

\begin{tabular}{|c|c|c|c|c|c|c|c|c|c|}
\hline \multirow{2}{*}{$\begin{array}{l}\mathrm{H} \\
\mathrm{P} \\
\mathrm{D}\end{array}$} & \multirow{2}{*}{ parameter } & \multicolumn{4}{|c|}{ Office } & \multirow{2}{*}{ chamber } & \multirow{2}{*}{$\begin{array}{l}\text { Avg } \\
\text { diff }\end{array}$} & \multirow{2}{*}{$\mathrm{N}$} & \multirow{2}{*}{ p-value } \\
\hline & & $0^{\circ}$ & $90^{\circ}$ & $180^{\circ}$ & Avg & & & & \\
\hline \multirow{2}{*}{ plug } & $\begin{array}{c}\text { Mean } \\
\text { (dBA) }\end{array}$ & 28.8 & 30.1 & 28.4 & 29.1 & 29.6 & 0.5 & 5 & 0.91 \\
\hline & STD & 6.1 & 7.3 & 6.1 & 6.4 & 7.0 & & & \\
\hline \multirow{2}{*}{ muff } & $\begin{array}{c}\text { Mean } \\
(\mathrm{dBA})\end{array}$ & 25.6 & 25.1 & 23.9 & 24.9 & 24.6 & 0.3 & 5 & 0.90 \\
\hline & STD & 2.5 & 3.9 & 3.8 & 3.4 & 4.2 & & & \\
\hline
\end{tabular}

\subsection{Results and discussion}

The results of the study are shown in Figures 4-3-1 and 4-3-2 as well as Table 4-3-1. For the five subjects used in the study and for both the earplug and the earmuff the maximum difference in NRA was less than $1.4 \mathrm{dBA}$ between the average value of the three orientations in the Lab 246 and the value found in the chamber. Student t-test showed that the difference was not significant at $\alpha=5 \%$.

\subsubsection{Conclusion}

The difference between $\mathrm{NR}_{\mathrm{AS}}$ determined in the chamber and the Lab 246 was modest, supporting the use of common rooms for MIRE fit-testing. 


\subsection{Studying the orientation effect on NRA}

This study was intended to determine if there are significant differences in NRA among three angles of orientation $\left(0^{\circ}, 90^{\circ}\right.$, and $\left.180^{\circ}\right)$ of the tested ear with the noise source in a common office environment. As a supplemental study, the effect of tested ear orientation to the noise source and the effect of test location (a common office vs. reverberatory chamber) on frequency-specific NR were examined.

\subsection{Methods}

The study did not collect more data. The data collected for 4.3 was analyzed to determine the effects of orientation to the source. Each of the five subjects rotated to each of three orientations to the source during fit-testing without adjusting the HPD fit during the testing. The NR at each frequency of $1 / 3^{\text {rd }}$ octave band were averaged across all the subjects for each orientation and also for the reverberatory chamber. Then the averaged $\mathrm{NR}$ at each frequency in every orientation as well as the reverbertory chamber was graphed and tabled to compare whether there was important difference.

Table 4-4- 1. ANOVA of orientation and subject effect on NRA of the E-A-R earplug

\begin{tabular}{|c|c|c|c|c|c|}
\hline Source & df & $\begin{array}{c}\text { Sums of } \\
\text { Squares }\end{array}$ & $\begin{array}{c}\text { Mean } \\
\text { Square }\end{array}$ & F-ratio & Prob \\
\hline Orientation & 2 & 8.2 & 4.1 & 3.6 & 0.075 \\
\hline Subject & 4 & 499.2 & 124.8 & 110.5 & $<0.0001$ \\
\hline Error & 8 & 9.0 & 1.1 & & \\
\hline Total & 14 & 516.5 & & & \\
\hline
\end{tabular}

Table 4-4- 2. ANOVA of orientation and subject effect on NRA of the Peltor earmuff

\begin{tabular}{|c|c|c|c|c|c|}
\hline Source & df & $\begin{array}{c}\text { Sums of } \\
\text { Squares }\end{array}$ & $\begin{array}{c}\text { Mean } \\
\text { Square }\end{array}$ & F-ratio & Prob \\
\hline Orientation & 2 & 8.1 & 4 & 4.3 & 0.05 \\
\hline Subject & 4 & 136.2 & 34.1 & 36.2 & $<0.0001$ \\
\hline Error & 8 & 7.5 & 0.9 & & \\
\hline Total & 14 & 151.8 & & & \\
\hline
\end{tabular}




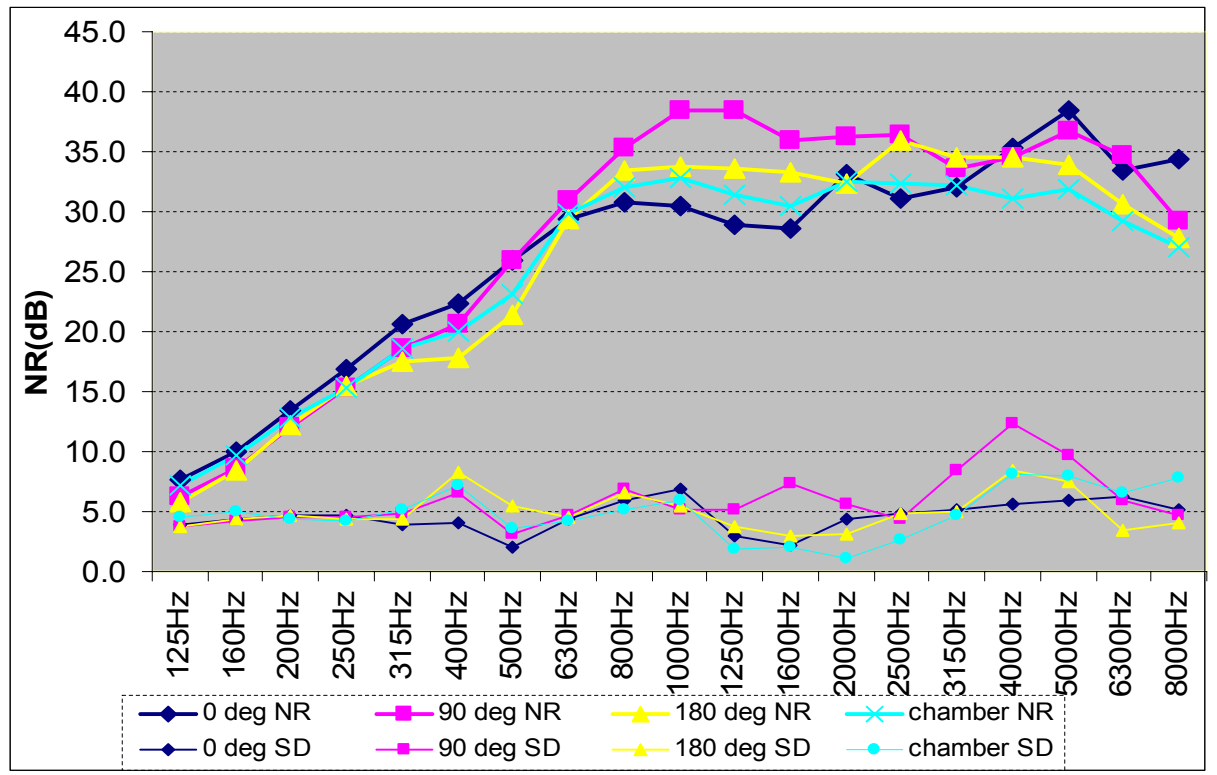

Figure 4-4- 1. Earmuff mean NR (dB) comparison at every frequency between chamber and office with different tested ear orientation

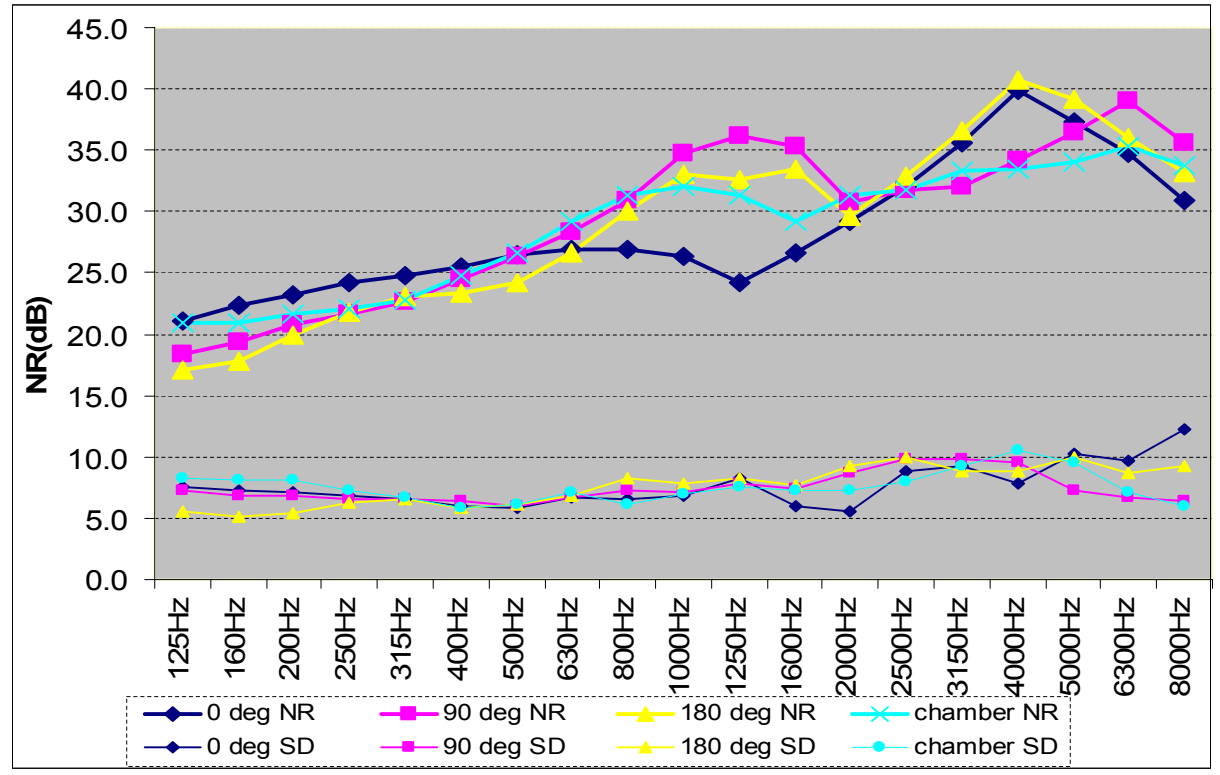

Figure 4-4- 2. Earplug NR (dB) mean comparison at every frequency between chamber and office with different tested ear orientation 
Table 4-4- 3. Earplugs NR (dB) mean comparison at every frequency between chamber and office with different tested ear orientation

\begin{tabular}{|c|c|c|c|c|c|c|c|c|c|}
\hline \multirow{2}{*}{ Frequency } & \multirow{2}{*}{$\begin{array}{c}\text { \# of } \\
\text { samples }\end{array}$} & \multicolumn{2}{|c|}{ Office $0^{0}$} & \multicolumn{2}{c|}{ Office $90^{0}$} & \multicolumn{2}{c|}{ Office $180^{0}$} & \multicolumn{2}{c|}{ Chamber } \\
\cline { 3 - 10 } & NR & SD & NR & SD & NR & SD & NR & SD \\
\hline $125 \mathrm{~Hz}$ & 5 & 21.1 & 7.5 & 18.4 & 7.2 & 17.1 & 5.5 & 20.9 & 8.2 \\
\hline $160 \mathrm{~Hz}$ & 5 & 22.4 & 7.2 & 19.4 & 6.9 & 17.8 & 5.1 & 20.9 & 8.1 \\
\hline $200 \mathrm{~Hz}$ & 5 & 23.2 & 7.1 & 20.9 & 6.8 & 20.0 & 5.4 & 21.6 & 8.1 \\
\hline $250 \mathrm{~Hz}$ & 5 & 24.2 & 6.9 & 21.7 & 6.6 & 21.8 & 6.2 & 22.0 & 7.3 \\
\hline $315 \mathrm{~Hz}$ & 5 & 24.8 & 6.6 & 22.7 & 6.5 & 23.0 & 6.5 & 22.8 & 6.7 \\
\hline $400 \mathrm{~Hz}$ & 5 & 25.5 & 6.0 & 24.5 & 6.4 & 23.3 & 5.9 & 24.8 & 5.8 \\
\hline $500 \mathrm{~Hz}$ & 5 & 26.5 & 5.9 & 26.4 & 6.0 & 24.2 & 6.1 & 26.6 & 6.1 \\
\hline $630 \mathrm{~Hz}$ & 5 & 27.0 & 6.7 & 28.4 & 6.7 & 26.6 & 6.8 & 29.3 & 7.1 \\
\hline $800 \mathrm{~Hz}$ & 5 & 26.9 & 6.6 & 30.9 & 7.2 & 30.1 & 8.3 & 31.3 & 6.1 \\
\hline $1000 \mathrm{~Hz}$ & 5 & 26.4 & 6.9 & 34.7 & 7.1 & 33.0 & 7.8 & 32.1 & 7.0 \\
\hline $1250 \mathrm{~Hz}$ & 5 & 24.3 & 8.2 & 36.1 & 7.9 & 32.6 & 8.2 & 31.3 & 7.5 \\
\hline $1600 \mathrm{~Hz}$ & 5 & 26.7 & 6.0 & 35.3 & 7.4 & 33.5 & 7.7 & 29.2 & 7.2 \\
\hline $2000 \mathrm{~Hz}$ & 5 & 29.1 & 5.5 & 30.7 & 8.7 & 29.6 & 9.2 & 31.3 & 7.3 \\
\hline $2500 \mathrm{~Hz}$ & 5 & 32.0 & 8.8 & 31.8 & 9.8 & 32.9 & 9.9 & 31.8 & 8.0 \\
\hline $3150 \mathrm{~Hz}$ & 5 & 35.7 & 9.3 & 32.1 & 9.8 & 36.6 & 8.9 & 33.3 & 9.2 \\
\hline $4000 \mathrm{~Hz}$ & 5 & 39.9 & 7.8 & 34.2 & 9.5 & 40.8 & 8.8 & 33.5 & 10.5 \\
\hline $5000 \mathrm{~Hz}$ & 5 & 37.4 & 10.2 & 36.4 & 7.3 & 39.1 & 10.0 & 34.0 & 9.6 \\
\hline $6300 \mathrm{~Hz}$ & 5 & 34.8 & 9.7 & 39.0 & 6.7 & 36.0 & 8.7 & 35.4 & 7.1 \\
\hline $8000 \mathrm{~Hz}$ & 5 & 30.9 & 12.3 & 35.6 & 6.4 & 33.2 & 9.2 & 33.8 & 6.0 \\
\hline
\end{tabular}


Table 4-4- 4. Earmuff NR (dB) mean comparison at every frequency between chamber and office with different tested ear orientation

\begin{tabular}{|c|c|c|c|c|c|c|c|c|c|}
\hline \multirow{2}{*}{ Frequency } & \multirow{2}{*}{$\begin{array}{c}\text { \# of } \\
\text { samples }\end{array}$} & \multicolumn{2}{|c|}{ Office $0^{0}$} & \multicolumn{2}{|c|}{ Office $90^{\circ}$} & \multicolumn{2}{|c|}{ Office $180^{\circ}$} & \multicolumn{2}{|c|}{ Chamber } \\
\hline & & NR & $\mathrm{SD}$ & NR & SD & NR & SD & NR & SD \\
\hline $125 \mathrm{~Hz}$ & 5 & 7.6 & 3.9 & 6.3 & 3.7 & 5.8 & 3.7 & 7.2 & 4.5 \\
\hline $160 \mathrm{~Hz}$ & 5 & 10.0 & 4.4 & 8.6 & 4.2 & 8.5 & 4.4 & 9.7 & 5.0 \\
\hline $200 \mathrm{~Hz}$ & 5 & 13.5 & 4.7 & 12.0 & 4.6 & 12.2 & 4.7 & 12.8 & 4.3 \\
\hline $250 \mathrm{~Hz}$ & 5 & 16.9 & 4.7 & 15.2 & 4.6 & 15.4 & 4.4 & 15.3 & 4.2 \\
\hline $315 \mathrm{~Hz}$ & 5 & 20.7 & 3.9 & 18.5 & 4.9 & 17.5 & 4.4 & 18.6 & 5.1 \\
\hline $400 \mathrm{~Hz}$ & 5 & 22.3 & 4.0 & 20.6 & 6.6 & 17.9 & 8.3 & 20.0 & 7.2 \\
\hline $500 \mathrm{~Hz}$ & 5 & 25.9 & 2.0 & 25.9 & 3.2 & 21.4 & 5.5 & 23.2 & 3.6 \\
\hline $630 \mathrm{~Hz}$ & 5 & 29.3 & 4.4 & 31.0 & 4.7 & 29.3 & 4.6 & 29.8 & 4.2 \\
\hline $800 \mathrm{~Hz}$ & 5 & 30.8 & 5.9 & 35.4 & 6.8 & 33.4 & 6.5 & 32.0 & 5.2 \\
\hline $1000 \mathrm{~Hz}$ & 5 & 30.5 & 6.8 & 38.4 & 5.1 & 33.8 & 5.5 & 32.8 & 6.0 \\
\hline $1250 \mathrm{~Hz}$ & 5 & 28.9 & 2.9 & 38.4 & 5.2 & 33.6 & 3.8 & 31.5 & 1.9 \\
\hline $1600 \mathrm{~Hz}$ & 5 & 28.6 & 2.2 & 36.0 & 7.4 & 33.3 & 3.0 & 30.5 & 2.1 \\
\hline $2000 \mathrm{~Hz}$ & 5 & 33.1 & 4.3 & 36.3 & 5.6 & 32.4 & 3.2 & 32.5 & 1.1 \\
\hline $2500 \mathrm{~Hz}$ & 5 & 31.1 & 4.9 & 36.4 & 4.4 & 35.9 & 4.9 & 32.3 & 2.7 \\
\hline $3150 \mathrm{~Hz}$ & 5 & 32.0 & 5.2 & 33.6 & 8.5 & 34.5 & 5.0 & 32.2 & 4.7 \\
\hline $4000 \mathrm{~Hz}$ & 5 & 35.3 & 5.7 & 34.5 & 12.3 & 34.5 & 8.5 & 31.0 & 8.2 \\
\hline $5000 \mathrm{~Hz}$ & 5 & 38.4 & 6.0 & 36.7 & 9.7 & 33.9 & 7.5 & 31.9 & 8.0 \\
\hline $6300 \mathrm{~Hz}$ & 5 & 33.4 & 6.3 & 34.7 & 5.9 & 30.6 & 3.5 & 29.3 & 6.5 \\
\hline $8000 \mathrm{~Hz}$ & 5 & 34.4 & 5.2 & 29.2 & 4.7 & 27.9 & 4.0 & 27.0 & 7.8 \\
\hline
\end{tabular}

\subsubsection{Results}

The results of the effect on the NRA are shown in Figures 4-3-1 and 4-3-2, and in Tables 4-3-1, 4-4-1, and 4-4-2. The average NRA difference across all the subjects among the three orientations in the office environment was only 1 or $2 \mathrm{dBA}$ for both the earplug and the earmuff, indicating that the average NRA varied little, regardless of orientation. In addition, it was also found that the difference was only 1 or $2 \mathrm{dBA}$ between any two of the three orientations in the office and the reverberatory chamber, indicating that any one of the three orientations could be used to do the fit-testing as a substitute of the reverberatory chamber.

The results of frequency-specific NR are shown in Figures 4-4-1 and 4-4-2 and in Tables 4-4-3 and 4-4-4. The NR values of the earplug or earmuff at low frequencies were comparable among the different orientations and the reverberatory chamber. The NR difference at middle and high frequencies exceeded $5 \mathrm{dBA}$ many times between different 
orientations or sound fields (office environment vs. reverberatory chamber). This was true for both the earmuff and the earplug.

In addition, the NR was usually small at low frequencies for the earmuff in any test condition. For example, it was less than $10 \mathrm{~dB}$ at $125 \mathrm{~Hz}$ and $160 \mathrm{~Hz}$, indicating that the earmuff did not provide good protection at low frequencies. The earplug was able to provide better NR at low frequency. For example, the NR ranged from $17.1 \mathrm{~dB}$ to 22.4 $\mathrm{dB}$ at $125 \mathrm{~Hz}$ and $160 \mathrm{~Hz}$. Both the earmuff and earplug provided NR protection mostly more than $30 \mathrm{~dB}$ at the middle and high frequencies.

\subsubsection{Discussion}

For the E-A-R earplug, ANOVA (see Tables 4-4-1) showed no significant difference among the three orientations (i.e., $0^{\circ}, 90^{\circ}$, and $180^{\circ}$ ) at the significance level of 0.05 . The subject effect on the NRA was significant $(\mathrm{p}<0.0001)$ for both the selected HPDs. For both selected HPDs, the interaction effect between the subject and the orientation could not be determined, due to the limited sample size.

For the earmuff (see Table 4-4-2), ANOVA showed that the orientation effect on NRA values was barely significant $(p=0.05)$. The Fisher's Least Significant Difference analysis showed that only $0^{0}$ and $180^{\circ}$ orientation were significantly different $(\mathrm{p}=0.02)$.

The results indicate that the orientation or test location (sound field) generally have an important effect on NR at middle and high frequencies but are not important at low frequencies. In addition, Berger (2000c) stated that it is common for low-recovery foam earplugs (i.e., the E-A-R earplug) to provide better noise protection than earmuff at low frequencies and equivalent or greater protection above $2000 \mathrm{~Hz}$. The result of this study supported Berger's statement.

\subsubsection{Conclusions}

The NRA changed little with testing orientation when the subjects were exposed to a sound source that was only 18 ' from their heads. Thus, any one of the three orientations could be used to do the fit-testing as a substitute of the reverberatory chamber. In addition, the orientation or test location (sound field) generally have an important effect on NR at middle and high frequencies but are not important at low frequencies. 


\section{CHAPTER 5: FIT TESTING COAL MINERS IN COAL MINE OFFICES}

The fit-testing protocol developed in the lab studies was employed to fit test coal miners' HPD in coal mine offices. The NRA of the HPDs was determined using Equation 2 (see Section 3.4). The NRA measured from the fit-testing was compared for the earplugs and earmuffs used by coal miners to determine which type of HPD was able to provide better noise protection. Additionally, the refitting effect on the NRA of coal miners' HPD was examined to determine if it was important. Moreover, the study examined whether orientation had an important effect on the NRA from fit-testing. Furthermore, this portion of the overall study determined whether different experiment order (sequences) had an important effect on the NRA in a coal miner's fit-testing measurements. As supplemental information from the fit-testing, the HPD NR at every frequency of $1 / 3^{\text {rd }}$ octave band was also reported, from which we may obtain a better understanding of the noise protection of these particular HPDs.

\subsection{Apparatus}

The apparatus employed in this study is described in the following sections.

\subsubsection{The tested HPDs}

If a miner wore an earplug for his daily noise protection in a coal mine, a customized E-A-R foam earplug (same as used in the lab studies) was provided by the investigator and worn by the coal miner during fit-tests. If a miner wore an earmuff for his daily noise protection, his own earmuff was fit tested on him. As it turned out, every subject in this study used the same low profile hardhat earmuff (Peltor, NRR 23) that had been previously employed in the lab studies. The Peltor had been selected for the lab studies because it was believed to be commonly used in the coal miners that would take part in the field studies.

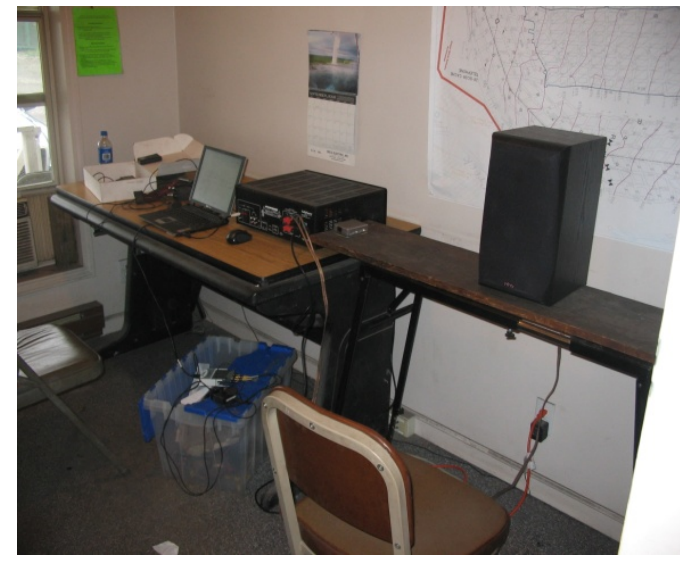

Figure 5-1- 1. Laptop, amplifier and speaker 


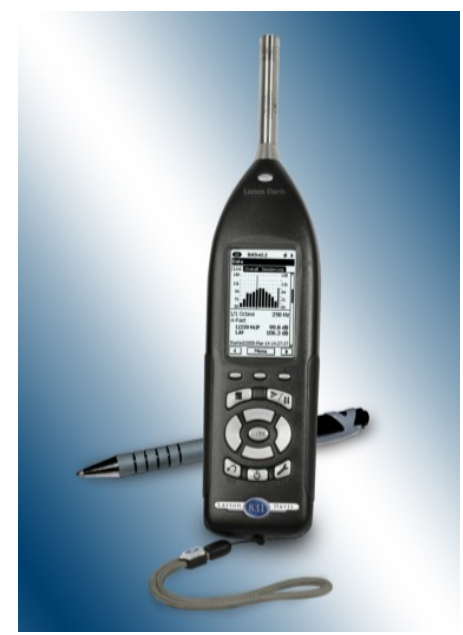

Figure 5-1-2. LXT sound level meter

\subsubsection{Instrument to generate fit-testing noise signal}

The noise signal was provided by playing an audio file on the Toshiba laptop. In coal mine fit-testing it was sent out to a Behringer Europower amplifier (EP1500) for amplification. The amplified noise signal drove an Infinity Primus P162 speaker for a 98 $\mathrm{dBA}$ near the tested ear location. A photo of the laptop, speaker, and the amplifier is shown as Figure 5-1-1. As shown in Figure 5-1-2, A "LXT" sound level meter (Larson Davis Model 831, Depew, NY) was used to assure the desired noise signal level was achieved prior to the dosimeter measurement.

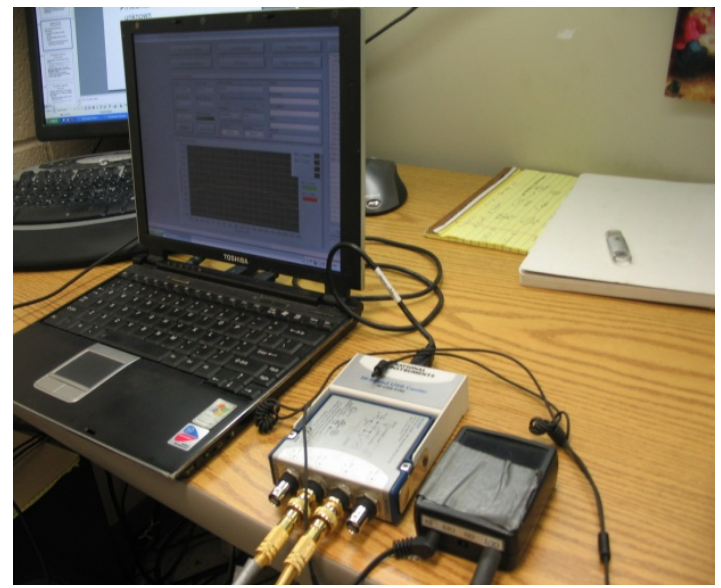

Figure 5-1- 3. Laptop, analyzer, and power source 


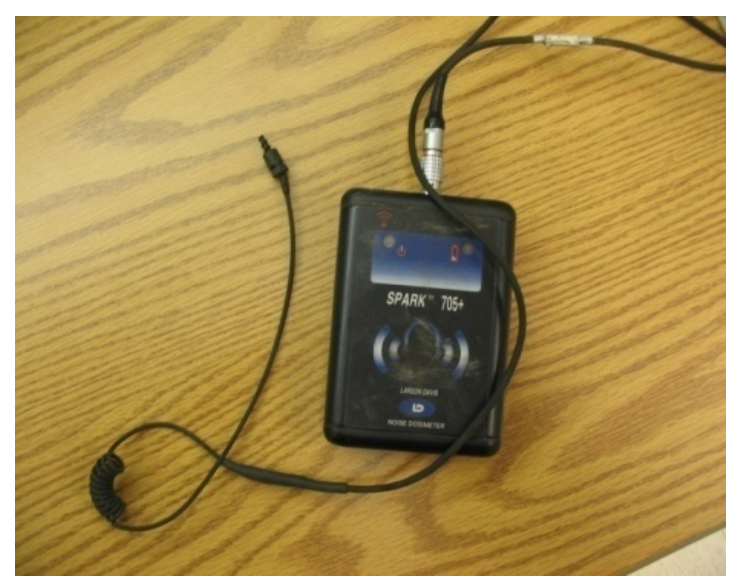

Figure 5-1- 4. Dosimeter

\subsection{Instrument used to determine $N R$}

Both a pair of dosimeters (Larson Davis Spark ${ }^{\circledR} 705+$, Depew, NY) and a National Instrument real-time analyzer (Data Wi-Fi Acquisition Hardware, Austin, TX) were employed, respectively, to measure SPLs for HPD fit-testing on the coal miner.

When the two dosimeters were used for the NR measurement, their respective microphone was used to sense the noise level, with one dosimeter microphone measuring the ambient noise level and the other measuring the noise level under the HPD. All noise level values were logged by the two dosimeters with time-stamps of every second. Both the dosimeters were operated through the Blaze software (Larson Davis, Depew, NY) installed on the Toshiba laptop for the set-up, calibration, data collection and so on. The data from the two dosimeters were retrieved later by the Blaze software and matched using their time stamp. The dosimeter could only measure the overall SPLA. A photo of the dosimeter is shown in the Figure 5-1-4.

When the analyzer was used for the fit-testing, each of the two microphones (doseBuster, USA) was connected to one of the two channels of the analyzer to simultaneously sense the noise levels, which were amplified by a power source (Michael Associates, USA) and sent to the analyzer for signal processing. Finally, the noise level information was presented on the laptop for analysis of noise levels. A photo of the laptop, analyzer \& power source are shown as Figure 5-1-3. The analyzer presented the SPL at each frequency of the $1 / 3^{\text {rd }}$ octave band ranging from $125 \mathrm{~Hz}$ to $8000 \mathrm{~Hz}$ (ANSI, $1995)$ as well as the overall noise level in $\mathrm{dBA}\left(\mathrm{SPL}_{\mathrm{A}}\right)$. In addition, it could automatically calculate the NR at each frequency as well as the overall A-weighted noise reduction, NRA, from the two microphones. 
Just before and after the fit-testing experiment, the microphones were calibrated against a standard pure tone noise signal of $114 \mathrm{~dB}$ at $1000 \mathrm{~Hz}$, which were generated by a Norsonic calibrator (Norsonic, AS, Norway, type 1251).

\subsection{Methods}

The method common throughout the coal mine fit-testing studies are described in the following sections. The methods unique to each study are presented in the individual sections pertaining to those studies.

\subsubsection{Human subjects}

A prep-plant and three underground coal mines were chosen for the field studies. Seventeen coal mine subjects from these facilities served as paid volunteer participants. They included prep-plant operators, underground continuous miners, shuttle-car operators, and roof bolters. Only those coal miners who said they "usually", "always", or "sometimes" wore a HPD in their work were allowed to participate in the study. That is, those who said they never wore their HPDs when they should have were excluded. Five of 22 coal miners were excluded from this study because they said they never wore HPD during their daily normal work. They were excluded because one of the research objectives was to examine if there was a relationship between $\mathrm{NR}_{\mathrm{A}}$ from the fit-testing and NRA during normal work. In addition, every coal miners said that they only wore either earmuff or earplug. None sometimes wore earmuffs and sometimes wore earplugs.

\subsubsection{Noise signal chosen for fit-testing}

The shuttle-car operator and the continuous miner were fit tested using the prerecorded underground noise signal since it more closely matched these work exposure than did pink noise. Likewise, the roof bolter and the prep-plant operator were fit tested with drilling noise and prep-plant noise, respectively. Each noise signal was converted into an audio wave file prior to the field studies.

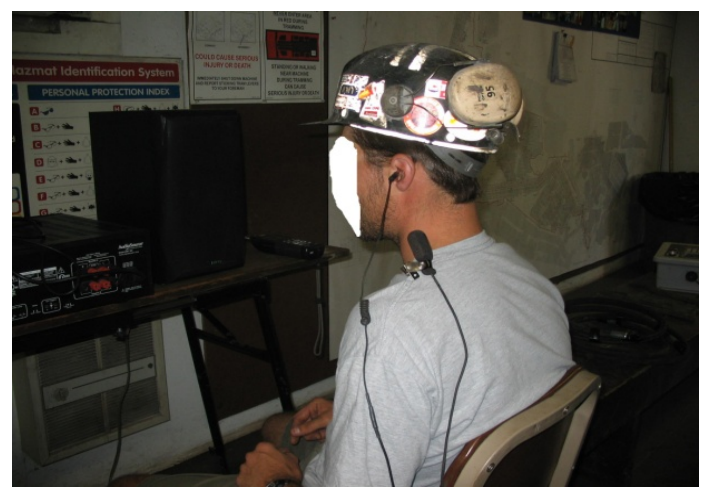

Figure 5-2- 1. Earmuff fit-testing 


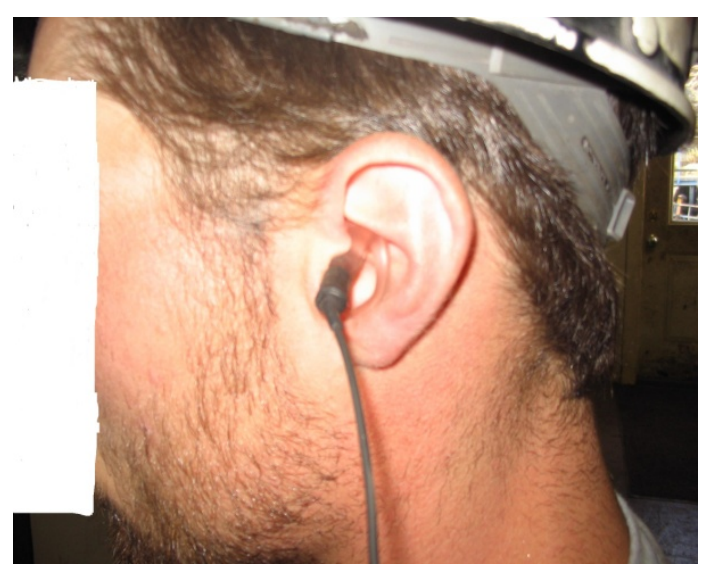

Figure 5-2-2. Earmuff fit-testing

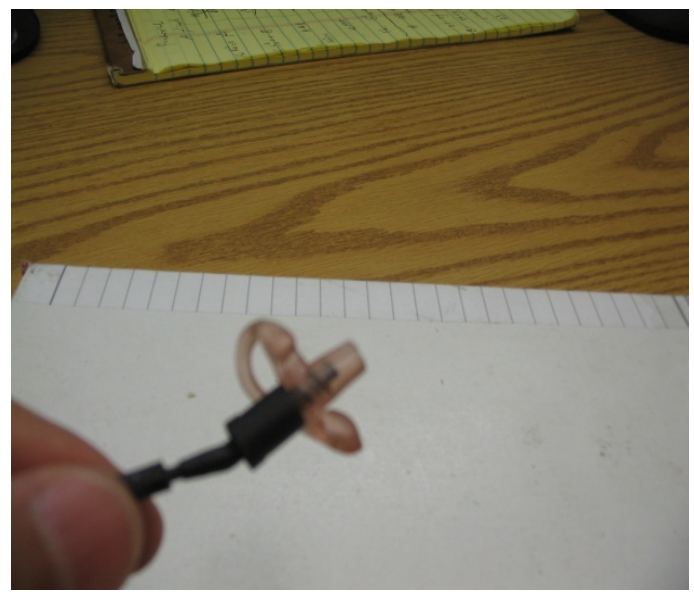

Figure 5-2-3. Microphone in earpiece

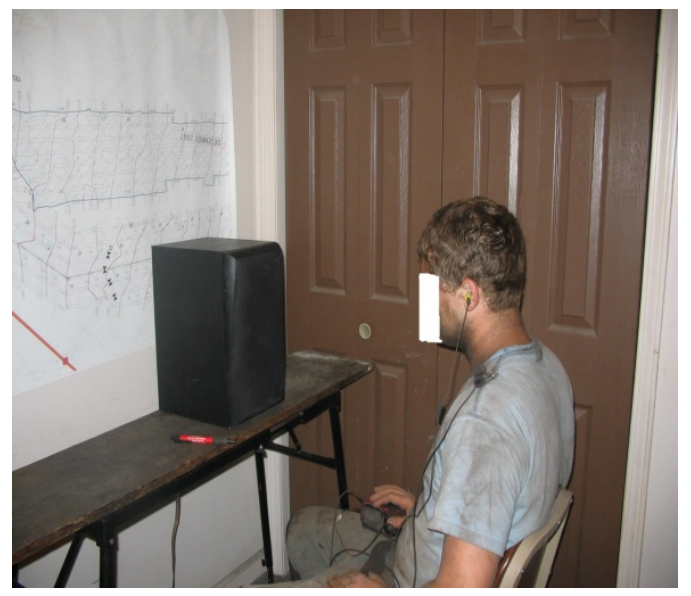

Figure 5-2- 4. Earplug fit-testing 


\subsubsection{NR measurement setting for fit-testing}

Both frequency-specific NR and overall noise reduction, NRA values, were determined by the analyzer. Only NRA values were achieved from the pair of dosimeters. The noise levels measured by the two dosimeters were compared to the values measured by the analyzers. The NRA differences were always within 1dBA. Therefore, the NRA measured by the dosimeters and by the analyzer can be considered to be the same if other conditions are identical.

As shown in Figures 5-2-1, 5-2-2, and 5-2-3 for earmuff fit-testing with the analyzer or the pair of dosimeters, one microphone was set on the middle point of the shoulder crest to measure the ambient noise level ( $\mathrm{SPL}_{\text {ambient }}$ ), while the other microphone was screwed into the hole of a soft plastic earpiece (SE-INJ Ear Tip, San Leandro, CA) (see Figure 5-2-3), which was mounted on the entrance to ear canal, with the other open end of the earpiece hole facing the ear drum ("earpiece-setting"). The earpiece was an approximately semi-circle shape with a 0.75 -inch diameter. The microphone with the earpiece on an ear was located under the earmuff to measure occluded noise level (SPLear with HPD). The noise reduction NR was computed using Equation 2.

Note that the microphone wire ran beneath the earmuff cup cushion, risking breaking the seal between earmuff cup and the subjects' flesh, and this allowing sound to leak into the muffs. The investigator compared the NRA values measured for the earpiece-setting and the standard microphone setting (see Section 4.2). The difference was about $2 \mathrm{dBA}$, a level too small to be important for decision-making concerning protection.

In the earplug fit-testing (See Figure 5-2-4) with the analyzer or the pair of dosimeters, one microphone was screwed and fixed to the end of the earplug and inserted into a mine subject's ear canal. The microphone was situated between the eardrum and the earplug, and thus measured the A-weighted noise level inside the ear canal (SPLear with HPD). The other microphone was set at the middle point of the shoulder crest to measure the Aweighted ambient noise level ( $\mathrm{SPL}_{\text {ambient }}$ ). The noise reduction NR was computed using Equation 2.

Both noise level values were logged by the two dosimeters with time-stamps of every second, with a total of fifteen SPLAs on each dosimeter. The fifteen SPLAs on each of the two dosimeters were retrieved later by the Blaze software and matched using their time stamp for calculating the NRA in each second, with a total of fifteen NRAs. The SPLA from each dosimeter and the NRA calculated in each second were examined for the response stability of the dosimeter. 


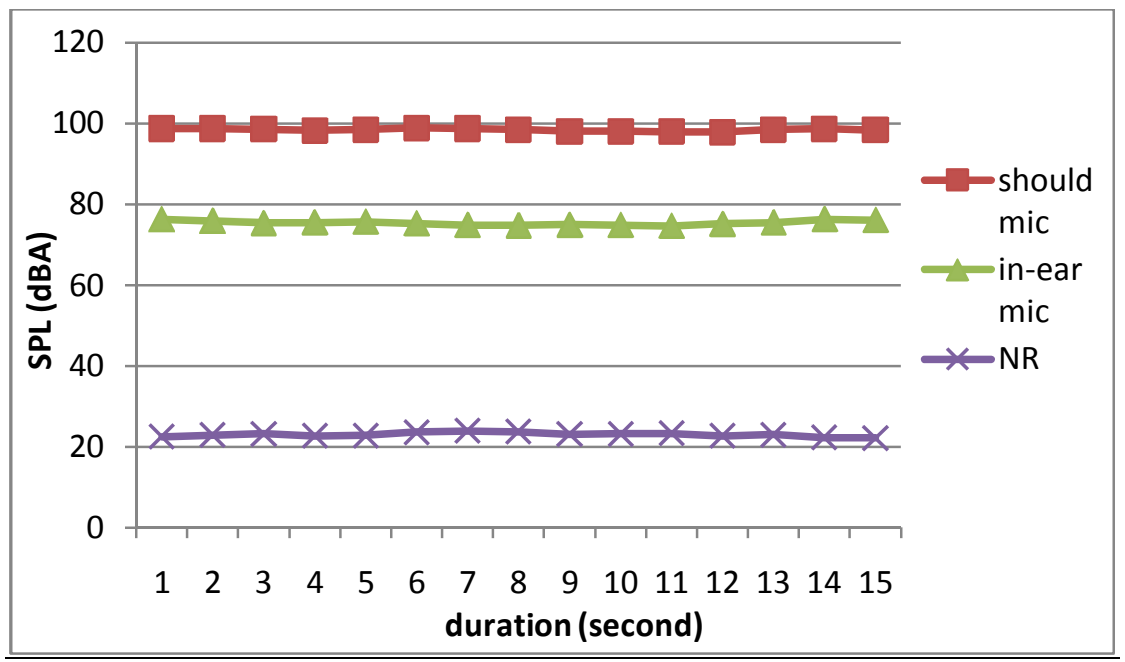

Figure 5-2- 5. Dosimeter stability testing: sampling time duration vs. NRA and SPLA (Subject 2)

Table 5-2- 1. Dosimeter stability testing (Subject 2)

\begin{tabular}{|c|c|c|c|}
\hline & $\begin{array}{c}\text { Shoulder mic } \\
\text { SPL }\end{array}$ & In-ear mic SPL & NRA \\
\hline Mean (dBA) & 98.4 & 75.4 & 23.0 \\
\hline SD (dBA) & 0.32 & 0.56 & 0.50 \\
\hline
\end{tabular}


Table 5-2- 2. Dosimeter stability testing: sampling time duration vs. NRA and SPLA (Subject 2)

\begin{tabular}{|c|c|c|c|c|}
\hline $\begin{array}{c}\text { Duration } \\
\text { (second) }\end{array}$ & Time stamp & $\begin{array}{c}\text { Should mic } \\
\text { SPL (dBA) }\end{array}$ & $\begin{array}{c}\text { In-ear mic } \\
\text { SPL (dBA) }\end{array}$ & NRA (dBA) \\
\hline 1 & $22: 50: 08$ & 98.7 & 76.2 & 22.5 \\
\hline 2 & $22: 50: 09$ & 98.7 & 75.8 & 22.9 \\
\hline 3 & $22: 50: 10$ & 98.5 & 75.3 & 23.2 \\
\hline 4 & $22: 50: 11$ & 98.2 & 75.5 & 22.7 \\
\hline 5 & $22: 50: 12$ & 98.4 & 75.6 & 22.8 \\
\hline 6 & $22: 50: 13$ & 98.8 & 75.2 & 23.6 \\
\hline 7 & $22: 50: 14$ & 98.7 & 74.8 & 23.9 \\
\hline 8 & $22: 50: 15$ & 98.4 & 74.7 & 23.7 \\
\hline 9 & $22: 50: 16$ & 98.0 & 74.9 & 23.1 \\
\hline 10 & $22: 50: 17$ & 98.0 & 74.8 & 23.2 \\
\hline 11 & $22: 50: 18$ & 97.9 & 74.6 & 23.3 \\
\hline 12 & $22: 50: 19$ & 97.8 & 75.1 & 22.7 \\
\hline 13 & $22: 50: 20$ & 98.4 & 75.4 & 23.0 \\
\hline 14 & $22: 50: 21$ & 98.6 & 76.3 & 22.3 \\
\hline 15 & $22: 50: 22$ & 98.3 & 76.1 & 22.2 \\
\hline
\end{tabular}

Figure 5-2-5, Table 5-2-1, and Table 5-2-2 showed an example how the measured SPL and NRA varied as the dosimeter sampling time lapsed for the purpose of the dosimeter stability testing. The SD of the SPLs or the NRAs measured was less than 0.6 $\mathrm{dBA}$, indicating that the second-by-second NRA and SPLs measured were approximately constant throughout the 15-second fit-testing period. Other subjects' dosimeter measurement had the same results. Therefore, the dosimeters were not a substantial source of NRA variability in the fit- testing.

Table 5-2-3. Fit-testing measurement order for the analyzer

\begin{tabular}{|c|l|c|c|c|}
\hline Replication & Refit & $0^{\circ}$ orientation & $90^{\circ}$ orientation & $180^{\circ}$ orientation \\
\hline 1 & Yes & $\sqrt{ }$ & $\sqrt{ }$ & $\sqrt{ }$ \\
\hline 2 & Yes & $\sqrt{ }$ & $\sqrt{ }$ & $\sqrt{ }$ \\
\hline 3 & Yes & & $\sqrt{ }$ & \\
\hline 4 & Yes & & $\sqrt{ }$ & \\
\hline
\end{tabular}


Table 5-2- 4. Fit-testing measurement order when using the two dosimeters

\begin{tabular}{|c|l|c|c|c|}
\hline Replication & Refit & $0^{\circ}$ orientation & $90^{\circ}$ orientation & $180^{\circ}$ orientation \\
\hline 1 & Yes & $\sqrt{ }$ & $\sqrt{ }$ & $\sqrt{ }$ \\
\hline 2 & Yes & & $\sqrt{ }$ & \\
\hline
\end{tabular}

\subsubsection{Fit-testing procedure}

The test conditions were the same for the two types of instruments (i.e., the analyzer and the dosimeters). The order of testing for the two dosimeters and the analyzer were chosen randomly. After all the measurements for the first instrument was completed, the tests were repeated using the other instrument.

The subject donned the HPD on his own effort in his "usual manner" without any help or instruction from the experimenter. He sat on a chair with the tested ear $18^{\text {" ' from }}$ the speaker for the NR measurement. The fixed orientation order of $90^{\circ}, 0^{\circ}$, and $180^{\circ}$ of the tested ear from the speaker were used in both the dosimeter and the analyzer measurements.

For the analyzer measurements, the subject was fit tested for his HPD at a fixed orientation order of $90^{\circ}, 0^{\circ}$, and $180^{\circ}$ while keeping the same HPD fitting (first replication). Then he refitted his HPD and was fit tested again at fixed order of $90^{\circ}, 0^{\circ}$, and $180^{\circ}$ while keeping the same HPD fitting (same procedure as the first replication). Then, he refitted the HPD again and was again fit tested with the tested ear only at of $90^{\circ}$. Finally, he refitted the HPD again and was fit tested with the tested ear only at $90^{\circ}$. As a result, the subject refitted his HPD four times. Accordingly, the fit-testing result from the analyzer was as follows (see Table 5-2-3): four NR measurements at $90^{\circ}$, two measurements at $0^{\circ}$ and two measurements at $180^{\circ}$.

In the two-dosimeter NRA experiment the subject fitted the HPD only once and did not refit for any test during a given replication (e.g., orientation $90^{\circ}, 0^{\circ}$, and $180^{\circ}$ ). Then he refitted the HPD again and was fit tested with the tested ear only at the $90^{\circ}$ orientation. Accordingly, the fit-testing result from the dosimeters was as follows (see Table 5-2-4): two NRA measurements at $90^{\circ}$, one measurement at $0^{\circ}$ and one measurement at $180^{\circ}$.

The detailed step-by-step experimental procedure of the fit-testing at coal mine offices were as follows:

1. The subject randomly chose the analyzer or two dosimeters for the fit-testing measurement for the first instrument. The same microphones were used for the analyzer and the dosimeters.

2. The subject sat on a chair with his tested ear 18 " away and 90 degree from the speaker. 
3. The experimenter set one microphone on the middle of the subject's shoulder crest (SPL shoulder). If the earplug was tested, the subject inserted it into his ear canal (a microphone was embedded in it) without any help or instruction. If earmuff was tested, the subject mounted the other microphone with the earpiece onto the entrance to his ear canal (see Figure 5-2-2). Then, the subject donned the earmuff without any help or instructions.

4. If an earplug was tested, the experimenter waited 30 seconds for the earplug to fully expand.

5. The experimenter turned the noise signal on and sampled the noise from the two microphones for fifteen seconds to obtain a set of SPL values (SPL shoulder and SPL ear with HPD).

6. Keeping the same microphone and HPD fitting in place, the subject changed his body position so that his tested ear was $0^{\circ}$ from the speaker.

7. Repeated Step 5.

8. Repeated Steps 6-7, except that the subject's ear was tested at $180^{\circ}$ from the speaker.

9. If the two dosimeters were used in above Steps 2-8, the subject refitted the HPD and was fit tested with his tested ear at $90^{\circ}$ from the speaker, following Steps 4-5. If the analyzer was used, went to the Step 11.

10. If the two dosimeters were used, repeated Step 9 to obtain another NR with another HPD fitting and with the tested ear at $90^{\circ}$ from the speaker, thus completed the measurement.

11. If the analyzer as used in Steps 2-8, the subject refitted the HPD and was fit tested with the same fit and with his tested ear in the fixed order of $90^{\circ}, 0^{\circ}$, and $180^{\circ}$ from the speaker, respectively. The measurements followed Steps 2-8.

12. If the analyzer was used the subject refitted the HPD and was fit tested with his tested ear at $90^{\circ}$ only from the speaker. The measurement followed Steps 4-5.

13. Repeated Step 12 for last analyzer measurement. Analyzer measurement now completed.

\subsection{Noise protection ability of the HPDs and the refitting effect}

It is first necessary to demonstrate that multiple fit-tests will produce consistent results. In addition, each times a user dons a hearing protector, a potentially different fit may be achieved. Testing after each of several re-fittings ideally would produce a narrow range of NRA values. If the range, instead, is broad, one should be concerned about the consistency and therefore the prediction of NRA value achieved by HPD. 


\subsubsection{Purpose}

This study determined the overall noise protection ability of coal miners' HPDs via fit-testing in coal mine offices. In addition, the study also determined the difference of NRA values between the earmuff and the earplug. Moreover, the refitting effect on the NRA of coal miners' HPD was examined to determine if it was important.

\subsubsection{Background}

Both Berger (2007) and Neitzel et al. (2005) indicated that a signal fit-test should accurately reflect the noise protection ability, NRA, of his (her) HPD while working. If one could prove that one-time fit-testing was accurate enough to represent a coal miner's actual fit-testing result, multiple fit-testing measurements were not necessary, which would save money and time. The experiment used common apparatuses and common method to obtain $\mathrm{NR}_{\mathrm{A}}$ in the HPD fit-testing as described in Section 5.2.

\subsubsection{Methods}

Student t-test was used to analyze the difference of NRA values between the earmuff and the earplug.

- Dependent variable: $\mathrm{NR}_{\mathrm{A}}=\left(\mathrm{SPL}_{\text {ambient }}-\mathrm{SPLear}\right.$ with $\left.\mathrm{HPD}\right)$

- Independent variable: HPD (i.e., earplug or earmuff)

- Ho: no effect of the HPD

- H1: significant effect of the HPD

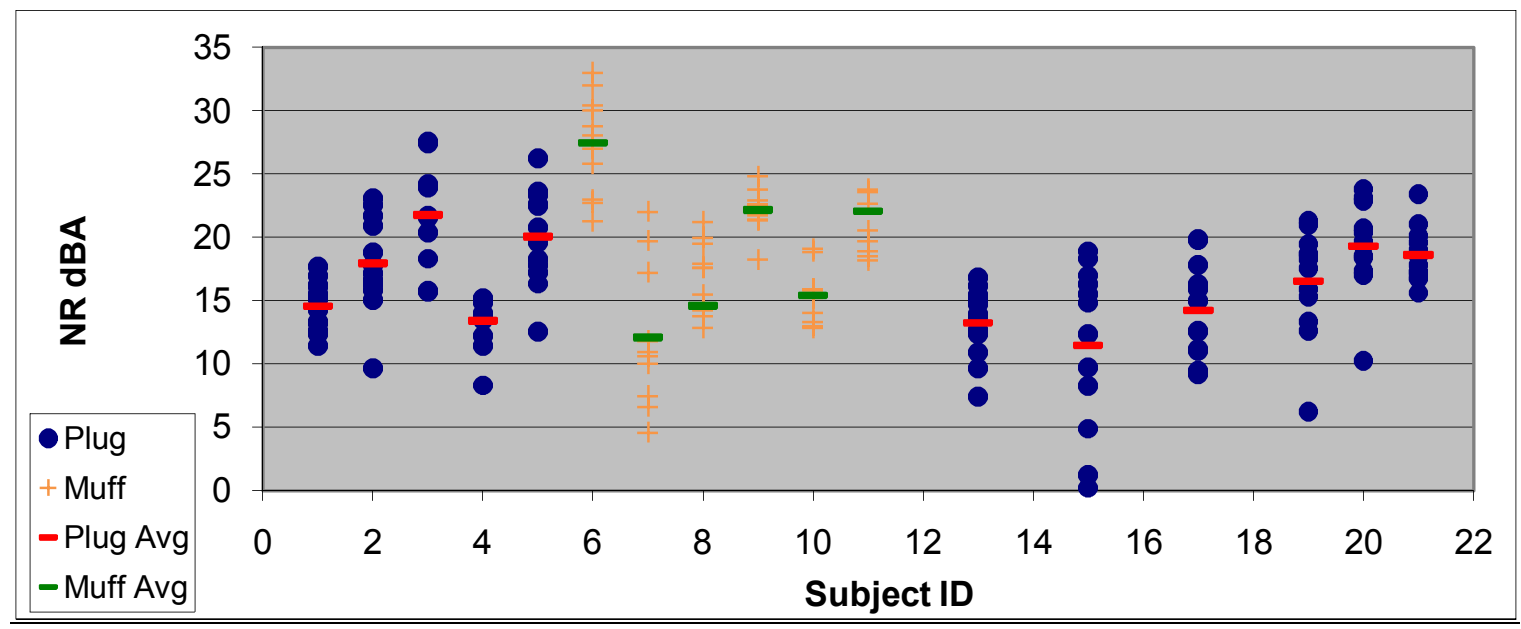

Figure 5-3-1. The HPD NRA for each individual with all measurements and orientations included 
Table 5-3- 1. The HPD NRA for each individual averaged across all measurements and orientations from fit-testing

\begin{tabular}{|c|c|c|c|c|c|}
\hline $\begin{array}{c}\text { Subject } \\
\text { ID }\end{array}$ & HPD & $\begin{array}{c}\text { Number of } \\
\text { measurements }\end{array}$ & $\begin{array}{c}\text { Mean } \\
(\mathrm{dBA})\end{array}$ & $\begin{array}{c}\text { SD } \\
(\mathrm{dBA})\end{array}$ & $\begin{array}{c}\text { Range } \\
(\mathrm{dBA})\end{array}$ \\
\hline 1 & earplug & 12 & 14.6 & 2.0 & 6.3 \\
\hline 2 & earplug & 12 & 18.0 & 3.8 & 13.5 \\
\hline 3 & earplug & 12 & 21.7 & 3.9 & 11.8 \\
\hline 4 & earplug & 12 & 13.4 & 2.0 & 6.9 \\
\hline 5 & earplug & 12 & 20.1 & 3.8 & 13.7 \\
\hline 13 & earplug & 12 & 13.2 & 2.8 & 9.4 \\
\hline 15 & earplug & 12 & 11.4 & 6.6 & 18.7 \\
\hline 17 & earplug & 12 & 14.2 & 3.8 & 10.6 \\
\hline 19 & earplug & 12 & 16.5 & 4.2 & 15.1 \\
\hline 20 & earplug & 12 & 19.3 & 3.6 & 13.6 \\
\hline 21 & earplug & 12 & 18.6 & 2.2 & 7.8 \\
\hline 6 & earmuff & 12 & 27.5 & 3.7 & 11.7 \\
\hline 7 & earmuff & 10 & 12.1 & 5.8 & 17.4 \\
\hline 8 & earmuff & 11 & 16.8 & 2.8 & 8.4 \\
\hline 9 & earmuff & 12 & 22.2 & 1.6 & 6.6 \\
\hline 10 & earmuff & 12 & 15.4 & 2.0 & 6.3 \\
\hline 11 & earmuff & 8 & 20.7 & 2.3 & 5.6 \\
\hline
\end{tabular}

Table 5-3-2. HPD NRA averaged across all measurements and orientations from fit-testing

\begin{tabular}{|c|c|c|c|}
\hline HPD & \# of subjects & Mean & SD \\
\hline Earplug & 11 & 16.5 & 3.3 \\
\hline Earmuff & 7 & 19.1 & 5.5 \\
\hline
\end{tabular}

\subsubsection{Results}

The results of the study are shown in Figure 5-3-1 and Tables 5-3-1and 5-3-2. Usable data were collected on seventeen coal mine subjects at each of three orientations (i.e., $0^{\circ}$, $90^{\circ}$, and $180^{\circ}$ ), including eleven subjects who wore the E-A-R earplug and six subjects who wore the Peltor earmuff.

Every subject achieved an average NRA value of more than $10 \mathrm{dBA}$. The mean value across all subjects was $16.5 \mathrm{dBA}$, with a SD of $3.3 \mathrm{dBA}$ for the earplug and $19.1 \mathrm{dBA}$ with a $\mathrm{SD}$ of $5.5 \mathrm{dBA}$ for the earmuff. Nine of seventeen mine subjects had a range more than $10 \mathrm{dBA}$. Every subject had a NRA range more than $5 \mathrm{dBA}$ across all his fit-testing measurements. 


\subsubsection{Discussion}

The result indicated that both the E-A-R earplug and the Peltor earmuff might be able to provide adequate noise protection, based on the fit-test result, as Berger (1996) indicated that 10- dBA noise reduction from a HPD can usually provide adequate noise protection for a person in workplace. Student t-test analysis using a pooled estimate of the variance indicated that there was no significant NRA difference $(p=0.37)$ between the earplug and the earmuff when the NRAs across all the subjects from all three orientations were averaged for the comparison. It indicated that the Peltor earmuff provided equal noise protection as the E-A-R earplug among these mine subjects.

Every mine subject had a highly variable fit-testing NRA value across all his measurements. The broad range of NRA value across all the measurements on each individual subject indicated that the NRA varied greatly from one fitting to another on each subject in his fit-testing. This was true for both the earplug and the earmuff. This broad range can make an important difference regarding the noise protection, because the protection status of a coal miner can vary from being well-protected to being in a risk of overexposure to the noise hazard, if the fit-testing result reflected his actual noise reduction during his coal mining work. Consequently, one-time fit-testing measurement was not adequate for these coal miners. Multiple fit-testing measurements were necessary to determine their actual NRA of the HPDs.

\subsubsection{Conclusions}

The noise protection provided by these two types of HPD was not different. Every coal miner was able to achieve an average NRA of more than $10 \mathrm{dBA}$ across all the fittesting measurements. However, each subject's fit-testing result was highly variable across the different fittings, indicating one-time fit-testing is not adequate, and multiple fit-testing measurements should be taken in order to determine the coal miner's actual HPD noise protection. The conclusion was true for both types of HPDs. 


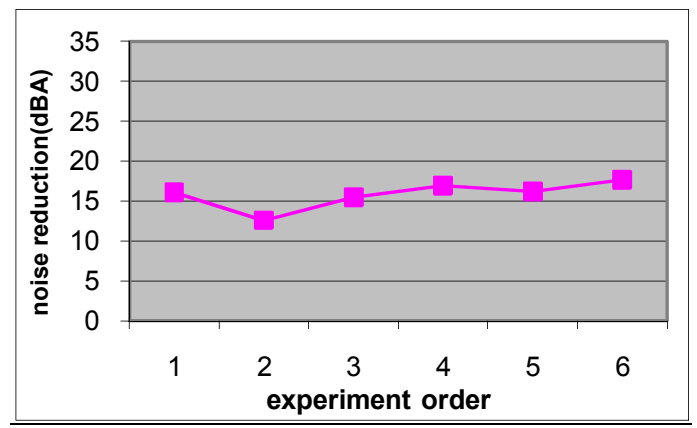

a. $\quad$ subject\#1

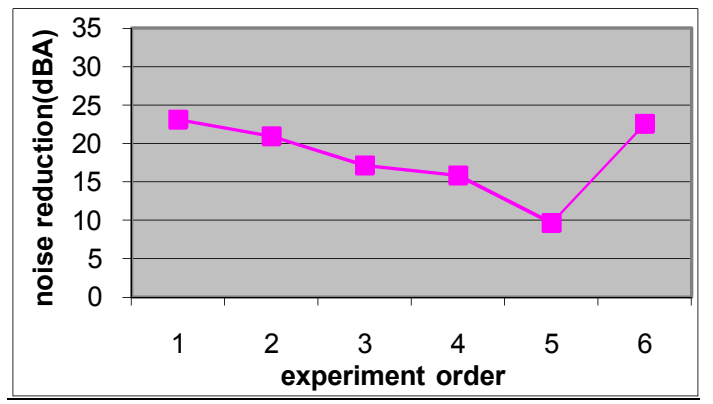

c. subject\#2

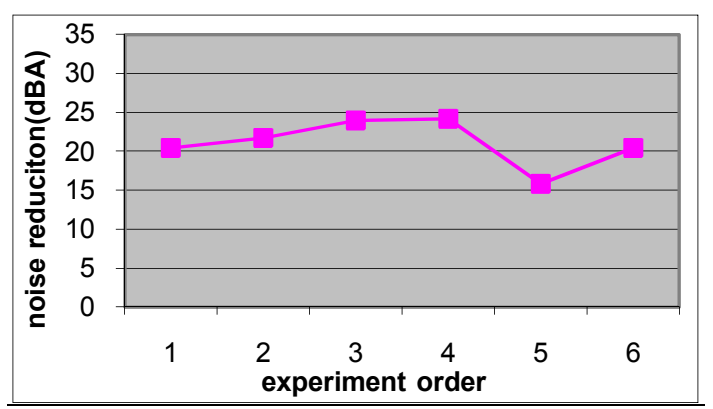

e. subject\#3

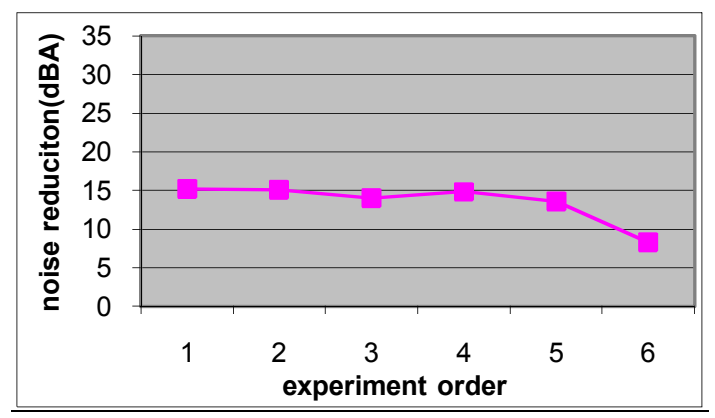

g. $\quad$ subject\#4
Note: Figure 5-4- 1. a-k individual subject results for $90^{\circ}$ orientation for E-A-R earplug fit-test

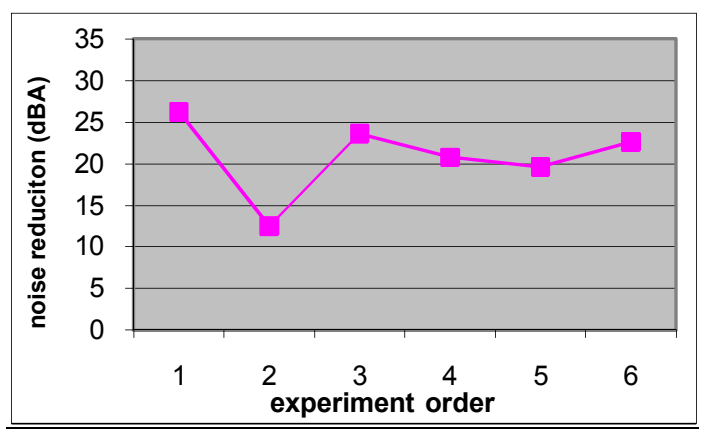

b. subject\#5

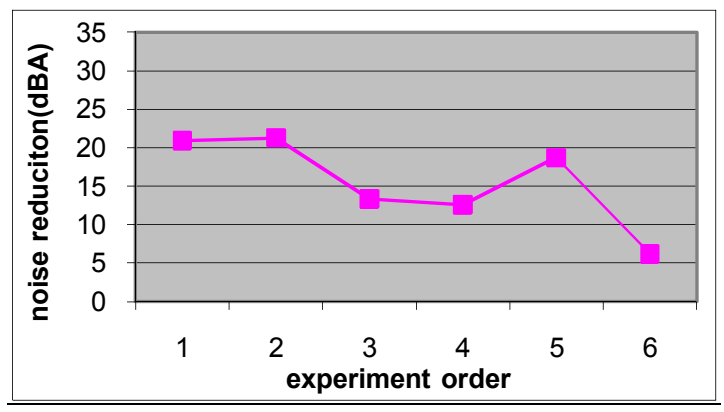

d. subject\#19

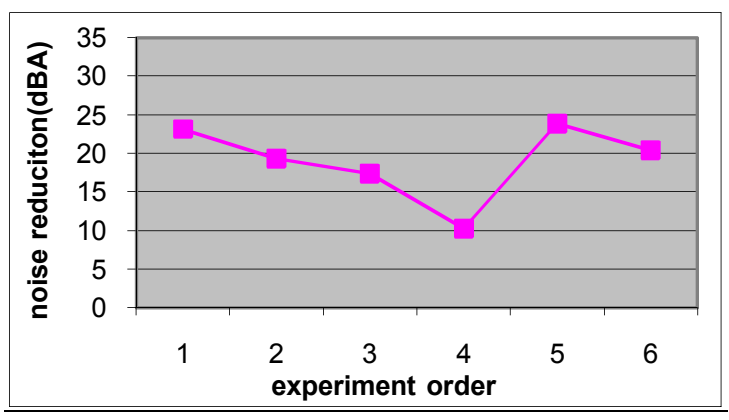

f. subject\#20

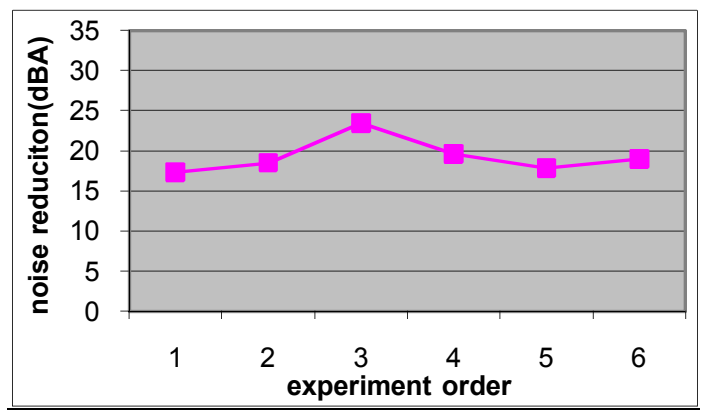

h. subject\#21 


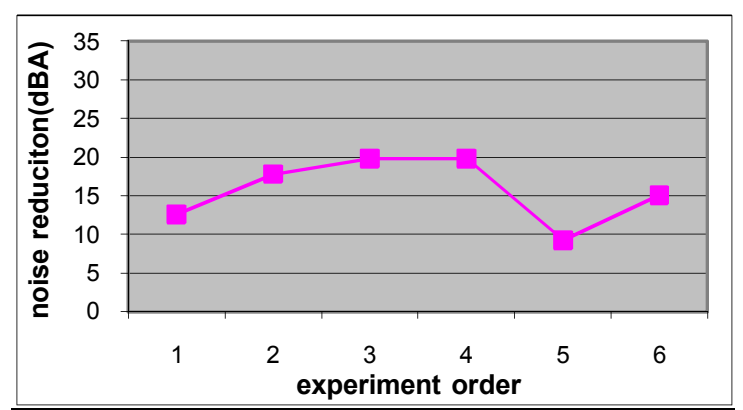

i. $\quad$ subject\#17

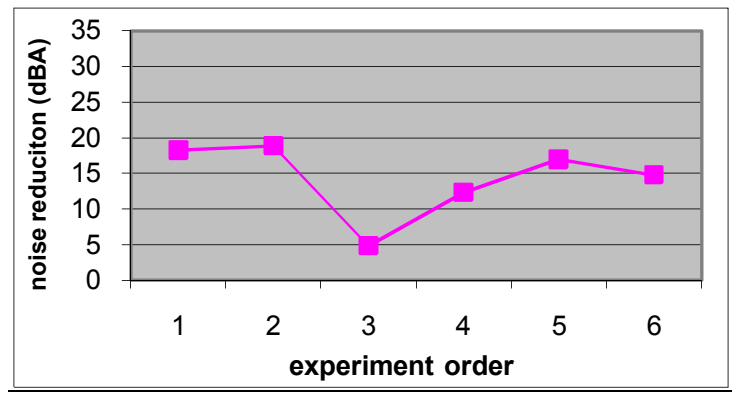

j. subject\#15

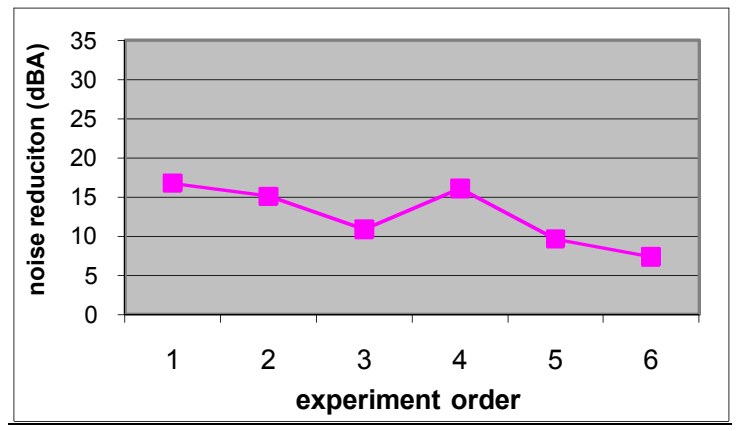

k. subject\#13

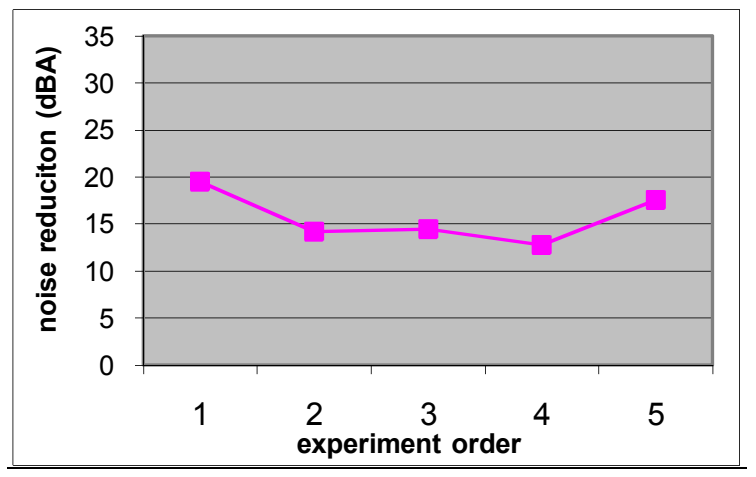

1. subject $\# 8$
Note: Figure 5-4- 2. 1-q individual subject results for 90 orientation for Peltor earmuff fit-test

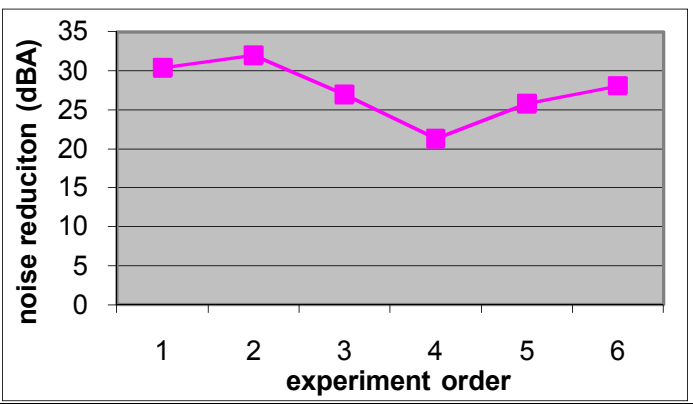

m. subject\#6

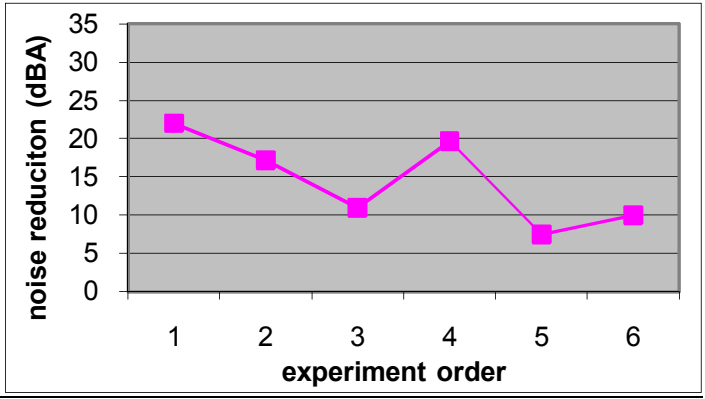

n. $\quad$ subject\#7

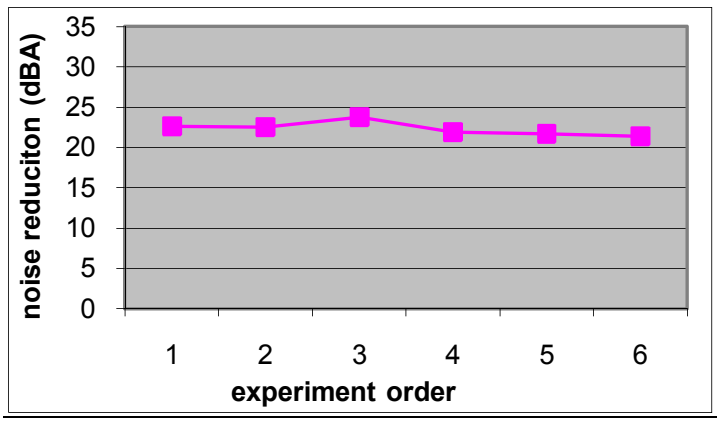

o. subject\#9

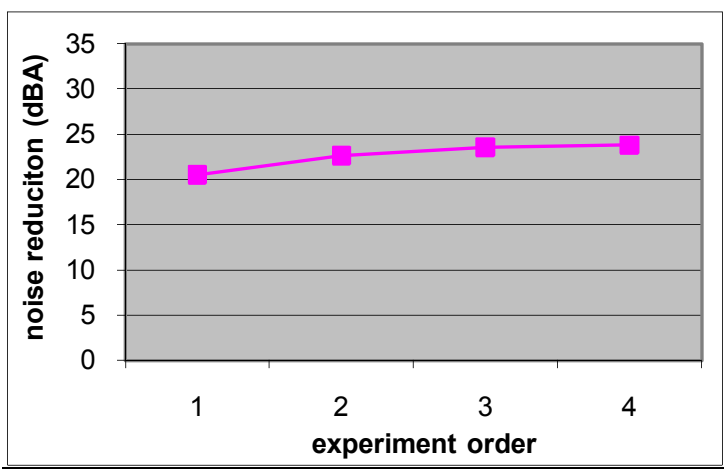

p. subject\#11 


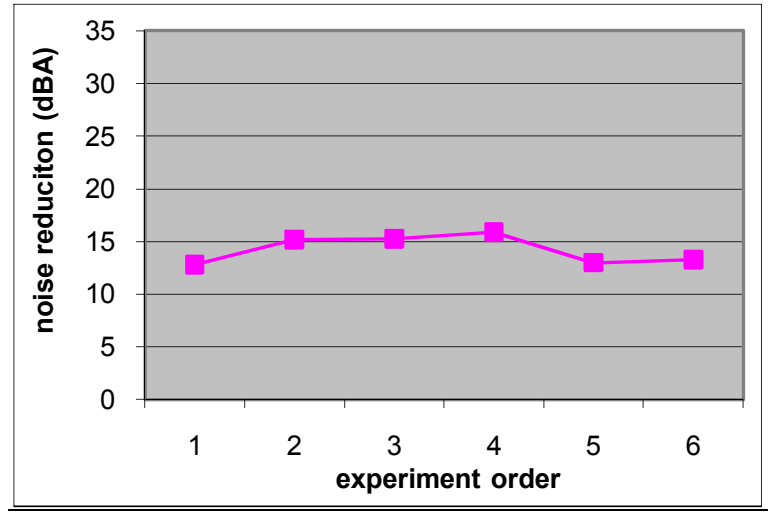

q. subject\#10

\subsection{Fit-test order effects}

One may be interested in whether the fit-test order had any effect on the NRA of mine subjects' HPDs in sequent fit-testing measurements. If the fit-test order affected the measured NRA, it would be important to determine the pattern if there was any, so that a more accurate fit-testing method may be developed to reflect the coal miners' actual noise protection provided by their HPDs.

\subsubsection{Methods}

This study did not collect more data. The fit-test order in the sequent measurements and NRA values achieved in Section 5.2 were analyzed to determine the possible effect. As described in Section 5.2., subjects were tested with a $90^{\circ}$ orientation with multiple times, each with a different fitting. Possible effects of testing order are plausible concern. All of NRAS measured were graphed and compared based on their sequent fitting order, examining if any fixed $\mathrm{NR}_{\mathrm{A}}$ change pattern could be found.

\subsubsection{Result and discussion}

The results of the study are shown Figure 5-4-1. a-k and Figure 5-4-2. L-q. In general, there were roughly three types of NRA patterns, including "V shape", "decreasing", and "random". The rough V shape pattern described six subjects $(2,5,6,8,15$, and 20); the rough decreasing pattern described five subjects $(4,7,9,13$, and 19); and the rough random pattern described six subjects $(1,3,10,11,17$, and 21$)$.

Hence, there was no consistent pattern of NRA change with the experiment (fit-test) order. Thus, it was not clear that the first, second, last or any other signal test was more consistent or a better proxy for the mean value than any other test in the sequences. We could not be based the fit-testing result on any one of these fit-testing measurements. 
The average NRA values from all of the fit-testing measurements should be used as the fit-testing result to best estimate a mine subject's real noise protection provided by the mine subject's HPD.

\subsubsection{Conclusions}

There was no fit-test order effect found. The best estimate of actual working $\mathrm{NR}_{\mathrm{A}}$ is likely to be the mean of many fit-tests.

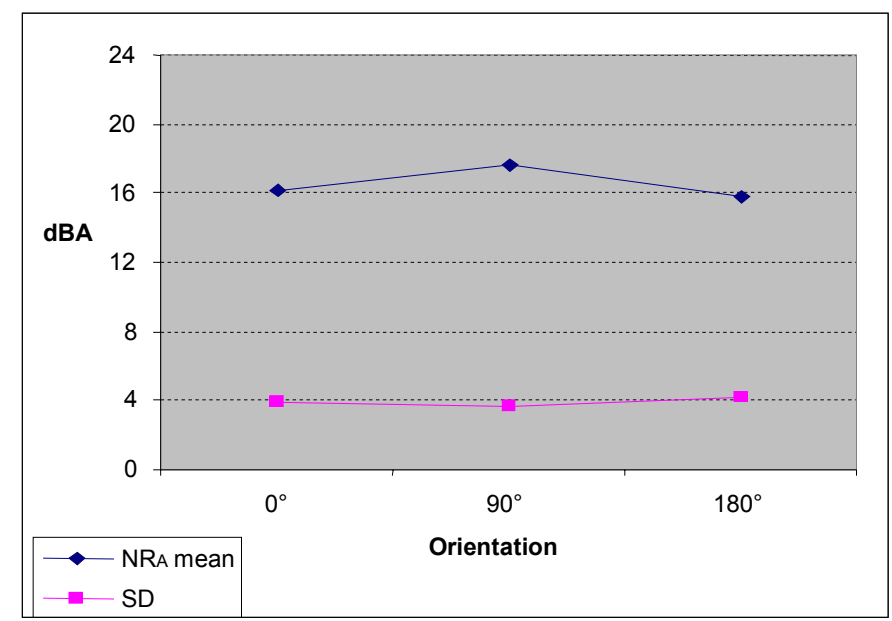

Figure 5-5- 1. NRA comparison of earplug among different orientations under the same fitting

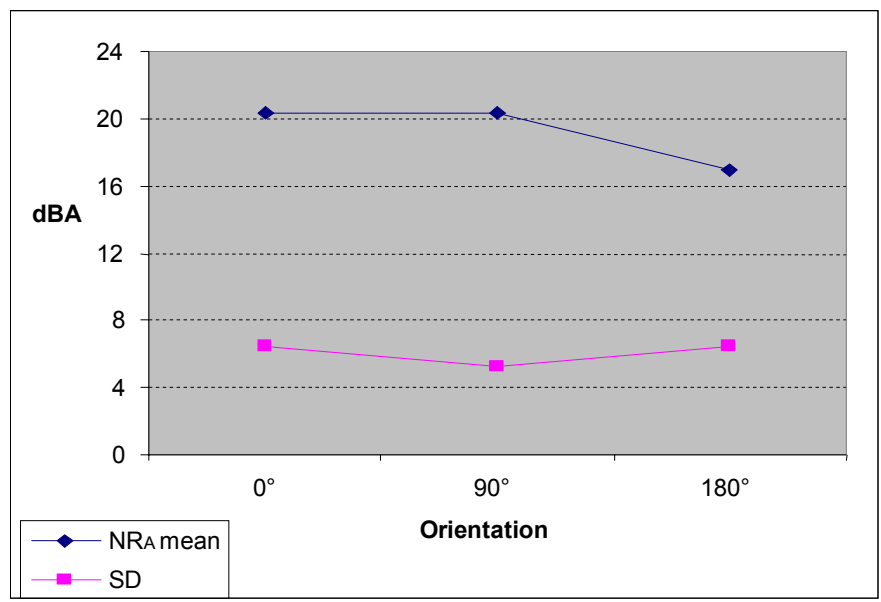

Figure 5-5-2. NRA comparison of earmuff among different orientations under the same fitting 
Table 5-5-1. NRA value for both HPDs among all three orientations with the same fitting

\begin{tabular}{|c|c|c|c|c|c|c|}
\hline HPD & Parameter & $\begin{array}{c}\# \text { of } \\
\text { subjects }\end{array}$ & $0^{\circ}$ & $90^{\circ}$ & $180^{\circ}$ & $\begin{array}{c}\text { All orientation } \\
\text { Avg }\end{array}$ \\
\hline \multirow{2}{*}{ Earplug } & $\begin{array}{c}\text { Mean } \\
(\mathrm{dBA})\end{array}$ & 11 & 16.2 & 17.6 & 15.8 & 16.5 \\
\cline { 2 - 7 } & $\mathrm{SD}(\mathrm{dBA})$ & & 3.9 & 3.7 & 4.2 & 3.3 \\
\hline \multirow{2}{*}{ Earmuff } & $\begin{array}{c}\text { Mean } \\
(\mathrm{dBA})\end{array}$ & 7 & 20.4 & 20.3 & 17 & 19.1 \\
\cline { 2 - 7 } & $\mathrm{SD}(\mathrm{dBA})$ & & 6.4 & 5.2 & 6.4 & 5.5 \\
\hline
\end{tabular}

Table 5-5-2. ANOVA of orientation and subject effect on NRA of the E-A-R earplug

\begin{tabular}{|c|c|c|c|c|c|}
\hline Source & df & $\begin{array}{c}\text { Sums of } \\
\text { Squares }\end{array}$ & $\begin{array}{c}\text { Mean } \\
\text { Square }\end{array}$ & F-ratio & Prob \\
\hline Subject & 10 & 450.6 & 45.1 & 54.8 & $<0.0001$ \\
\hline Orientation & 2 & 20.1 & 10.0 & 12.2 & 0.0003 \\
\hline Error & 20 & 16.5 & 0.8 & & \\
\hline Total & 32 & 487.2 & & & \\
\hline
\end{tabular}

Table 5-5-3. ANOVA of orientation and subject effect on NRA of the Peltor earmuff

\begin{tabular}{|c|c|c|c|c|c|}
\hline Source & df & $\begin{array}{c}\text { Sums of } \\
\text { Squares }\end{array}$ & $\begin{array}{c}\text { Mean } \\
\text { Square }\end{array}$ & F-ratio & Prob \\
\hline Subject & 5 & 489.9 & 98.0 & 16.7 & $<0.0001$ \\
\hline Orientation & 2 & 46.7 & 23.4 & 4.0 & 0.05 \\
\hline Error & 10 & 58.6 & 5.9 & & \\
\hline Total & 17 & 595.3 & & & \\
\hline
\end{tabular}

\subsection{Orientation effect on the NRA of coal miners' HPDs}

This study examined if orientation had important effect on the NRA of the coal miners' HPDs in the fit-testing in the common coal mine offices.

\subsubsection{Background}

Coal miners' ear may have different orientation from noise source during their normal coal mining work. Likewise, the coal miner's ear might be at different orientation from the noise signal in fit-testing in a coal mine office. As a result, different NRA may be obtained due to the orientation effect. Therefore, it is necessary to examine if the orientation effect on the NRA of the coal miners' HPDs exist in the fit-testing in the coal mine offices. 


\subsubsection{Methods}

This study did not collect more data. The NRA values achieved in Section 5.2 were analyzed to determine if there was any orientation effect. Those $\mathrm{NR}_{\mathrm{A}}$ values with the same fitting but at different orientation (i.e., $0^{\circ}, 90^{\circ}$, and $180^{\circ}$ ) were compared to determine whether there was significant and important effect. A total of three $\mathrm{NR}_{\mathrm{A}}$ values at each orientation met the comparison requirement. The average of three $\mathrm{NR}_{\mathrm{A}}$ values at $0^{\circ}$, the average of three $\mathrm{NR}_{\mathrm{A}}$ values at $90^{\circ}$, and the average of three $\mathrm{NR}_{\mathrm{A}}$ values at $180^{\circ}$ were compared with each other for the orientation effect study.

\section{Study design (earplug or earmuff)}

- Dependent variable: $\mathrm{NR}_{\mathrm{A}}=\left(\mathrm{SPL}_{\text {ambient }}-\mathrm{SPL}_{\text {ear with } \mathrm{HPD}}\right)$

- Independent variable: subject, orientation

- Two-way ANOVA factorial

- H0: no effect of the orientation, subject, and interaction;

- H1: significant effect of orientation, subject, and interaction

\subsubsection{Results}

The results of the study are shown in Figures 5-5-1 and 5-5-2 and Tables 5-5-1, 5-5-2, and 5-5-3. To the E-A-R earplug, the difference in mean NRA value among these three orientations was less than $2 \mathrm{dBA}$ (see Table 5-5-1). The ANOVA (see Table 5-5-2) showed the orientation effect was significant $(\mathrm{p}=0.0003)$ on the NRA. LSD Post Hoc Tests showed that the $90^{\circ}$ and $0^{\circ}$ were significantly different $(\mathrm{p}=0.001)$; the $90^{\circ}$ and $180^{\circ}$ orientation were significantly different $(p=0.0001)$, and the $0^{\circ}$ and $180^{\circ}$ were not significantly different $(\mathrm{p}=0.35)$. Note that the mean of $90^{\circ}$ and $180^{\circ}$ was not significantly different from $0^{0} .0^{0}$ is the preferable orientation for fit-test.

To the Peltor earmuff, the difference of mean NRA value among these three orientations was at most $3 \mathrm{dBA}$ (see Table 5-5-1). ANOVA (see Table 5-5-3) showed the orientation effect was significant $(\mathrm{p}=0.05)$ on the NRA. LSD Post Hoc Tests showed that the $90^{\circ}$ and $0^{\circ}$ were not significantly different $(\mathrm{p}=0.93)$; the $90^{\circ}$ and $180^{\circ}$ were significantly different $(\mathrm{p}=0.04)$, and the $0^{\circ}$ and $180^{\circ}$ were significantly different $(\mathrm{p}=$ $0.03)$.

Moreover, ANOVA showed that NRA values for different subject were significantly different $(p<0.0001)$ for both of the HPDs. 


\subsubsection{Discussion}

The results showed that orientation did not substantially affect the NRA value from fit-testing. Its effect was not important to the E-A-R earplug and the Peltor earmuff, since NRA difference between any two orientations was less than $2 \mathrm{dBA}$ for the E-A-R earplug and $3 \mathrm{dBA}$ at most for the Peltor earmuff. In addition, the average NRA at 1800 was less than that at either of other two orientations, which held true for both the earplug and the earmuff. The smaller NRA observed at 1800 was most likely because the head and body shielded the tested ear. The effect was more dramatic at the high frequencies than the low frequencies (J. A. Burks, personal communication, 2007). Nevertheless, the NRA differences between 1800 and other two orientations were not more than $3 \mathrm{dBA}$ and they are not important to fit-testing.

\subsubsection{Conclusion}

The orientation was not an important factor when fit-testing either the earplug or the earmuff.

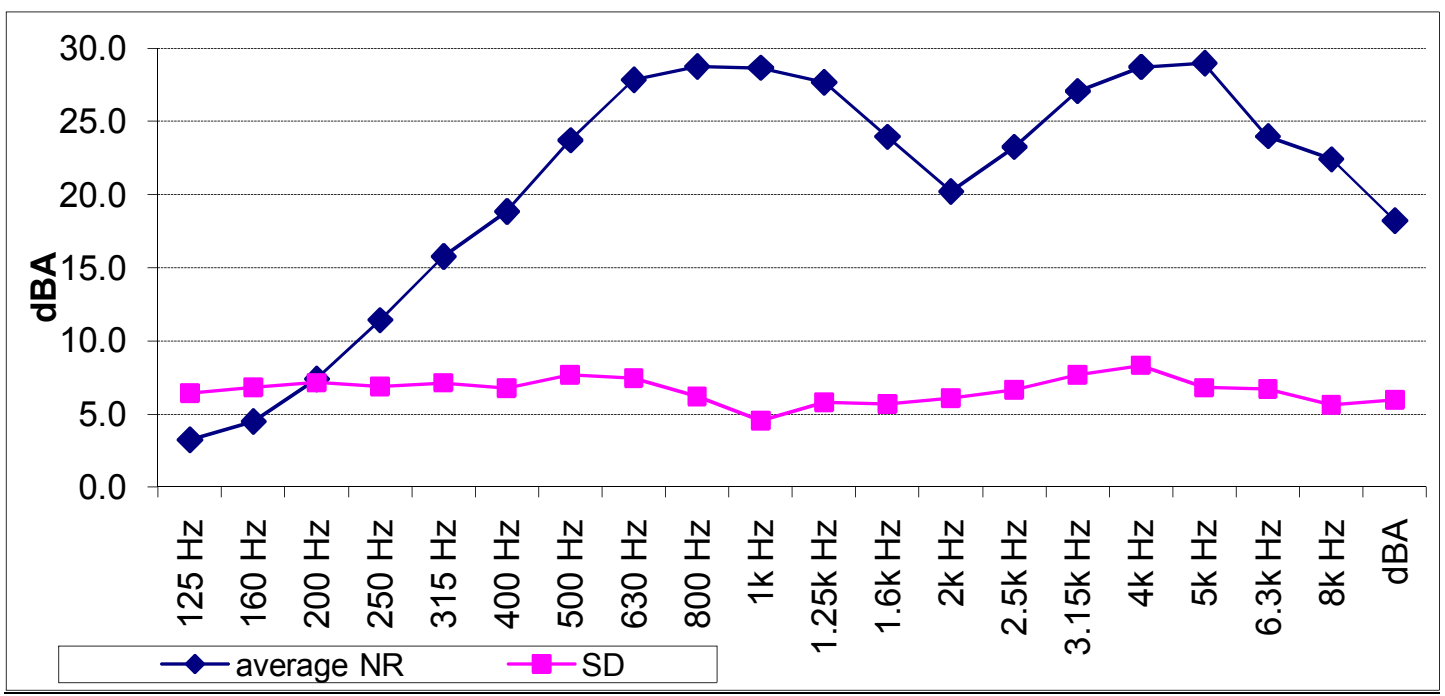

Figure 5-6- 1. Frequency-specific NR of the earmuff averaged over all orientations in the fittesting at the coal mine office 


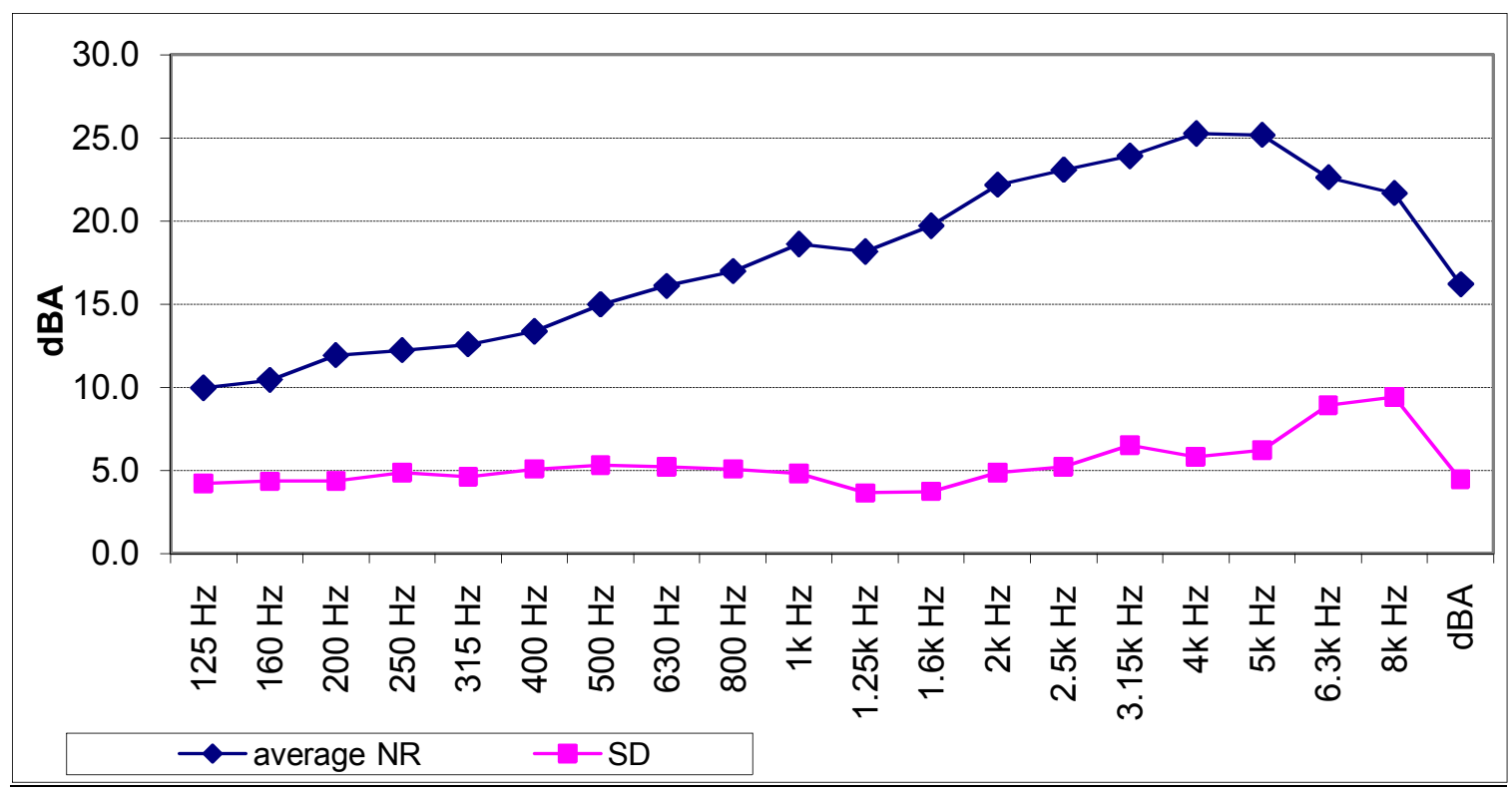

Figure 5-6- 2. Frequency-specific NR of the earplug averaged over all orientations in the fittesting at the coal mine office 
Table 5-6- 1. Frequency-specific NR of the HPDs averaged by all orientations in the fit-testing at the coal mine office

\begin{tabular}{|c|c|c|c|c|c|c|c|}
\hline HPD & Frequency & $\begin{array}{c}\text { Average } \\
\text { (dBA) }\end{array}$ & $\begin{array}{c}\mathrm{SD} \\
(\mathrm{dBA})\end{array}$ & HPD & Frequency & $\begin{array}{c}\text { Average } \\
(\mathrm{dBA})\end{array}$ & $\begin{array}{c}\mathrm{SD} \\
(\mathrm{dBA})\end{array}$ \\
\hline earmuff & $125 \mathrm{~Hz}$ & 3.2 & 6.4 & earplug & $125 \mathrm{~Hz}$ & 10 & 4.2 \\
\hline earmuff & $160 \mathrm{~Hz}$ & 4.5 & 6.8 & earplug & $160 \mathrm{~Hz}$ & 10.4 & 4.3 \\
\hline earmuff & $200 \mathrm{~Hz}$ & 7.4 & 7.1 & earplug & $200 \mathrm{~Hz}$ & 11.9 & 4.4 \\
\hline earmuff & $250 \mathrm{~Hz}$ & 11.4 & 6.9 & earplug & $250 \mathrm{~Hz}$ & 12.2 & 4.9 \\
\hline earmuff & $315 \mathrm{~Hz}$ & 15.8 & 7.1 & earplug & $315 \mathrm{~Hz}$ & 12.6 & 4.6 \\
\hline earmuff & $400 \mathrm{~Hz}$ & 18.8 & 6.8 & earplug & $400 \mathrm{~Hz}$ & 13.3 & 5.1 \\
\hline earmuff & $500 \mathrm{~Hz}$ & 23.7 & 7.7 & earplug & $500 \mathrm{~Hz}$ & 15.0 & 5.3 \\
\hline earmuff & $630 \mathrm{~Hz}$ & 27.8 & 7.4 & earplug & $630 \mathrm{~Hz}$ & 16.1 & 5.2 \\
\hline earmuff & $800 \mathrm{~Hz}$ & 28.7 & 6.2 & earplug & $800 \mathrm{~Hz}$ & 17.0 & 5.1 \\
\hline earmuff & $1 \mathrm{k} \mathrm{Hz}$ & 28.7 & 4.6 & earplug & $1 \mathrm{k} \mathrm{Hz}$ & 18.6 & 4.8 \\
\hline earmuff & $1.25 \mathrm{k} \mathrm{Hz}$ & 27.7 & 5.8 & earplug & $1.25 \mathrm{k} \mathrm{Hz}$ & 18.2 & 3.6 \\
\hline earmuff & $1.6 \mathrm{k} \mathrm{Hz}$ & 23.9 & 5.7 & earplug & $1.6 \mathrm{k} \mathrm{Hz}$ & 19.7 & 3.7 \\
\hline earmuff & $2 \mathrm{k} \mathrm{Hz}$ & 20.2 & 6.1 & earplug & $2 \mathrm{k} \mathrm{Hz}$ & 22.2 & 4.9 \\
\hline earmuff & $2.5 \mathrm{k} \mathrm{Hz}$ & 23.2 & 6.7 & earplug & $2.5 \mathrm{k} \mathrm{Hz}$ & 23.1 & 5.2 \\
\hline earmuff & $3.15 \mathrm{k} \mathrm{Hz}$ & 27.1 & 7.7 & earplug & $3.15 \mathrm{k} \mathrm{Hz}$ & 23.9 & 6.5 \\
\hline earmuff & $4 \mathrm{k} \mathrm{Hz}$ & 28.7 & 8.3 & earplug & $4 \mathrm{k} \mathrm{Hz}$ & 25.3 & 5.8 \\
\hline earmuff & $5 \mathrm{k} \mathrm{Hz}$ & 29.0 & 6.8 & earplug & $5 \mathrm{k} \mathrm{Hz}$ & 25.2 & 6.2 \\
\hline earmuff & $6.3 \mathrm{k} \mathrm{Hz}$ & 24.0 & 6.7 & earplug & $6.3 \mathrm{k} \mathrm{Hz}$ & 22.6 & 8.9 \\
\hline earmuff & $8 \mathrm{k} \mathrm{Hz}$ & 22.4 & 5.6 & earplug & $8 \mathrm{k} \mathrm{Hz}$ & 21.7 & 9.4 \\
\hline
\end{tabular}

\subsection{Frequency-specific NR values}

As a supplemental study, the frequency-specific NR was examined, by which the protection ability of the HPDs on each specific frequency was examined.

\subsubsection{Background}

If an industrial hygienist knows the noise reduction ability of a particular HPD for a coal miner at each frequency, he may help the miner to choose an appropriate HPD for reducing the noise levels of dominant frequencies, which is a more effective way for hearing protection with HPDs. 


\subsubsection{Method}

This study did not collect more data. It utilized the data achieved in Section 5.2 to do the NR analysis at each frequency of $1 / 3^{\text {rd }}$ octave band. The NR at each frequency was averaged across all the three orientations and all the subjects, which was graphed and tabled to examine the noise protection ability of the HPDs at each frequency.

\subsubsection{Result and discussion}

The results of average frequency-specific NR from all the subjects with all measurements and orientations included are shown in Figures 5-6-1 and 5-6-2, and Table 5-6-1. The observed average earmuff NR was less than $10 \mathrm{dBA}$ at the frequency of 125 , 160 and $200 \mathrm{~Hz}$, indicating that the Peltor earmuff was not able to reduce much of the noise level at the low frequencies, which is a common finding for earmuffs (Berger, 2000c). The observed average earplug NR at the low frequencies was at or above 10 $\mathrm{dBA}$, indicating the E-A-R earplug was able to provide better protection than the earmuff at the low frequencies. At middle and high frequencies, the NR from both types of HPDs exceeded $20 \mathrm{dBA}$, and the earmuff was able to reduce the noise level more than the earplug at every frequency except for the $2 \mathrm{k} \mathrm{Hz}$.

\subsubsection{Conclusions}

The earmuff was not able to reduce much of the noise level at the low frequencies; the earplug was able to provide better noise protection at low frequencies than the earmuff; at other frequencies both the HPDs were able to provide good noise protection. 


\section{CHAPTER 6: COAL MINE NOISE SAMPLING STUDIES}

It is a common practice that coal miners take off their HPDs and put them back on alternatively during their work for various reasons such as communication, comfort, etc. It is important to study the coal miner's HPD wearing behavior to examine whether a coal miner donned his HPD when the ambient noise was loud enough to be able to hurt his hearing (e.g., $85 \mathrm{dBA}$ ) and doff it if the ambient noise level was low (e.g., less than 80 dBA). If not, an appropriate noise protection program may be developed to train workers to don and doff their HPDs at appropriate times. Therefore, this study examined whether the ambient noise level had any relationship with a coal miner's HPD wearing behavior.

In the study the investigator observed each coal mine subject's use of HPD during his normal coal mining work while his noise exposure was sampled for SPL $L_{\mathrm{EAR}}$ and SPL $L_{\text {SHOULDER }}$ with noise dosimeters. The real-time NRA values for each minute throughout the sampling period were determined using Equation 2 (see Section 3.4).

Roughly $30-50 \%$ of exposure minutes were observed for HPD use for each of the coal miners. This allowed comparison of observed use of HPD to observed real-time NRA value for each minute. An algorithm developed from that data was used to determine whether a miner was wearing his HPD during unobserved minutes.

The investigator noted miner body movements and talking as often as possible, allowing the possibility of relating to the observed NRA values for the determination of their effect.

Furthermore, one may be interested in the overall noise reduction (overall NRA) of each coal miner's HPD throughout his noise sampling during his normal work, since this NRA is the real noise protection a HPD can provide for a particular miner. Therefore, this study also examined it to determine how much noise protection each HPD was able to provide to the coal miner.

Moreover, the study determined both coal miners' ambient (unprotected) noise dose and ear (protected) noise dose during their normal work. The proportion of the coal miners' ear noise dose due to failure to wear their HPDs was established, from which the importance of the coal miners' failure to wear their HPDs were examined for hearing protection.

\subsection{Field study apparatus}

The same dosimeters, HPDs, microphone earpiece, and the calibrator used in the fittesting above ground at mine offices were used at the coal mining worksites. The dosimeters were calibrated before and after the sampling. In every case the calibration 
result showed that the microphone SPL deviation from the standard pure tone signal was within $0.4 \mathrm{~dB}$ at $1000 \mathrm{~Hz}$.

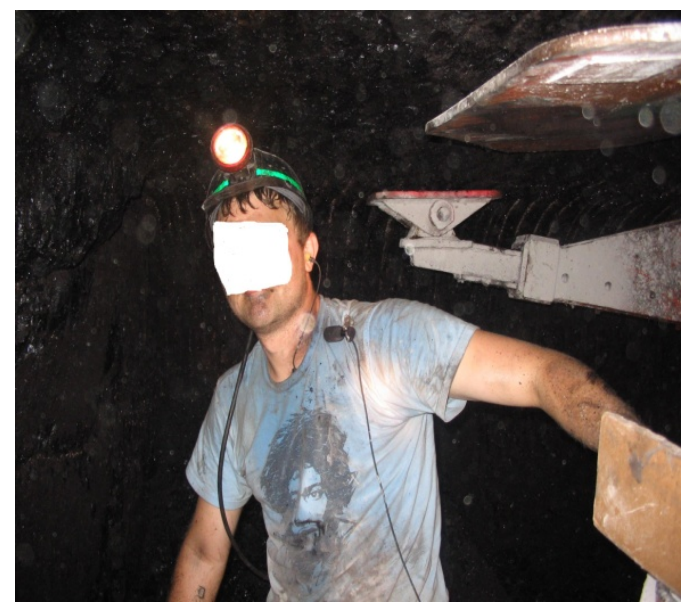

Figure 6-1 - 1. Noise sampling with two dosimeters on a mine subject at worksite

\subsection{Methods}

The methods common throughout the field studies are described in this section. The methods unique to each study are presented in the individual sections pertaining to those studies.

The same miners who had been fit-tested in the mine office wore the same HPD used for fit-testing and wore the same two dosimeters for the noise sampling during their normal coal mining work. The method to measure noise levels was the same as used in fit-testing. Namely, one microphone was mounted on the middle point of the shoulder

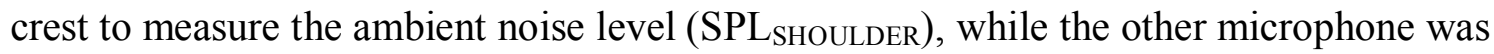
mounted under the HPD to measure the in-ear noise level (SPLEAR). The two dosimeters on a miner simultaneously sampled the second-by-second noise levels while he performed his normal work, producing time-series of exposures.

The investigator instructed each coal miner how to mount the earpiece with the microphone onto his left ear (see Figure 5-2-2 in Section 5.2) if a coal miner wore earmuff for his noise protection. The mine subject was instructed to otherwise wear the HPD (earmuff or earplug) in his usual manner. No other special instructions were given, and no advice was given to the miner when he fitted his HPD. All the coal miners tested worked an 8-hour work shift and were sampled for their full shifts. The miners stated that their work shifts had been normal. 
After both the field studies and the office fit-testing were completed, both the ambient (SPLSHOULDER $)$ noise and ear $\left(\mathrm{SPL}_{\mathrm{EAR}}\right)$ noise measurements and the corresponding sample times were downloaded from their respective dosimeters. The two sets of values were matched using their respective time and data. The NRA for each minute throughout the sampling time was calculated using Equation 2 (see Section 3.2).

\subsection{Comparing observed HPD use and tasks with body movements to observed NRA values}

This study determined whether NRA values were constant when coal miners wore their HPDs doing their normal work. If not, the low causes of NRA of the coal miners' HPDs such as movements, non-wearing and so on were examined.

\subsubsection{Background}

It is unknown if $\mathrm{NR}_{\mathrm{A}}$ of coal miners' HPDs was constant during their normal work. Some plausible factors in coal mines may lower the NRA of coal miners' HPDs. During the normal work, coal miners make various body movements to perform their work. Consequently, their HPDs may loosen and be compromised. Additionally, coal miners may not wear their HPDs correctly. Actually, some researchers (Berger, 1980c \& 1986c; Chung et al, 1983b) have suggested that improper wearing, failure to wear, and body movement seems to be the main factors to affect NRA in field. It is important to check these factors with quantitatively experimental data for their effect on NRA in coal mining work.

\subsubsection{Methods}

This study employed the method described in Section 6.2 to determine NRA values. In addition, at opportune times, the investigator observed and noted whether each mine subject was wearing his HPD or not and also noted his tasks with body movements. This allowed comparison of observed use of the miner's HPD and his body movements in his task to observed NRA value of their HPDs. 


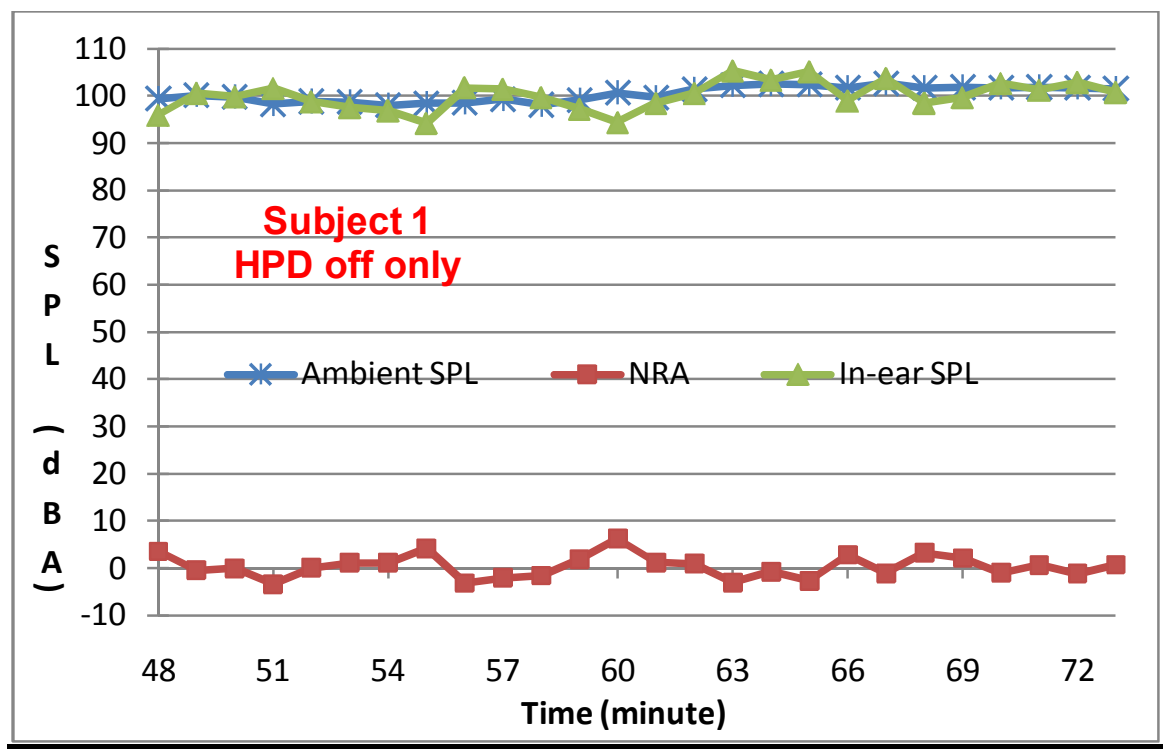

Figure 6-3-1. Observed NRA vs. time for Subject 1 with HPD off during normal work (Average $\mathrm{NRA}=0.4 \mathrm{dBA}$ )

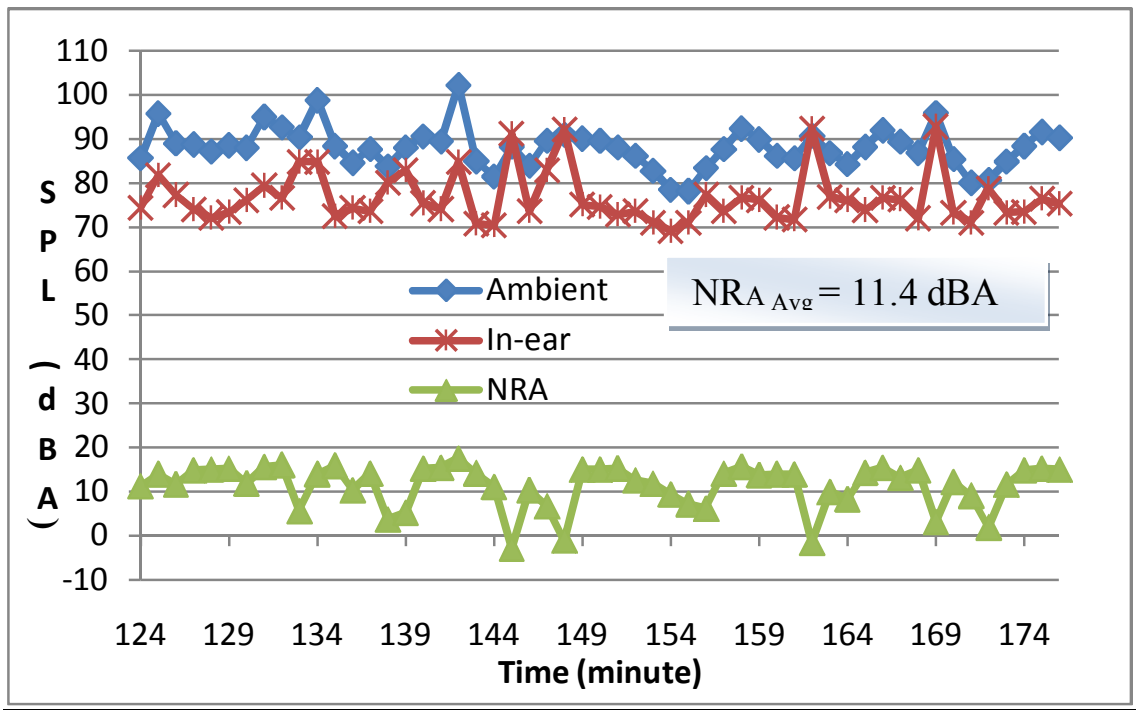

Figure 6-3-2. Observed NRA vs. time for Subject 13 with HPD on during normal work (Average NRA $=11.4 \mathrm{dBA}$ ) 
Table 6-3- 1. Observed NRA vs. time for Subject 1 with HPD off during normal work

\begin{tabular}{|c|c|c|c|}
\hline $\begin{array}{c}\text { Time } \\
(\mathrm{min})\end{array}$ & $\begin{array}{c}\mathrm{SPL} \text { ambient } \\
(\mathrm{dBA})\end{array}$ & $\begin{array}{c}\mathrm{SPL} \text { ear } \\
(\mathrm{dBA})\end{array}$ & $\begin{array}{c}\text { NRA } \\
(\mathrm{dBA})\end{array}$ \\
\hline 48 & 99.4 & 95.9 & 3.5 \\
\hline 49 & 100.1 & 100.6 & -0.5 \\
\hline 50 & 99.7 & 99.8 & -0.1 \\
\hline 51 & 98.2 & 101.6 & -3.4 \\
\hline 52 & 98.8 & 98.8 & 0 \\
\hline 53 & 98.7 & 97.6 & 1.1 \\
\hline 54 & 98.0 & 96.9 & 1.1 \\
\hline 55 & 98.4 & 94.2 & 4.2 \\
\hline 56 & 98.5 & 101.7 & -3.2 \\
\hline 57 & 99.3 & 101.4 & -2.1 \\
\hline 58 & 98.1 & 99.7 & -1.6 \\
\hline 59 & 99.1 & 97.2 & 1.9 \\
\hline 60 & 100.6 & 94.4 & 6.2 \\
\hline 61 & 99.6 & 98.4 & 1.2 \\
\hline 62 & 101.4 & 100.5 & 0.9 \\
\hline 63 & 102.2 & 105.3 & -3.1 \\
\hline 64 & 102.5 & 103.3 & -0.8 \\
\hline 65 & 102.4 & 105.1 & -2.7 \\
\hline 66 & 101.7 & 98.9 & 2.8 \\
\hline 67 & 102.6 & 103.7 & -1.1 \\
\hline 68 & 101.7 & 98.5 & 3.2 \\
\hline 69 & 101.8 & 99.7 & 2.1 \\
\hline 70 & 101.7 & 102.7 & -1 \\
\hline 71 & 101.8 & 101.2 & 0.6 \\
\hline 72 & 101.7 & 102.9 & -1.2 \\
\hline 73 & 101.5 & 100.8 & 0.7 \\
\hline Avg & 100.4 & 100.0 & 0.4 \\
\hline
\end{tabular}

Table 6-3- 2. Observed NRA vs. time for Subject 13 with HPD on during normal work

\begin{tabular}{|c|c|c|c|}
\hline $\begin{array}{l}\text { Time } \\
(\mathrm{min})\end{array}$ & $\begin{array}{c}\text { SPL ambient } \\
(\mathrm{dBA})\end{array}$ & $\begin{array}{l}\text { SPL ear } \\
\text { (dBA) }\end{array}$ & $\begin{array}{l}\text { NRA } \\
\text { (dBA) }\end{array}$ \\
\hline 124 & 85.7 & 74.4 & 11.3 \\
\hline 125 & 95.8 & 81.8 & 14 \\
\hline 126 & 89 & 77.3 & 11.7 \\
\hline 127 & 88.8 & 74 & 14.8 \\
\hline 128 & 87.2 & 72.1 & 15.1 \\
\hline 129 & 88.6 & 73.4 & 15.2 \\
\hline 130 & 88 & 76.1 & 11.9 \\
\hline 131 & 95 & 79.4 & 15.6 \\
\hline 132 & 92.7 & 76.6 & 16.1 \\
\hline 133 & 90.4 & 84.8 & 5.6 \\
\hline 134 & 98.8 & 84.8 & 14 \\
\hline 135 & 88.4 & 72.5 & 15.9 \\
\hline 136 & 84.6 & 74.3 & 10.3 \\
\hline 137 & 87.7 & 73.6 & 14.1 \\
\hline 138 & 83.8 & 80.1 & 3.7 \\
\hline 139 & 88.1 & 82.9 & 5.2 \\
\hline 140 & 90.6 & 75.4 & 15.2 \\
\hline 141 & 89.5 & 74.1 & 15.4 \\
\hline 142 & 102.2 & 84.7 & 17.5 \\
\hline 143 & 85 & 70.8 & 14.2 \\
\hline 144 & 81.5 & 70.4 & 11.1 \\
\hline 145 & 88.3 & 91.2 & -2.9 \\
\hline 146 & 84 & 73.6 & 10.4 \\
\hline 147 & 89.6 & 82.9 & 6.7 \\
\hline 148 & 91 & 92.1 & -1.1 \\
\hline 149 & 90.1 & 75.1 & 15 \\
\hline 150 & 89.6 & 74.6 & 15 \\
\hline 151 & 88.1 & 72.8 & 15.3 \\
\hline 152 & 86.2 & 73.6 & 12.6 \\
\hline 153 & 82.8 & 71 & 11.8 \\
\hline 154 & 78.5 & 69.1 & 9.4 \\
\hline 155 & 78.2 & 71 & 7.2 \\
\hline 156 & 83.4 & 77.3 & 6.1 \\
\hline 157 & 87.7 & 73.6 & 14.1 \\
\hline 158 & 92.4 & 76.7 & 15.7 \\
\hline 159 & 89.9 & 76.1 & 13.8 \\
\hline
\end{tabular}


Table 6-3-2 (cont.). Observed NRA vs. time for Subject 13 with HPD on during normal work

\begin{tabular}{|c|c|c|c|}
\hline $\begin{array}{c}\text { Time } \\
(\mathrm{min})\end{array}$ & $\begin{array}{c}\mathrm{SPL} \text { ambient } \\
(\mathrm{dBA})\end{array}$ & $\begin{array}{c}\mathrm{SPL} \text { ear } \\
(\mathrm{dBA})\end{array}$ & $\begin{array}{c}\mathrm{NRA} \\
(\mathrm{dBA})\end{array}$ \\
\hline 160 & 86.2 & 72.2 & 14 \\
\hline 161 & 85.6 & 71.7 & 13.9 \\
\hline 162 & 90.7 & 92.3 & -1.6 \\
\hline 163 & 86.8 & 76.9 & 9.9 \\
\hline 164 & 84.3 & 76 & 8.3 \\
\hline 165 & 88.2 & 73.9 & 14.3 \\
\hline 166 & 92 & 76.6 & 15.4 \\
\hline 167 & 89.4 & 76.2 & 13.2 \\
\hline 168 & 86.9 & 72 & 14.9 \\
\hline 169 & 95.9 & 92.8 & 3.1 \\
\hline 170 & 85.4 & 73.2 & 12.2 \\
\hline 171 & 80.1 & 71 & 9.1 \\
\hline 172 & 80.7 & 78.8 & 1.9 \\
\hline 173 & 84.9 & 73.3 & 11.6 \\
\hline 174 & 88.4 & 73.5 & 14.9 \\
\hline 175 & 91.6 & 76.4 & 15.2 \\
\hline 176 & 90.3 & 75.3 & 15 \\
\hline Avg & 88.1 & 76.7 & 11.4 \\
\hline $\mathrm{SD}$ & 4.6 & 5.8 & 5.0 \\
\hline
\end{tabular}

Table 6-3- 3. The effect of task with movements (tramming vs. drilling \& bolting) on the observed NRA for subjects with their HPDs on

\begin{tabular}{|c|c|c|c|c|c|}
\hline \multirow{2}{*}{$\begin{array}{c}\text { Subject } \\
\text { ID }\end{array}$} & \multirow[b]{2}{*}{ Job title } & \multicolumn{2}{|c|}{ Task: drilling and bolting } & \multicolumn{2}{|c|}{ Task: tramming } \\
\hline & & $\begin{array}{c}\text { Mean NRA } \\
(\mathrm{dBA})\end{array}$ & $\begin{array}{l}\text { Duration } \\
\text { (minute) }\end{array}$ & $\begin{array}{c}\text { Mean NRA } \\
(\mathrm{dBA})\end{array}$ & $\begin{array}{l}\text { Duration } \\
\text { (minute) }\end{array}$ \\
\hline 6 & $\mathrm{RB}$ & 23.9 & 183 & 19.8 & 17 \\
\hline 7 & $\mathrm{RB}$ & 11.6 & 154 & 8.8 & 13 \\
\hline 11 & $\mathrm{RB}$ & 22.7 & 108 & 16.4 & 26 \\
\hline 15 & RB & 15.9 & 26 & 7.6 & 8 \\
\hline 17 & $\mathrm{RB}$ & 16.9 & 30 & -0.4 & 3 \\
\hline 20 & $\mathrm{RB}$ & 15.3 & 143 & 6.7 & 37 \\
\hline 21 & $\mathrm{RB}$ & 17.8 & 144 & 11 & 33 \\
\hline \multicolumn{2}{|c|}{ Average } & 17.7 & 113 & 10.0 & 20 \\
\hline
\end{tabular}


Table 6-3- 4. Observed individual coal miner's task(s) vs. the observed NRA

(HPDs on and $\mathrm{SPL}_{\text {ambient }} \geq 80 \mathrm{dBA}$ )

\begin{tabular}{|c|c|c|c|c|c|}
\hline $\begin{array}{l}\text { Subject } \\
\text { ID }\end{array}$ & Job title & Task & $\begin{array}{l}\text { Duration } \\
\text { (minute) }\end{array}$ & Mean NRA (dBA) & $\begin{array}{c}\mathrm{SD} \\
(\mathrm{dBA})\end{array}$ \\
\hline 1 & $\begin{array}{c}\text { Prep- } \\
\text { operator }\end{array}$ & $\begin{array}{l}\text { Walk around for } \\
\text { equipment check }\end{array}$ & 171 & 13.2 & 5.9 \\
\hline 2 & $\begin{array}{c}\text { Prep- } \\
\text { operator }\end{array}$ & $\begin{array}{l}\text { Walk around for } \\
\text { equipment check }\end{array}$ & 115 & 18.0 & 2.7 \\
\hline \multirow[t]{2}{*}{3} & \multirow{2}{*}{$\begin{array}{l}\text { Prep- } \\
\text { operator }\end{array}$} & $\begin{array}{l}\text { Walk around for } \\
\text { equipment check }\end{array}$ & 83 & 21.9 & 6.7 \\
\hline & & Repair control panel & 30 & 22.0 & 1 \\
\hline 4 & $\begin{array}{c}\text { Prep- } \\
\text { operator }\end{array}$ & $\begin{array}{l}\text { Walk around for } \\
\text { equipment check }\end{array}$ & 52 & 14.1 & 4.8 \\
\hline \multirow{2}{*}{5} & \multirow{2}{*}{$\begin{array}{l}\text { Prep- } \\
\text { operator }\end{array}$} & $\begin{array}{l}\text { Walk around for } \\
\text { equipment check }\end{array}$ & 84 & 18.7 & 3.2 \\
\hline & & $\begin{array}{c}\text { Replace } \\
\text { transmission shaft }\end{array}$ & 56 & 20.9 & 3.6 \\
\hline \multirow{2}{*}{6} & \multirow{2}{*}{ Roof bolter } & Drilling and bolting & 183 & 23.9 & 6 \\
\hline & & Tramming & 17 & 19.8 & 6.1 \\
\hline \multirow{2}{*}{7} & \multirow{2}{*}{ Roof bolter } & Drilling and bolting & 154 & 11.6 & 4.9 \\
\hline & & Tramming & 13 & 8.8 & 3.5 \\
\hline \multirow{2}{*}{8} & \multirow{2}{*}{$\begin{array}{l}\text { Continuous } \\
\text { miner }\end{array}$} & Mining & 140 & 12.1 & 2.9 \\
\hline & & Loading & 50 & 11.9 & 3.4 \\
\hline \multirow{2}{*}{10} & \multirow{2}{*}{ Shuttle car } & Driving & 162 & 14.7 & 4.4 \\
\hline & & Loading & 109 & 16.6 & 3.3 \\
\hline \multirow{2}{*}{11} & \multirow{2}{*}{ Roof bolter } & Drilling and bolting & 108 & 22.7 & 8.1 \\
\hline & & Tramming & 26 & 16.4 & 4.1 \\
\hline \multirow{2}{*}{13} & \multirow{2}{*}{ Shuttle car } & Driving & 71 & 10.9 & 5.5 \\
\hline & & Loading & 49 & 13.9 & 4.2 \\
\hline \multirow{2}{*}{15} & \multirow{2}{*}{ Roof bolter } & Drilling and bolting & 26 & 15.9 & 7.5 \\
\hline & & Tramming & 8 & 7.6 & 4.9 \\
\hline \multirow{2}{*}{17} & \multirow{2}{*}{ Roof bolter } & Drilling and bolting & 30 & 16.9 & 6.2 \\
\hline & & Tramming & 3 & -0.4 & 5 \\
\hline \multirow{3}{*}{19} & \multirow{3}{*}{$\begin{array}{l}\text { Continuous } \\
\text { miner }\end{array}$} & Mining & 144 & 16.8 & 3.1 \\
\hline & & Loading & 54 & 17.5 & 2 \\
\hline & & Tramming & 50 & 12.2 & 5.2 \\
\hline \multirow{2}{*}{20} & \multirow{2}{*}{ Roof bolter } & Drilling and bolting & 143 & 15.3 & 5.4 \\
\hline & & Tramming & 37 & 6.7 & 5.9 \\
\hline \multirow{2}{*}{21} & \multirow{2}{*}{ Roof bolter } & Drilling and bolting & 144 & 17.8 & 5.1 \\
\hline & & Tramming & 33 & 11.0 & 5 \\
\hline
\end{tabular}




\subsubsection{Results}

The on-site observation durations of these coal miners' task performance during their normal work ranged from 119 to 363 minutes, with an average observation time of 217 minutes. The investigator observed that mine subjects took their HPDs off and put them back on alternatively at work. The duration between re-donning varied from one subject to another. The investigator observed no instances of improper wearing, either because they did not occurred or because the visual evidence was unclear. Therefore, there were no clear evidences that improper wearing was a cause of low NRA value. The mine subjects seldom touched their HPDs during the normal work activities, unless they wanted to take them off.

Figure 6-3-1 and Table 6-3-1 show a typical example of the observed NRA values from Subject 1 when his HPD was off his ear. As shown, the majority of the NRA values were either negative or close to $0 \mathrm{dBA}$. This demonstrated the obvious point that failure to wear a HPD dramatically affected the level of protection, and it was an important cause of low NRA values.

In addition, the observed NRA varied for each subject when his HPD was worn. Figure 6-3-2 and Table 6-3-2 show a typical example of the observed NRA values from Subject 13, as he wore his HPD doing his normal work. As shown, his observed NRA varied greatly over a broad range from negative to positive values ( -2.9 to $17.5 \mathrm{dBA}$ ). The standard deviation of the NRA was high, yet the investigator saw no refitting or adjustment of his HPD despite continuous observation by the investigator over the entire period. Hence, there was no obvious source of the high variability. Clearly, NRA was far from constant but fluctuated widely during coal miners' normal work.

Tables 6-3-3 shows the observed NRA values from each of the mine subjects as he wore his HPD to perform typical tasks, each of which involved a diverse (but different) set of body movements. Some subjects were observed only for one type of task (e.g., the task of "walk around for equipment check" from Subject 1. In that situation it was difficult to characterize degrees of movement effects in order to relate them to observed NRA values. Other subjects were observed for two or more tasks with different movements involved. However, these different tasks (e.g., "Shuttle Car," which involved driving task and loading) did not appear to have obviously different vigor of movements, again making it difficult to compare the movements in order to relate them to NRA values. However, seven coal miners whose job title was "Roof Bolter" were observed to do two clearly different tasks, "Drilling and Bolting" and "Tramming", which had clearly different degrees of energetic movements. The task of drilling and bolting appeared having much more energetic movements than the task of tramming did. The latter mostly involved walking along following the mining machine. These seven coal miners' average NRA was compared for the two different tasks to examine the movement effect. As 
shown in Table 6-3-3, the average NRA during the task of drilling and bolting was 17.7 $\mathrm{dBA}$ and only $10 \mathrm{dBA}$ during the task of tramming. This result suggested that the vigor of movements did not reduce NR values. Hence, there was no basis to judge vigor of movements to be an important cause of low NRA values.

\subsubsection{Discussion}

Earshen (2003) stated that humidity may have some substantial effect on microphones. During the coal mining related work activities the coal miner made a lot of torso and head movements. As a result, they might sweat, which would generate a highly humid environment for a prolonged period of time to the microphone under the HPDs. Therefore, it was conceivable that the effect of humidity on the microphone was a contributory cause of highly variable NRA.

\subsubsection{Conclusions}

The NRA of coal miners' HPDs was not constant but fluctuated widely for all subjects for both earplugs and earmuffs. Failure to wear the HPD was a main cause of the low NRA values. Since the improper HPD wearing was not found on current mine subjects, it did not lead to the low NRA values. Moreover, vigor of movement in tasks was not related to variability. The humidity conceivably could affect the microphone readings.

\subsection{Estimating HPD use (i.e., wearing or non-wearing) during non- observed periods}

The purpose of this study was to determine the coal miners' HPD use (i.e., wearing or non-wearing) during non-observing periods.

\subsubsection{Background}

If the values were zero when HPD were not worn and were never zero when they wore, this would be a trivial exercise. Instead, as discussed earlier, NRA values ranged from negative to positive when the HPD was worn, making it less than clear from the sound level readings when they were worn and when not. However, it was not feasible in this study for the investigator to observe each subject at all times to determine when they did and did not wear their HPDs. In addition, it is likely that the miners' use of HPD was different when observed than when they were not observed.

For those reasons, this study developed and validated a method to use patterns in NRA values to identify when HPD were not worn., which made the method to judge the wearing status complicated. 


\subsubsection{Methods}

This study employs NRA data described in Section 6.2.

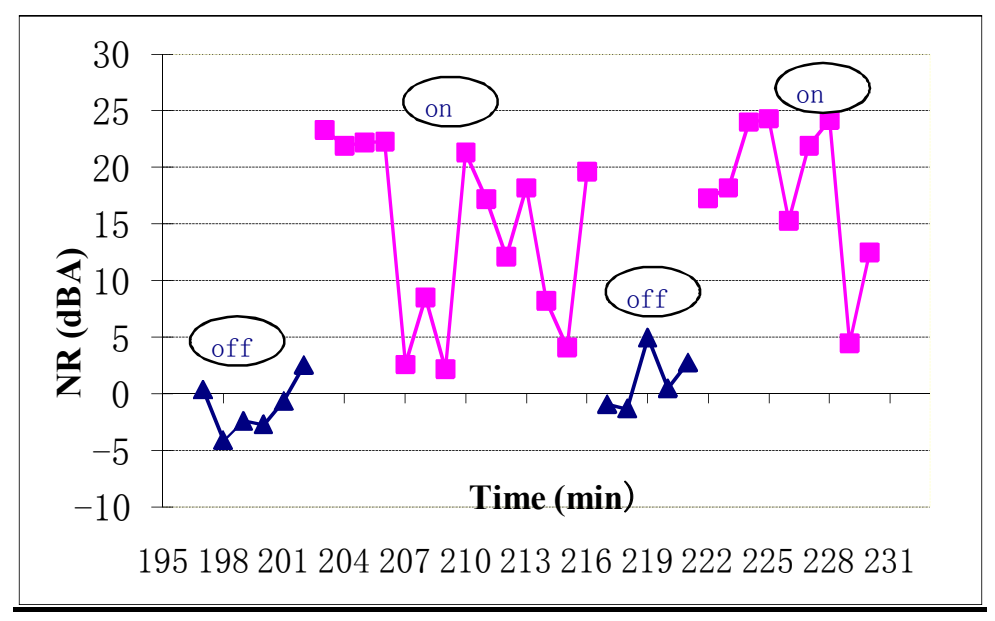

Figure 6-4- 1. HPD wearing status ("off" or "on") for observed periods for Subject 15 (Judged totally agreed with observed in this example) 
Table 6-4- 1. Judgment method example of the HPD wearing status ("off" or "on") for observed periods for Subject 15

\begin{tabular}{|c|c|c|c|c|}
\hline $\begin{array}{l}\text { Time } \\
\text { (min) }\end{array}$ & $\begin{array}{c}\mathrm{NR} \\
(\mathrm{dBA})\end{array}$ & $\begin{array}{c}\text { 1/3 Median } \\
(\mathrm{dBA})\end{array}$ & $\begin{array}{c}\text { Observed } \\
\text { HPD }\end{array}$ & $\begin{array}{c}\text { Judged } \\
\text { HPD }\end{array}$ \\
\hline 197 & 0.4 & 5.7 & off & 1 \\
\hline 198 & -4.1 & 5.7 & off & 1 \\
\hline 199 & -2.4 & 5.7 & off & 1 \\
\hline 200 & -2.7 & 5.7 & off & 1 \\
\hline 201 & -0.6 & 5.7 & off & 1 \\
\hline 202 & 2.6 & 5.7 & off & 1 \\
\hline 203 & 23.3 & 5.7 & on & 0 \\
\hline 204 & 21.9 & 5.7 & on & 0 \\
\hline 205 & 22.2 & 5.7 & on & 0 \\
\hline 206 & 22.3 & 5.7 & on & 0 \\
\hline 207 & 2.6 & 5.7 & on & 0 \\
\hline 208 & 8.5 & 5.7 & on & 0 \\
\hline 209 & 2.2 & 5.7 & on & 0 \\
\hline 210 & 21.3 & 5.7 & on & 0 \\
\hline 211 & 17.2 & 5.7 & on & 0 \\
\hline 212 & 12.1 & 5.7 & on & 0 \\
\hline 213 & 18.2 & 5.7 & on & 0 \\
\hline 214 & 8.2 & 5.7 & on & 0 \\
\hline 215 & 4.1 & 5.7 & on & 0 \\
\hline 216 & 19.6 & 5.7 & on & 0 \\
\hline 217 & -0.9 & 5.7 & off & 1 \\
\hline 218 & -1.3 & 5.7 & off & 1 \\
\hline 219 & 5 & 5.7 & off & 1 \\
\hline 220 & 0.5 & 5.7 & off & 1 \\
\hline 221 & 2.8 & 5.7 & off & 1 \\
\hline 222 & 17.3 & 5.7 & on & 0 \\
\hline 223 & 18.2 & 5.7 & on & 0 \\
\hline 224 & 24 & 5.7 & on & 0 \\
\hline 225 & 24.3 & 5.7 & on & 0 \\
\hline 226 & 15.3 & 5.7 & on & 0 \\
\hline 227 & 21.9 & 5.7 & on & 0 \\
\hline 228 & 24.2 & 5.7 & on & 0 \\
\hline 229 & 4.5 & 5.7 & on & 0 \\
\hline 230 & 12.5 & 5.7 & on & 0 \\
\hline
\end{tabular}

$*(0=$ off; $1=$ on $)$ 


\subsubsection{Method}

A "wearing status judgment method" was developed based on periods when the subjects were observed wearing or not wearing their HPDs. An original goal to also observe periods of "poor" fit proved unworkable because the investigator saw no visible evidence of poor fit besides failure to wear.

To make the judgments, the particular minute being judged was included in a row of five continuous minutes (one $\mathrm{NR}_{\mathrm{A}}$ for each minute) with two prior to the current minute and the two following. The HPD was judged to be off for this particular minute if the following two conditions could be met: (1) at least three of the five NRA values from the five continuous minutes were each less than $1 / 3^{\text {rd }}$ of median $\mathrm{NR}_{\mathrm{A}}$ as calculated from all the field $\mathrm{NR}_{\mathrm{A}}$ data for this particular subject for that day, and (2) the $\mathrm{NR}_{\mathrm{A}}$ of the "judged" minute (the median minute) was less than $1 / 3^{\text {rd }}$ of the median. Otherwise, the HPD was judged to be worn for the current minute.

Figure 6-4-1 and Table 6-4-1 shows an example application of the judgment method to each-minute HPD wearing status of Subject 1 for an observed period. For instance (see Table 6-4-1), to determine the wearing status for the $202^{\text {nd }}$ sampling minute, one can find that the NRA at the $202^{\text {nd }}$ minute was $2.6 \mathrm{dBA}$. The row of five continuous minutes for the $202^{\text {nd }}$ minute was $200^{\text {th }}, 201^{\text {st }}, 202^{\text {nd }}, 203^{\text {rd }}$, and $204^{\text {th }}$ minute, in which the $202^{\text {nd }}$ minute was the median minute. The corresponding NRAS for these minutes were -2.7, - 0.6 , 2.6, 23.3, and 21.9 dBA. It was found that the median $\mathrm{NR}_{\mathrm{A}}$ of all the field $\mathrm{NR}_{\mathrm{A}}$ data for Subject 1 was $17.2 \mathrm{dBA}$. One third of the median $\mathrm{NR}_{\mathrm{A}}$ was thus $5.7 \mathrm{dBA}$. Based on the two conditions for the judgment as shown above, (1) The corresponding $\mathrm{NR}_{\mathrm{A}}$ for the $200^{\text {th }}, 201^{\text {st, }}$ and $202^{\text {nd }}$ minute was each less than the $5.7 \mathrm{dBA}$, indicating that at least three $\mathrm{NR}_{A S}$ in the row of the five minutes were less than the $1 / 3^{\text {rd }}$ of median $\mathrm{NR}_{\mathrm{A}}$, and (2) the $\mathrm{NR}_{\mathrm{A}}$ at the $202^{\text {nd }}$ minute was also less than the $1 / 3^{\text {rd }}$ of median NRA. Thus the HPD was judged to be off (not worn) in the $202^{\text {nd }}$ minute.

It should be pointed out that, when applied to the first and the last minutes of the sampling period, the judgment method was necessarily modified, since the prior or post minutes respectively were not present. Judgment was nearly always clear in these cases and three-minute-in-a-row was adequate for making an adequate judgment. Moreover, many times the usage behavior (wearing status) of these minutes at the very beginning or toward the end of the sampling period was known since the investigator was present to observe it and confirm the predictions from the three available NRA values.

Both MSHA and NIOSH employ a sampling threshold of $80 \mathrm{dBA}$, below which the noise dose is considered to be zero. Therefore, the investigator only analyzed data for which $\mathrm{SPL}_{\text {ambient }} \geq 80 \mathrm{dBA}$. 
The judgment method of the wearing status was applied to every NRA in every minute throughout the non-observed sampling time, so that the time periods for wearing and non-wearing could be determined.

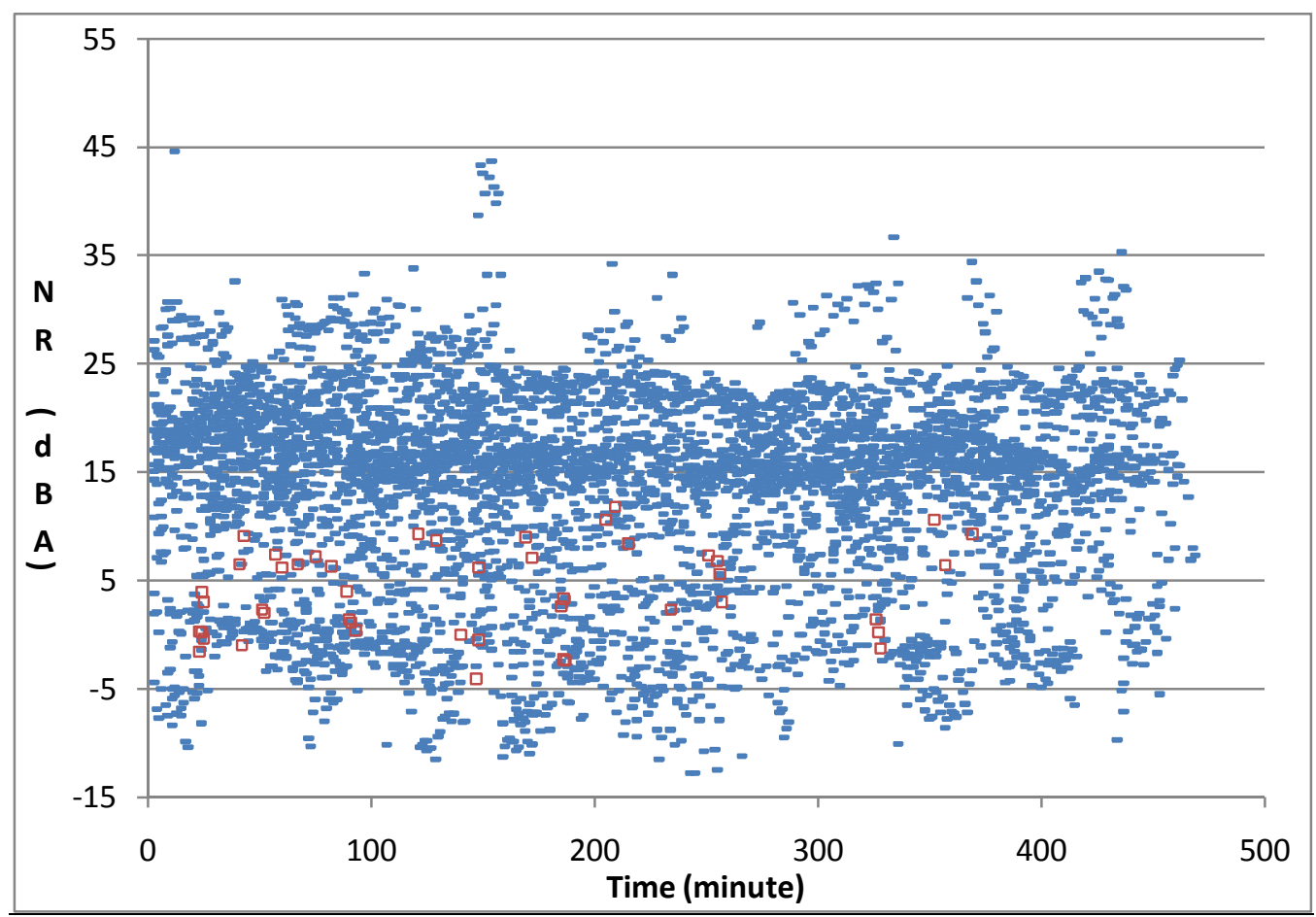

Figure 6-4- 2. Compare "judged" with observed use of HPD during work (The red hollow squares were the $2 \%$ of cases where judged disagreed with observed)

\subsubsection{Results and discussion}

The wearing status was compared for the "judged" and the observed actual use of HPD. The results are shown in Figure 6-4-2. The red hollow squares were cases where judged minutes disagreed with observed minutes. Less than 125 of 6281 were disagreed, an error rate of less than $2 \%$, indicating that the judgment method was accurate enough to determine a coal miner's HPD wearing status for non-observed periods. Therefore, the judgment method was applied to every minute for each subject for both the observed and unobserved periods.

\subsubsection{Conclusions}

The wearing status judgment method was correct over $98 \%$ of the time when the wearing status was known. 


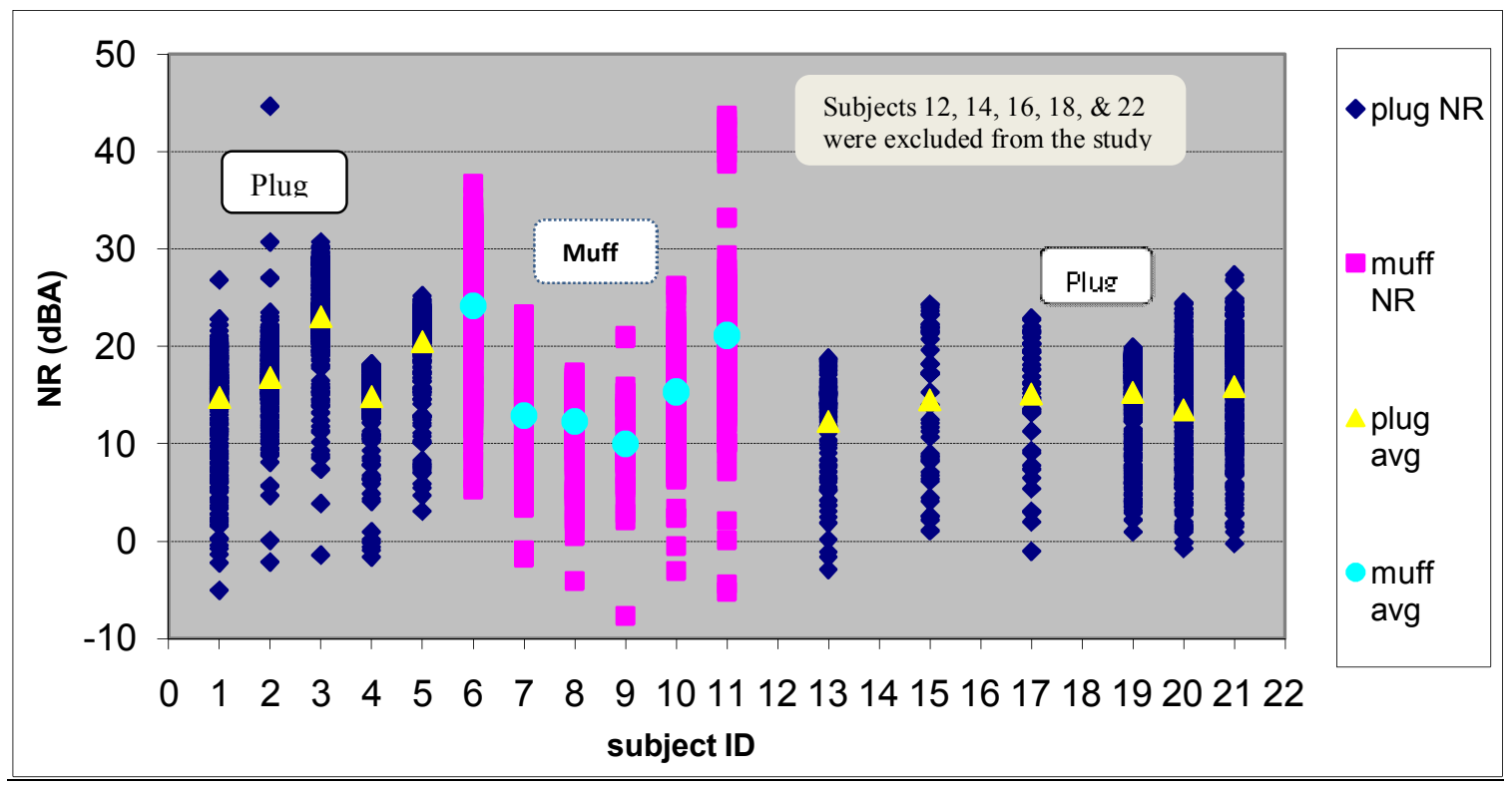

Figure 6-5- 1. On-the-job NRA (dBA) mean for each subject throughout sampling time during work excluding data when $\mathrm{SPL}_{\text {ambient }}<80 \mathrm{dBA}$ or subject judged not wearing HPD 
Table 6-5- 1. On-the-job NRA (dBA) mean for each subject throughout sampling time during work excluding data when $\mathrm{SPL}_{\text {ambient }}<80 \mathrm{dBA}$ or subject judged not wearing HPD

\begin{tabular}{|c|c|c|c|c|}
\hline Subject ID & HPD & $\begin{array}{c}\text { Sampling time } \\
\text { (minute) }\end{array}$ & NRA mean (dBA) & NRA SD (dBA) \\
\hline 1 & earplug & 460 & 14.7 & 4.7 \\
\hline 2 & earplug & 407 & 16.8 & 3.4 \\
\hline 3 & earplug & 461 & 23.0 & 3.9 \\
\hline 4 & earplug & 397 & 14.8 & 3.3 \\
\hline 5 & earplug & 336 & 20.5 & 3.9 \\
\hline 13 & earplug & 193 & 12.3 & 5.0 \\
\hline 15 & earplug & 230 & 14.5 & 7.4 \\
\hline 17 & earplug & 135 & 15.1 & 6.2 \\
\hline 19 & earplug & 437 & 15.3 & 4.3 \\
\hline 20 & earplug & 401 & 13.5 & 5.8 \\
\hline 21 & earplug & 444 & 15.9 & 5.8 \\
\hline \multicolumn{2}{|c|}{ Avg } & 355 & 16.4 & 5.0 \\
\hline 6 & earmuff & 451 & 24.2 & 6.2 \\
\hline 7 & earmuff & 444 & 12.9 & 5.0 \\
\hline 8 & earmuff & 451 & 12.3 & 3.2 \\
\hline 9 & earmuff & 397 & 10.0 & 5.1 \\
\hline 10 & earmuff & 481 & 15.3 & 3.8 \\
\hline 11 & earmuff & 156 & 21.1 & 7.9 \\
\hline \multicolumn{2}{|c|}{ Avg } & 397 & 16.0 & 3.3 \\
\hline \multicolumn{2}{|c|}{ Overall Avg } & 369 & 16.2 & 4.1 \\
\hline \multicolumn{2}{|c|}{12} & \multicolumn{3}{|c|}{ Excluded from the study } \\
\hline \multicolumn{2}{|c|}{14} & \multicolumn{3}{|c|}{ Excluded from the study } \\
\hline \multicolumn{2}{|c|}{16} & \multicolumn{3}{|c|}{ Excluded from the study } \\
\hline \multicolumn{2}{|c|}{18} & \multicolumn{3}{|c|}{ Excluded from the study } \\
\hline \multicolumn{2}{|c|}{22} & \multicolumn{3}{|c|}{ Excluded from the study } \\
\hline
\end{tabular}

\subsection{Overall on-the-job NRA values}

This study determined the overall noise reduction NRA for each coal miner's HPD during his noise sampling, from which the overall noise protection of each of the coal miner's HPD was established.

\subsection{Background}

The NRR method is unrealistic because the tested period is short and the subject fitting is directed (Berger, 1999a; Durkt, 1993), with the consequence that NRR overestimates the NRA during the actual work. This section describes an investigation of NRA values throughout full shifts of actual coal mining work. 


\subsection{Methods}

This study employed the method described in Section 6.2 to determine NRA values. After the judgment method of HPD use was applied, the investigator was able to determine the HPD wearing status (on or off) throughout the sampling minutes for each subject. The overall NRA was thus computed by averaging all of the NRA values when the HPD was worn and when the ambient noise level was at least $80 \mathrm{dBA}$.

\subsection{Results}

The results for overall NRA are shown in Figure 6-5-1 and Table 6-5-1, excluding data when $\mathrm{SPL}_{\mathrm{ambient}}<80 \mathrm{dBA}$ and when the subject was judged not to be wearing HPD. The observed average earmuff NRA across all the subjects was $16.0 \mathrm{dBA}$, ranging from 12.1 to $27.5 \mathrm{dBA}$ with a SD of $5.5 \mathrm{dBA}$. The average earplug NRA was $16.0 \mathrm{dBA}$, ranging from 11.4 to $21.7 \mathrm{dBA}$ with a $\mathrm{SD}$ of $3.1 \mathrm{dBA}$. Hence, there was no difference on effectiveness of the earplug and earmuff. In addition, every mine subject was able to achieve an average NRA of more than $10 \mathrm{dBA}$ averaged over his entire sampling time when he wore his HPD.

\subsection{Discussion}

The results showed that the average on-the-job NRA over the sampling time varied greatly (11.4 to $27.5 \mathrm{dBA}$ ) among the coal miners when they wore their HPDs. However, the average NRA (overall noise protection) on each individual was more than $10 \mathrm{dBA}$, a level that may be adequate for most work exposures (Berger, $2000 \mathrm{c}$ ).

However, only 6 mine subjects from one company wore earmuffs in the study. If more subjects from more coal mine companies participated, the data might be different. Nevertheless, the advantage of the current study was that long sampling duration was used to take the measurements on the coal miners. Nearly $60 \%$ of the coal miners (see Table 6-5-1) were sampled for more than 400 minutes (nearly 7 hours) for their HPD NRA performance.

\subsubsection{Conclusions}

The coal miners received different degrees of noise protection from their HPDs. Nevertheless, the average NRA for each exceeded $10 \mathrm{dBA}$ during periods when they wore their HPD during the periods when ambient noise levels exceeded $80 \mathrm{dBA}$. 


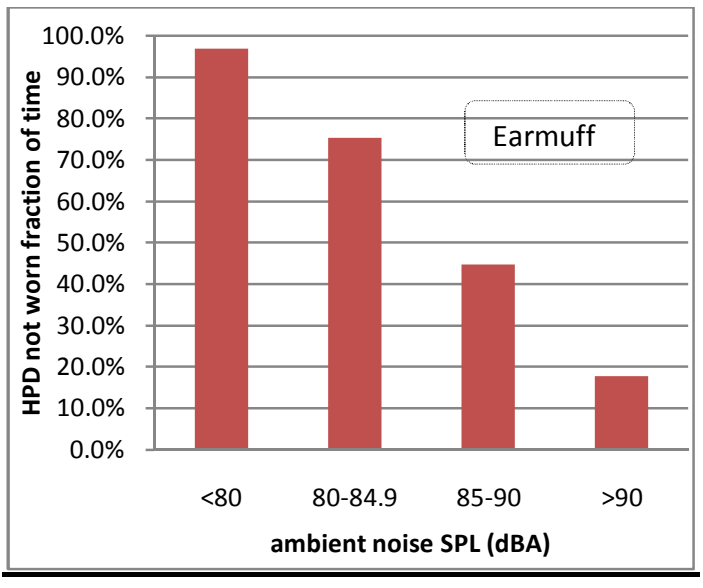

Figure 6-6- 1. HPD usage results for Subject 6: ambient noise SPL vs. HPD not worn fraction of time

\subsection{Determining relationships between the ambient noise level and the miner's HPD use and determining the difference of fraction of time not worn between the earplugs and earmuffs}

When noise levels are excessive coal miners are at the risk of noise induced hearing loss. Proper use of their HPDs can protect them but only if they wear HPD when they are needed. One may be interested in whether the coal miners in current study wore their HPDs for noise protection purpose in excessive noise (i.e., $\geq 90 \mathrm{dBA}$ ) and take them off when the environment is relatively quiet (i.e., $<80 \mathrm{dBA}$ ). If so, their behavior is rational. In addition, one may be interested in whether the two groups of coal miners as a whole had different fraction of time wearing their earmuff and earplugs when all noise levels are considered.

This study was to examine if there was any relationship between the ambient noise

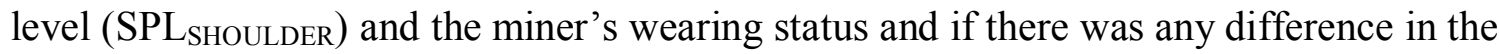
use of the HPD between those who wore earmuffs and those who wore earplugs.

\subsection{Background}

Based on literature review, none has studied the relationship between ambient noise levels and coal miners' HPD usage. Usually, coal miners don and doff their HPDs alternatively during their normal work for various reasons such as communication, comfort, etc. It is necessary to study coal miners' HPD wearing behavior to examine whether they dons their HPD when environmental noise was loud enough (e.g., $90 \mathrm{dBA}$ ) and doff it if the ambient noise level was low (e.g., less than $80 \mathrm{dBA}$ ). If noise level SPL is below $80 \mathrm{dBA}$ a coal miner's hearing loss risk is trivial. Eighty-five and $90 \mathrm{dBA}$ are the values of MSHA AL and PEL, respectively. This information is useful in current study. 


\subsection{Methods}

This portion of the study did not collect additional data. Instead, the data achieved in Section 6.2 was analyzed in a different way. Every coal miner's ambient noise level and his HPD not worn fraction of time were graphed (see Figures 6-6-2 and 6-6-3).

Four categories of ambient noise levels were chosen as the independent variable on the graph: $\mathrm{SPL}<80 \mathrm{dBA}, \mathrm{SPL}=80-84.9 \mathrm{dBA}, \mathrm{SPL}=85-90 \mathrm{dBA}$, and $\mathrm{SPL}>90 \mathrm{dBA}$. The dependent variable on the graph was HPD "not-worn" fraction of time, which is the fraction of exposure time at each specific noise level range (e.g., SPL $<80 \mathrm{dBA}$ ), not of the entire work shift exposure time across various noise levels. 


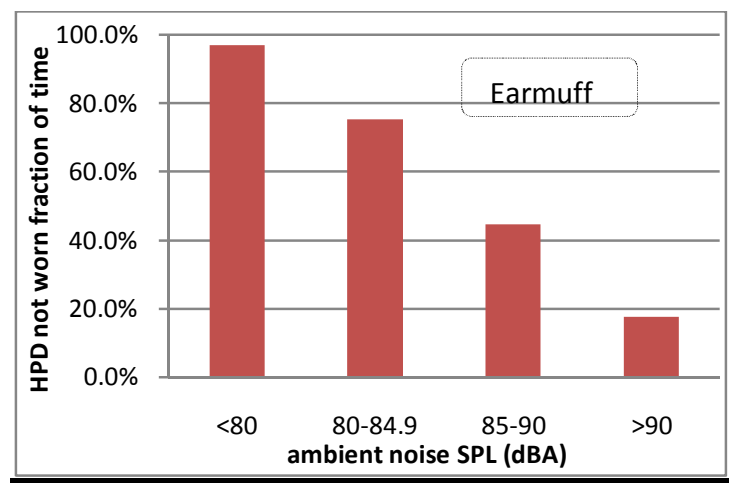

a. Subject 6

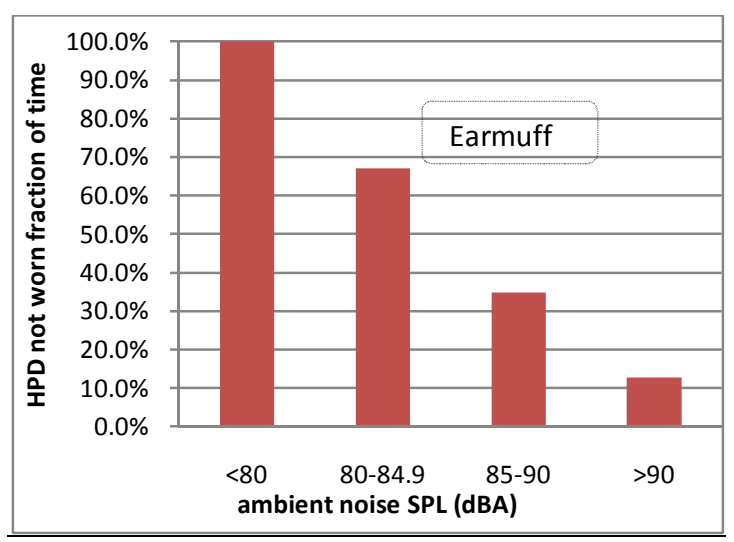

b. Subject 7

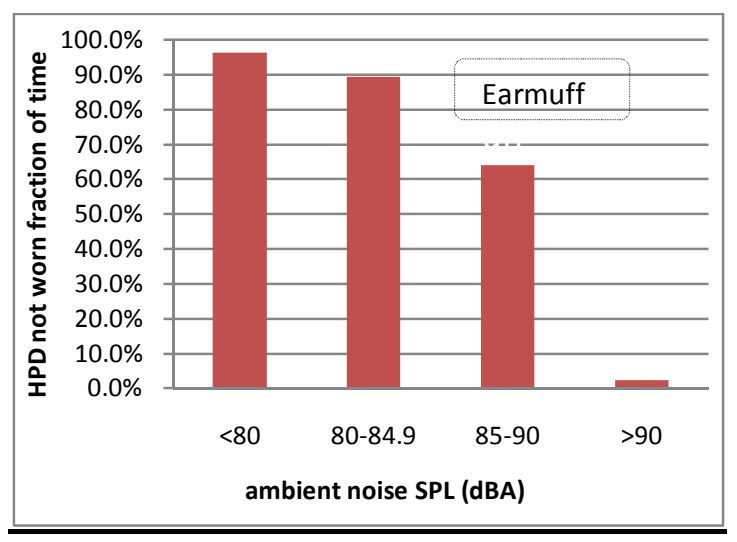

c. $\quad$ Subject 8

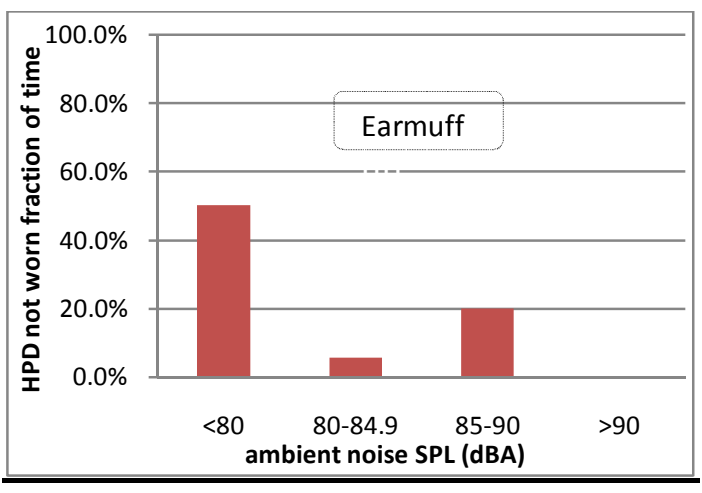

d. Subject 9

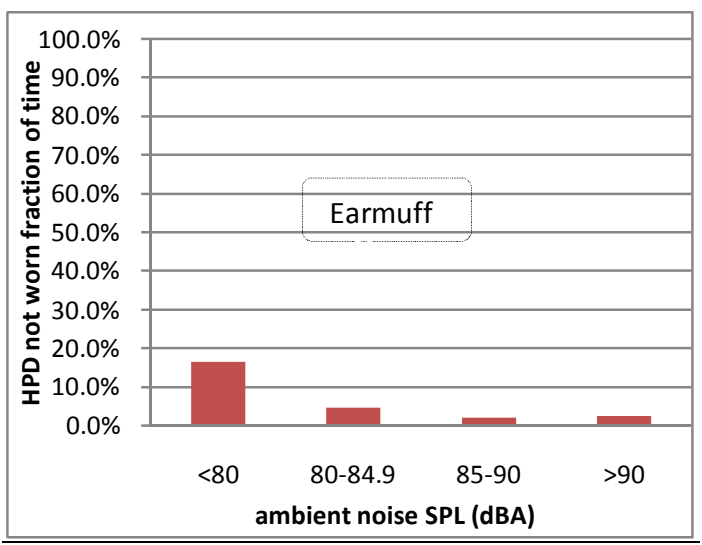

e. Subject 10

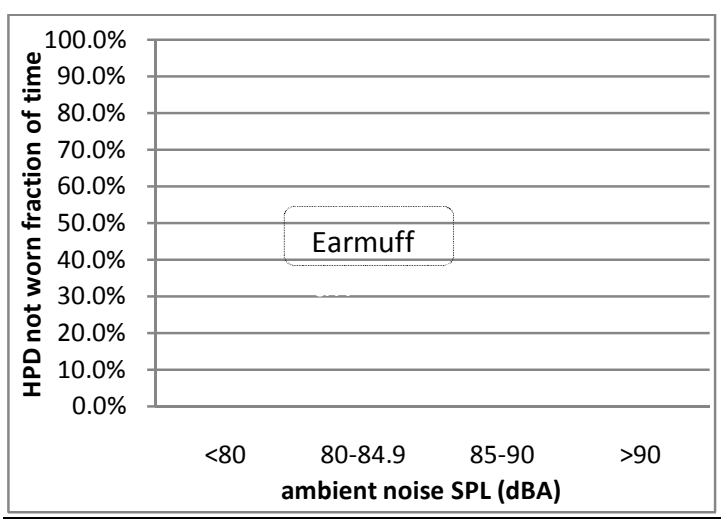

f. Subject 11

Figure 6-6- 2. a-f. Individual miner's earmuff usage results: ambient noise SPL

vs. HPD not worn fraction of time

Note: HPD not worn fraction of time $=($ not worn time for some specific noise levels $\div$ exposure time for the corresponding noise levels) $\times 100 \%$ 


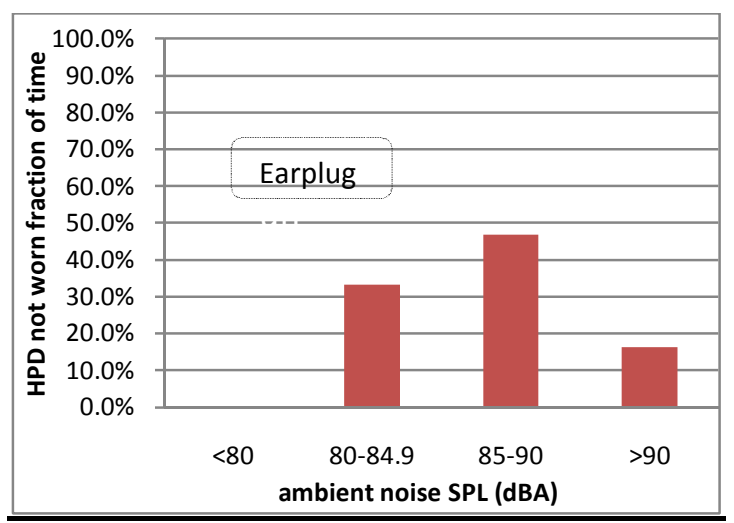

g. Subject 1

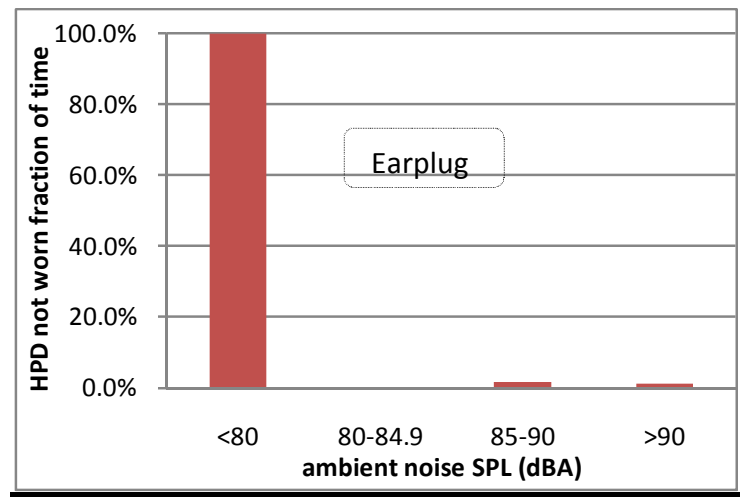

h. Subject 2

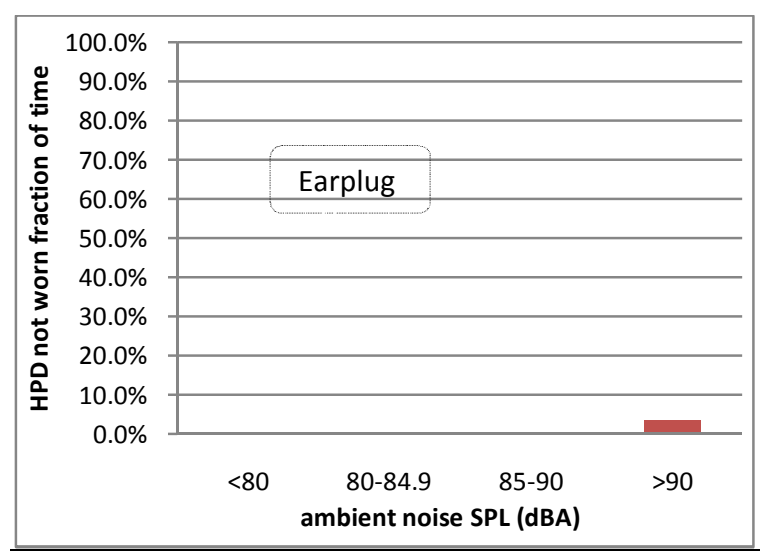

i. Subject 3

Figure 6-6- 3. g-q. Individual miner's earplug usage results: ambient noise SPL vs. HPD not worn fraction of time

Note: HPD not worn fraction of time $=($ not worn time for some specific noise levels $\div$ exposure time for the corresponding noise levels) $\times 100 \%$

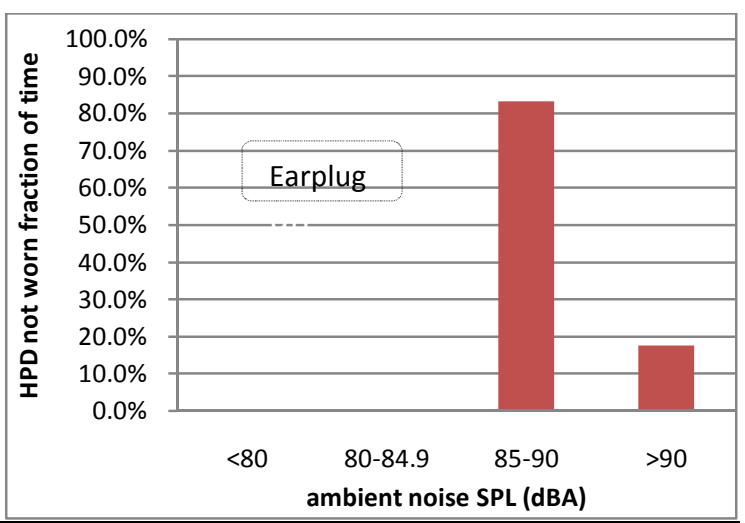

j. $\quad$ Subject 4

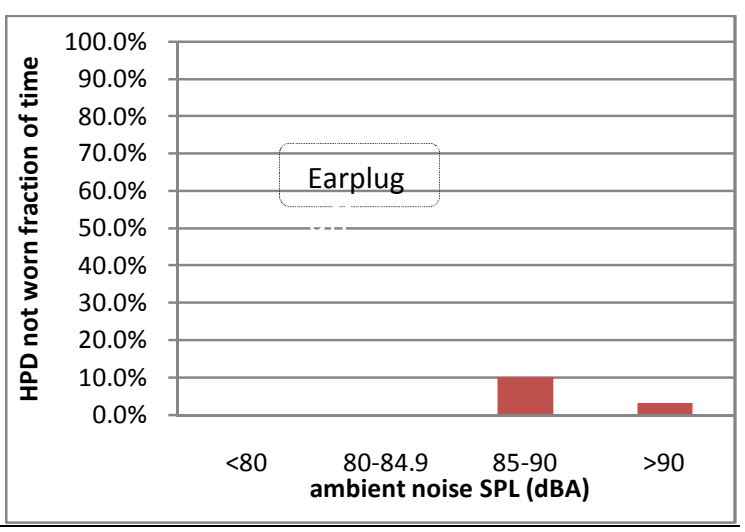

k. Subject 5

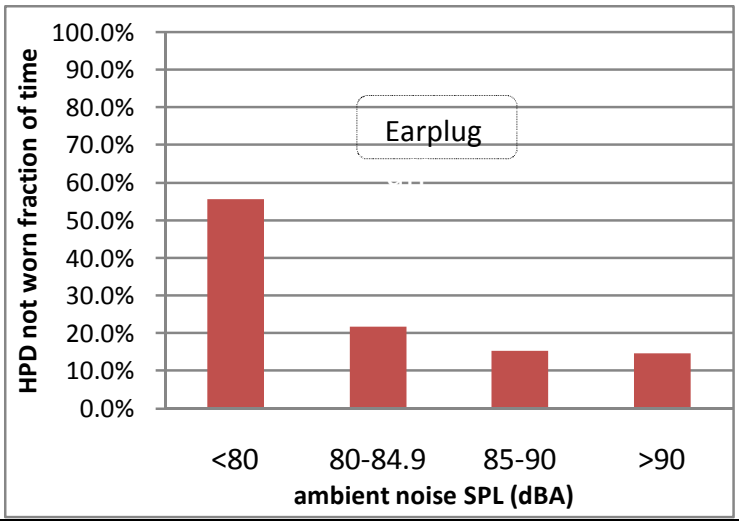

1. Subject 13 


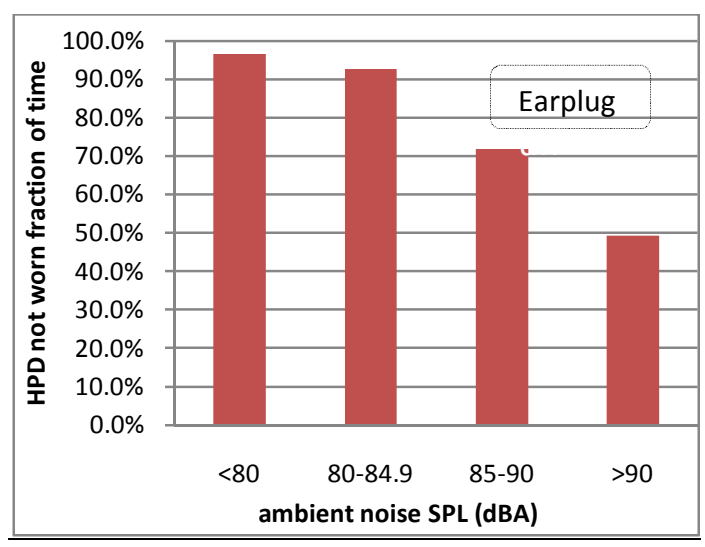

m. Subject 15

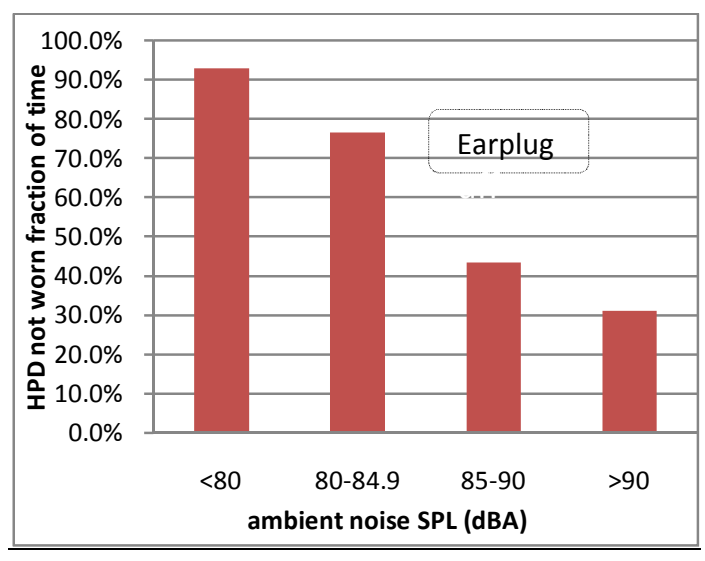

n. $\quad$ Subject 17

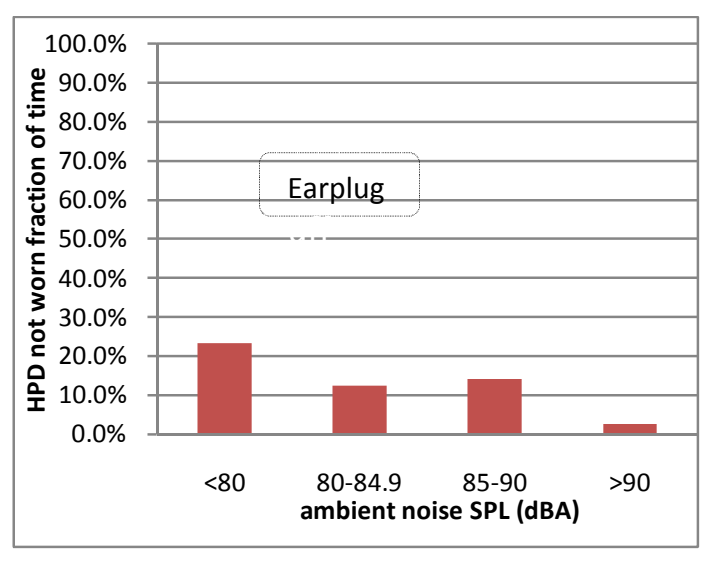

o. Subject 19

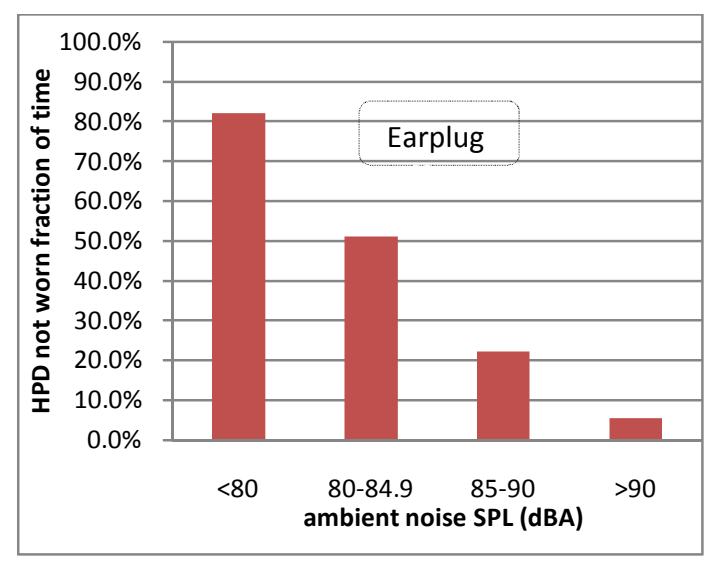

p. Subject 20

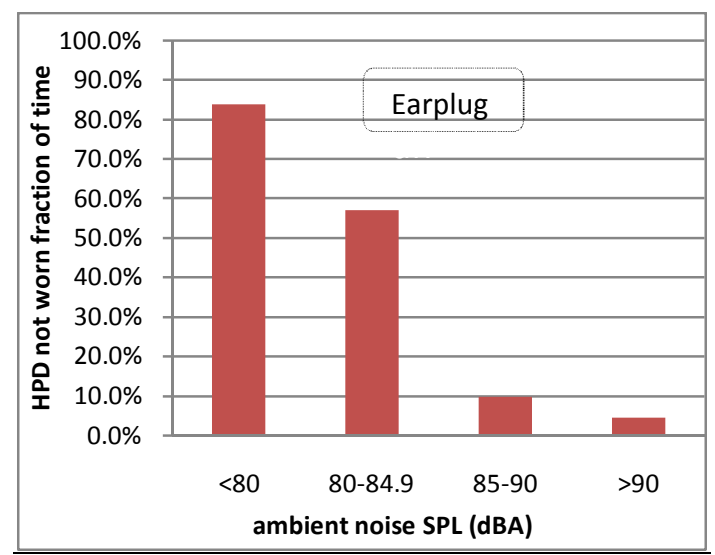

q. Subject 21

Figure 6-6-3. g-q. Individual miner's earplug usage results: ambient noise SPL vs. HPD not worn fraction of time

Note: HPD not worn fraction of time $=($ not worn time at some specific noise levels $\div$ exposure time at the corresponding noise levels) $\times 100 \%$ 
Table 6-6- 1. Individual miner's HPD usage results: ambient noise SPL vs. HPD not worn fraction of time

\begin{tabular}{|c|c|c|c|c|c|c|c|c|c|c|}
\hline \multirow[b]{2}{*}{$\begin{array}{c}\text { Subj } \\
\text { ID }\end{array}$} & \multirow[b]{2}{*}{$\begin{array}{l}\mathrm{H} \\
\mathrm{P} \\
\mathrm{D}\end{array}$} & \multicolumn{2}{|c|}{$\mathrm{SPL}<80 \mathrm{dBA}$} & \multicolumn{2}{|c|}{$80 \mathrm{dBA} \leq \mathrm{SPL} \leq 84.9 \mathrm{dBA}$} & \multicolumn{2}{|c|}{$85 \mathrm{dBA} \leq \mathrm{SPL} \leq 90 \mathrm{dBA}$} & \multicolumn{2}{|c|}{ SPL $>90 \mathrm{dBA}$} & \multirow[b]{2}{*}{$\begin{array}{l}\text { Overall no } \\
\text { worn } \\
\text { fraction of } \\
\text { time }(\%)\end{array}$} \\
\hline & & $\begin{array}{c}\text { Exposure } \\
\text { time (min) }\end{array}$ & $\begin{array}{l}\text { Not worn } \\
\text { fraction of } \\
\text { time }(\%)\end{array}$ & $\begin{array}{c}\text { Exposure } \\
\text { time (min) }\end{array}$ & $\begin{array}{l}\text { Not worn } \\
\text { fraction of } \\
\text { time }(\%)\end{array}$ & $\begin{array}{c}\text { Exposure } \\
\text { time (min) }\end{array}$ & $\begin{array}{l}\text { Not worn } \\
\text { fraction of } \\
\text { time }(\%)\end{array}$ & $\begin{array}{c}\text { Exposure } \\
\text { time (min) }\end{array}$ & $\begin{array}{l}\text { Not worn } \\
\text { fraction of } \\
\text { time }(\%)\end{array}$ & \\
\hline 1 & plug & 4 & $0.0 \%$ & 18 & $33.3 \%$ & 47 & $46.8 \%$ & 391 & $16.4 \%$ & 20.0 \\
\hline 2 & plug & 1 & $100.0 \%$ & 8 & $0.0 \%$ & 60 & $1.7 \%$ & 338 & $1.2 \%$ & 1.7 \\
\hline 3 & plug & 1 & $0.0 \%$ & 7 & $0.0 \%$ & 42 & $0.0 \%$ & 411 & $3.4 \%$ & 3.0 \\
\hline 4 & plug & 0 & $0.0 \%$ & 0 & $0.0 \%$ & 12 & $83.3 \%$ & 385 & $17.7 \%$ & 19.6 \\
\hline 5 & plug & 0 & $0.0 \%$ & 5 & $0.0 \%$ & 10 & $10.0 \%$ & 321 & $3.1 \%$ & 3.3 \\
\hline 13 & plug & 36 & $55.6 \%$ & 37 & $21.6 \%$ & 65 & $15.4 \%$ & 55 & $14.5 \%$ & 23.8 \\
\hline 15 & plug & 85 & $96.5 \%$ & 41 & $92.7 \%$ & 39 & $71.8 \%$ & 65 & $49.2 \%$ & 78.3 \\
\hline 17 & plug & 42 & $92.9 \%$ & 34 & $76.5 \%$ & 30 & $43.3 \%$ & 29 & $31.0 \%$ & 64.4 \\
\hline 19 & plug & 43 & $23.3 \%$ & 64 & $12.5 \%$ & 57 & $14.0 \%$ & 273 & $2.6 \%$ & 7.6 \\
\hline 20 & plug & 39 & $82.1 \%$ & 47 & $51.1 \%$ & 81 & $22.2 \%$ & 234 & $5.6 \%$ & 21.7 \\
\hline 21 & plug & 37 & $83.8 \%$ & 49 & $57.1 \%$ & 91 & $9.9 \%$ & 267 & $4.5 \%$ & 18.0 \\
\hline \multicolumn{2}{|c|}{ Average } & 26 & $48.5 \%$ & 28 & $31.3 \%$ & 49 & $29.0 \%$ & 252 & $13.6 \%$ & 23.8 \\
\hline 6 & muff & 66 & $97.0 \%$ & 73 & $75.3 \%$ & 103 & $44.7 \%$ & 209 & $17.7 \%$ & 44.8 \\
\hline 7 & muff & 46 & $100.0 \%$ & 82 & $67.1 \%$ & 135 & $34.8 \%$ & 181 & $12.7 \%$ & 39.2 \\
\hline 8 & muff & 53 & $96.2 \%$ & 103 & $89.3 \%$ & 53 & $64.2 \%$ & 242 & $2.5 \%$ & 40.6 \\
\hline 9 & muff & 354 & $50.3 \%$ & 36 & $5.6 \%$ & 5 & $20.0 \%$ & 2 & $0.0 \%$ & 45.6 \\
\hline 10 & muff & 91 & $16.5 \%$ & 86 & $4.7 \%$ & 145 & $2.1 \%$ & 159 & $2.5 \%$ & 5.4 \\
\hline 11 & muff & 4 & $0.0 \%$ & 19 & $0.0 \%$ & 39 & $0.0 \%$ & 94 & $0.0 \%$ & 0.0 \\
\hline \multicolumn{2}{|c|}{ Average } & 102 & $60.0 \%$ & 67 & $40.3 \%$ & 80 & $27.6 \%$ & 148 & $5.9 \%$ & 29.3 \\
\hline
\end{tabular}

$*$ HPD not worn fraction of time $=($ not worn time at some specific noise levels $\div$ exposure time at the corresponding noise levels $) \times 100 \%$ 


\subsubsection{Results and discussion}

The results are shown in Figures 6-6-2 a-f for earmuffs and Figures 6-6-3 g-q for earplugs, which together include all coal miners. Note that Subject 11 did not remove his earmuff at any time during his noise sampling time, and so his HPD Not-Worn time fraction was zero on his graph.

On average, the coal miners failed to wear their earmuffs a remarkably low $5.9 \%$ of the time during their exposure period when the ambient noise levels exceeded $90 \mathrm{dBA}$. They did not wear them $60 \%$ of the time during their exposure period when the ambient noise levels were less than $80 \mathrm{dBA}$ and they did not need them. The difference is substantial and statistically significant $(\mathrm{p}=0.007)$. For the earplugs, the compliance, surprisingly, was not quite as good as with the earmuffs. The coal miners did not wear their plugs $13.6 \%$ of the time during exposure periods when the ambient noise levels exceeded $90 \mathrm{dBA}$. They wore them $48.5 \%$ of the time when the ambient noise levels were less than $80 \mathrm{dBA}$, a differences that also is substantial and statistically significant $(p=0.01)$. These results indicate that these coal miners tended to take off their HPDs (i.e., earmuff or earplug) when the environment was relatively quiet and wore them when it was noisy, just as one would hope.

The overall results when various ambient noise levels were considered show that the miners' not worn fraction of time for earmuff s $(29.3 \%)$ was greater than that for earplug $(23.8 \%)$. The difference was not significant $(p=0.38)$. This suggested that there was no time fraction difference for wearing these two different types of HPDs among these two groups of mine HPD users over their entire sampling time.

\subsubsection{Conclusions}

The coal miners generally wear their HPDs when the ambient noise levels were above $90 \mathrm{dBA}$ and did not wear them when noise levels were below $80 \mathrm{dBA}$. There was no difference in the overall fraction of time they wore earmuffs and earplugs.

\subsection{Coal miners' ambient (unprotected) noise dose and ear (protected) noise dose}

The intent of this portion of the field study was to determine the coal miners' ambient (unprotected) noise dose and ear (protected) noise dose during normal work. In particularly, the goal was to determine the portion of ear noise dose due to failure to wear HPD. 


\subsection{Background}

It is a common practice that coal miners don and doff their HPDs alternatively during their normal work (T. Stockdale and T. Brandon, personal communication, 2008). It was necessary to know how much portion of noise dose was due to failure to wear the HPDs, from which one was able to assess the importance of failure to wear. The MSHA regulations have an action level (AL) that requires integration of SPLs from 80 to at least $130 \mathrm{dBA}$. Therefore, only the average SPL over any minute that was at least $80 \mathrm{dBA}$ (threshold) was integrated for the AL dose calculation in the coal mine study for both the ambient noise dose and protected ear dose. If the ambient total dose measured on the shoulder exceeded $50 \%$, this subject's potential noise exposure would be above the AL, indicating the subject shall be included in the Hearing Conservation Program regardless of his actual ear dose exposure (MSHA, 1999).

\subsection{Method: noise dose calculation}

This study did not collect additional data. The data achieved in Section 6.2 was analyzed. The noise dose (ambient or protected ear dose) on a particular coal miner was calculated using MSHA allowed exposure as:

$$
\begin{gathered}
D_{\text {total }}=\sum_{i=1}^{n}\left(\frac{T_{\text {Observed }_{i}}}{T_{\text {Allowed }_{i}}}\right) \\
T_{\text {Allowed }}=\left(\frac{8 \mathrm{hrs}}{2^{(L-90) / 5}}\right) \ldots \ldots .
\end{gathered}
$$

Where:

$\mathrm{D}_{\text {total }}=$ either the total ambient noise dose or protected ear dose

$\mathrm{L}=$ measured A-weighted sound level SPL

$$
\text { For SPL }<80 \mathrm{dBA}, \mathrm{T}_{\text {allowed }} \text { is infinity }
$$

Both the ambient noise dose and also the protected noise dose (ear dose) were calculated, respectively, to examine the mine subject's potential noise exposure and actual noise protection in ear. In addition, to calculate the noise dose due to failure to wear the HPD, only these time periods the miners did not wear their HPD were used. Then, the percentage of noise dose due to failure to wear in the entire ear dose was determined.

In case that the full-shift noise sampling was not taken, the projected full-shift (8 Hrs) noise dose (ambient or protected ear dose) was extrapolated from the noise sampling result with the following equation: 
Dose $8-\mathrm{hr}=$ Dose $_{\text {observed }}\left(\frac{480 \text { minutes }}{\mathrm{T}_{\text {sampling }}}\right)$

Where:

Dose $8 h r=$ projected full-shift $(8 \mathrm{Hrs})$ noise dose

Dose $_{\text {observed }}=$ actual noise dose from sampling result

$\mathrm{T}_{\text {sampling }}=$ actual noise sampling minutes

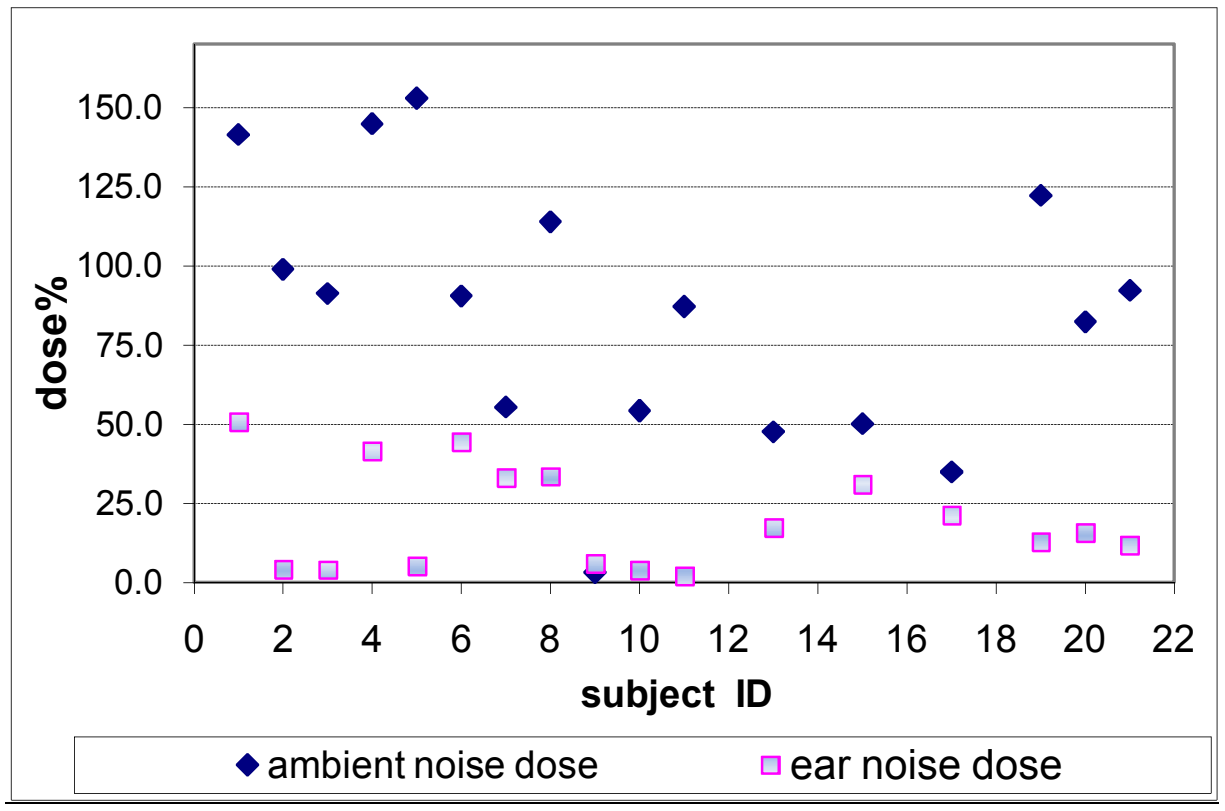

Figure 6-7- 1. Projected (8 Hrs) ambient noise \% dose and in-ear noise \% dose for each individual 
Table 6-7- 1. Noise dose sampling result from each miner

\begin{tabular}{|c|c|c|c|c|c|c|c|c|c|}
\hline \multirow{2}{*}{$\begin{array}{l}\text { Subject } \\
\text { ID }\end{array}$} & \multirow{2}{*}{ Job title } & \multirow{2}{*}{$\begin{array}{l}\text { Sampling } \\
\text { minutes }\end{array}$} & \multicolumn{2}{|c|}{ Actual dose\% } & \multicolumn{2}{|c|}{ Projected dose\% } & \multirow{2}{*}{$\begin{array}{l}\text { 8-hr TWA } \\
\text { of ambient } \\
\text { noise (dBA) }\end{array}$} & \multirow{2}{*}{$\begin{array}{c}\% \text { of ear } \\
\text { dose due } \\
\text { to not } \\
\text { worn }\end{array}$} & \multirow{2}{*}{$\begin{array}{c}\% \min \\
\text { not worn }\end{array}$} \\
\hline & & & Ambient & Ear & Ambient & Ear & & & \\
\hline 1 & operator & 460 & 135.5 & 48.7 & 141.4 & 50.8 & 92.5 & $72 \%$ & $20.0 \%$ \\
\hline 2 & operator & 407 & 83.8 & 3.6 & 98.8 & 4.2 & 89.9 & $36 \%$ & $2.0 \%$ \\
\hline 3 & operator & 461 & 87.6 & 3.9 & 91.2 & 4.1 & 89.3 & $82 \%$ & $3.0 \%$ \\
\hline 4 & operator & 397 & 119.7 & 34.3 & 144.7 & 41.5 & 92.7 & $61 \%$ & $19.6 \%$ \\
\hline 5 & operator & 336 & 107.0 & 3.7 & 152.9 & 5.3 & 93.1 & $46 \%$ & $3.3 \%$ \\
\hline 6 & roof bolter & 451 & 85.0 & 41.7 & 90.5 & 44.4 & 89.3 & $99 \%$ & $44.8 \%$ \\
\hline 7 & roof bolter & 444 & 51.2 & 30.6 & 55.4 & 33.1 & 85.7 & $86 \%$ & $38.5 \%$ \\
\hline 8 & cont miner & 451 & 107.0 & 31.5 & 113.9 & 33.5 & 90.9 & $47 \%$ & $40.6 \%$ \\
\hline 9 & shuttle car & 397 & 2.6 & 5.0 & 3.1 & 6.0 & 65.0 & $76 \%$ & $45.6 \%$ \\
\hline 10 & shuttle car & 481 & 54.3 & 4.0 & 54.2 & 4.0 & 85.6 & $50 \%$ & $5.4 \%$ \\
\hline 11 & roof bolter & 156 & 28.3 & 0.7 & 87.1 & 2.2 & 89.0 & $0 \%$ & $0.0 \%$ \\
\hline 13 & shuttle car & 193 & 19.1 & 7.0 & 47.5 & 17.4 & 84.6 & $41 \%$ & $23.8 \%$ \\
\hline 15 & roof bolter & 230 & 24.0 & 14.9 & 50.1 & 31.1 & 85 & $87 \%$ & $78.3 \%$ \\
\hline 17 & roof bolter & 135 & 9.8 & 6.0 & 34.8 & 21.3 & 82.4 & $83 \%$ & $64.4 \%$ \\
\hline 19 & cont miner & 437 & 111.2 & 11.8 & 122.1 & 13.0 & 91.4 & $27 \%$ & $7.6 \%$ \\
\hline 20 & roof bolter & 401 & 68.7 & 13.2 & 82.2 & 15.8 & 88.6 & $42 \%$ & $21.7 \%$ \\
\hline 21 & roof bolter & 444 & 85.2 & 11 & 92.1 & 11.9 & 89.4 & $55 \%$ & $18.0 \%$ \\
\hline \multicolumn{2}{|c|}{ Avg } & 369 & 69.4 & 16.0 & 86.0 & 20.0 & 87.3 & $58 \%$ & $25.7 \%$ \\
\hline
\end{tabular}




\subsubsection{Results}

The results of the ambient noise and in-ear noise dose are shown in Figure 6-7-1 and Table 6-7-1. Complete full-shift sampling was not achieved on most of the subjects due to instrument problems and, mostly, due to work shift interruptions by MSHA inspectors, etc. The actual noise sampling duration ranged from 135 to 481 minutes, with most of the sampling times exceeding 400 minutes (see Table 6-7-1). Full-shift ( 8 hours) dose of the ambient noise and in-ear noise exposure was extrapolated, respectively, from the noise sampling result on each subject.

Fourteen out of the seventeen coal miners had projected ambient noise doses above the MSHA Action Limit (AL) of 50\%. Nearly every miner experienced protected (ear)

noise exposures less than the MSHA AL dose of $50 \%$. The exception was Subject 1, who had a dose of $50.8 \%$, a level that barely exceeds the AL. The protected noise doses under the coal miners' HPDs varied from the $2.2 \%$ to $50.8 \%$, with an average of $20 \%$.

Finally, the portion of the ear dose due to failure to wear ranged from 0 to $99 \%$ with an average of $58 \%$ across all the subjects. Additionally, the percentage of time the coal miners failed to wear their HPDs ranged from 0 to $78.3 \%$, with an average of $26 \%$.

\subsubsection{Discussion}

The results indicated that most of the coal miners ( $82 \%)$ was overexposed to coal mining noise and were at risk of noise induced hearing loss. However, sixteen of seventeen coal miners (94\%) received adequate noise protection, indicating that these HPDs were adequately effective. In addition, the result indicated that coal miners' ear dose due to failure to wear their HPDs varied from one subject to another (SD $=16 \%$ ). Subject 11, for example, did not have any noise dose due to failure to wear while Subject 6 had $99 \%$ of ear dose due to failure to wear his HPD. Nevertheless, most of the coal miners $(60 \%)$ had a percentage of ear doses due to failure to wear that exceeded $50 \%$, indicating that failure to wear was an important factor affecting their noise protection. Furthermore, from the onsite observation, the investigator found some coal miners appeared to wear their HPDs most of the time while some others wore them much less.

\subsubsection{Conclusions}

The coal miners were exposed to excessive noise in their workplace and were at risk of noise induced hearing loss. Failure to wear the HPD was an important factor to account for the coal miners' ear doses, accounting for $58 \%$ of their doses on average. 


\section{CHAPTER 7: COMPARING HPD NRA FOR FIT-TEST TO COAL MINING WORK}

Only the noise attenuation of a HPD during a coal miner's normal work can reflect his real (not assumed) protection from hearing loss. Therefore, it is important to determine whether coal miners' HPD fit-test can predict their noise protection while working.

This study determined the degree to which NRA value of a coal miner's HPD (i.e., earplug or earmuff) in fit-test predicted the NRA observed during the same miner's work while wearing the same HPD in normal work. Specifically, both the average NRA of multiple fit-tests and of the NRA of $1^{\text {st }}$ fit-test was compared, respectively, with the average NRA in work.

\subsection{Background}

Researchers (Berger, 2007; Neitzel et al., 2006) have indicated their expectation that individual HPD fit-test results will predict a worker's actual noise protection during normal work. However, this assumption has not been confirmed with experimental testing. In current study the NRA values of coal miners' HPDs were determined both during fit-test measurement at coal mine offices (see Chapter 5) and during work the same day (see Chapter 6).

\subsection{Methods}

No additional data was collected for this study. The data achieved in the fit-test (see Sections 5.2) and in coal mine worksite (see Sections 6.2) was re-analyzed to investigate the relationship between fit-test and work experience. A linear regression model was used for the study design (earplug or earmuff) as follows:

- Dependent variable: NRA in fit-test

- Independent variable: $\mathrm{NR}_{\mathrm{A}}$ in work

- Linear regression analysis

- Ho: NRA is constant

- $\mathrm{H} 1: \mathrm{NR}_{\mathrm{A}}=f$ (fit-test) 


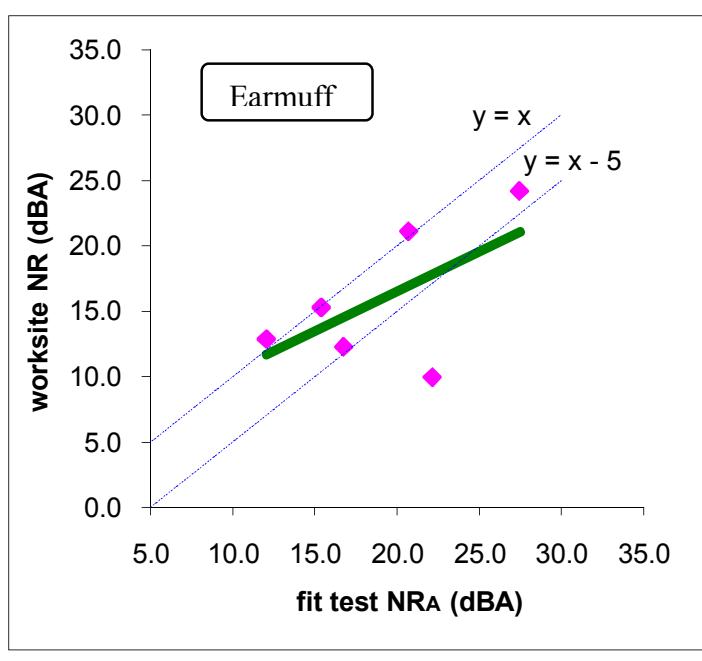

Figure 7-1 - 1. Compare earmuff NRA for multiple fit-tests and work

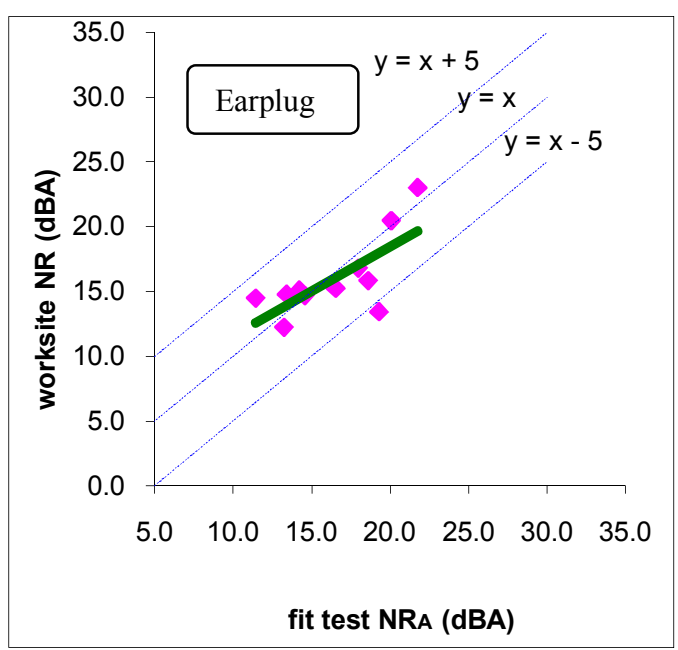

Figure 7-1-2. Compare earplug NRA for multiple fit-tests and work

Table 7-1- 1. Compare HPD NRA for fit-test and work on each subject

\begin{tabular}{|c|c|c|c|c|c|c|c|}
\hline $\begin{array}{c}\text { Subj } \\
\text { ID }\end{array}$ & $\begin{array}{c}\text { H } \\
\text { D }\end{array}$ & $\begin{array}{c}\text { Mean NRA } \\
\text { of multiple } \\
\text { fit-tests } \\
(\mathrm{dBA})\end{array}$ & $\begin{array}{c}\text { CI of } \\
\text { multiple } \\
\text { fit-test } \\
(\mathrm{dBA})\end{array}$ & $\begin{array}{c}\text { NRA } \\
\text { of } 1^{\text {st }} \\
\text { fit-test } \\
(\mathrm{dBA})\end{array}$ & $\begin{array}{c}\text { Mean NRA } \\
\text { of worksite } \\
(\mathrm{dBA})\end{array}$ & $\begin{array}{c}\text { SD of } \\
\text { multiple fit- } \\
\text { tests (dBA) }\end{array}$ & $\begin{array}{c}\text { SD of } \\
\text { work } \\
(\mathrm{dBA})\end{array}$ \\
\hline 1 & plug & 14.6 & $(13.4,15.7)$ & 16.1 & 14.7 & 2.0 & 4.7 \\
\hline 2 & plug & 18.0 & $(15.8,20.1)$ & 23.1 & 16.8 & 3.8 & 3.4 \\
\hline 3 & plug & 21.7 & $(19.5,24)$ & 20.4 & 23.0 & 3.9 & 3.9 \\
\hline 4 & plug & 13.4 & $(12.3,14.5)$ & 15.2 & 14.8 & 2.0 & 3.3 \\
\hline 5 & plug & 20.1 & $(17.9,22.2)$ & 26.3 & 20.5 & 3.8 & 3.9 \\
\hline 13 & plug & 13.2 & $(11.7,14.8)$ & 16.8 & 12.3 & 2.8 & 5.0 \\
\hline 15 & plug & 11.4 & $(7.7,15.2)$ & 18.3 & 14.5 & 6.6 & 7.4 \\
\hline 17 & plug & 14.2 & $(12.1,16.3)$ & 12.6 & 15.1 & 3.8 & 6.2 \\
\hline 19 & plug & 16.5 & $(14.1,18.9)$ & 21.0 & 15.3 & 4.2 & 4.3 \\
\hline 20 & plug & 19.3 & $(17.2,21.3)$ & 23.1 & 13.5 & 3.6 & 5.8 \\
\hline 21 & plug & 18.6 & $(17.4,19.8)$ & 17.3 & 15.9 & 2.2 & 5.8 \\
\hline 6 & muff & 27.5 & $(25.3,29.6)$ & 30.4 & 24.2 & 3.7 & 6.2 \\
\hline 7 & muff & 12.1 & $(8.5,15.7)$ & 22.0 & 12.9 & 5.8 & 5.0 \\
\hline 8 & muff & 16.8 & $(15.1,18.4)$ & 19.5 & 12.3 & 2.8 & 3.2 \\
\hline 9 & muff & 22.2 & $(21.3,23.1)$ & 22.6 & 10.0 & 1.6 & 5.1 \\
\hline 10 & muff & 15.4 & $(14.3,16.6)$ & 12.8 & 15.3 & 2.0 & 3.8 \\
\hline 11 & muff & 20.7 & $(19.1,22.3)$ & 20.5 & 21.1 & 2.3 & 7.9 \\
\hline \multicolumn{2}{|c|}{ Avg } & 17.4 & & 20 & 16 & 3.3 & 5 \\
\hline
\end{tabular}


Table 7-1 - 2. HPD regression analysis between multiple fit-tests and work

\begin{tabular}{|c|c|c|c|c|}
\hline \multicolumn{5}{|c|}{$\begin{array}{l}\mathrm{R}^{2}=36.1 \% \text { with } 6-2=4 \text { degrees of freedom for earmuff } \\
\mathrm{R}^{2}=52.7 \% \text { with } 11-2=9 \text { degrees of freedom for earplug } \\
\mathrm{R}^{2}=38.0 \% \text { with } 17-2=15 \text { degrees of freedom for earmuff and earplug combined }\end{array}$} \\
\hline Variables & Coefficient & s.e. of Coeff & t-ratio & Prob \\
\hline Fit-test mean of earmuff & 0.61 & 0.40 & 1.5 & 0.21 \\
\hline Fit-test mean of earmuff & 0.68 & 0.21 & 3.16 & 0.01 \\
\hline Fit-test mean of earmuff and earplug combined & 0.57 & 0.19 & 3.03 & 0.37 \\
\hline
\end{tabular}

\subsection{Results and Discussion}

The results and discussions of the prediction relationship between multiple fit-tests and work NRA, and between $1^{\text {st }}$ fit-test and work NRA for earmuff, earplug, and combination of earmuff and earplug are presented in the following sections. In addition, as supplemental information, the comparison result of NRA variability for multiple fittests and work was also presented.

\subsubsection{Earmuff prediction relationship between average of multiple fit-tests and work NRA average}

The results of the linear regression analysis between the average of multiple fit-tests and the average work NRA for each subject for the earmuff are shown in Figure 7-1-1, Tables 7-1-1 and 7-1-2. The slope of the regression line was not significantly different from zero $(p=0.21)$, and the coefficient of determination $\mathrm{R}^{2}$ was only 0.36 , indicating there was no predictive relationship between the average of the fit-test and the average of normal work NRA for earmuff. When the data of an outlier (from Subject 9) was removed the linear regression analysis for the earmuff showed a slope $(0.81)$ of the regression line that was significantly different $(\mathrm{p}=0.03)$ from zero with a coefficient of determination $\mathrm{R}^{2}$ of 0.84 , a strong prediction relationship between the fit-testing and the normal work conditions. However, there was no justification for removing the outlier other than its disagreement with other data.

It should be noted that there were limited data points (6 pairs of data) obtained in the earmuff comparison, which increased the possibility that any conclusion from the earmuff is due to chance. More mine subjects are needed to confirm the validity of the conclusion in earmuff study. 


\subsubsection{Earplug predictive relationship between NRA for the average of multiple fit-tests and work}

The results of the linear regression analysis between multiple fit-tests and work for the earplugs are shown in Figure 7-1-2, Tables 7-1-1 and 7-1-2. The slope (0.68) of the regression line on Figure 7-1-2 was significantly different from zero $(\mathrm{p}=0.01)$, and the coefficient of determination $\mathrm{R}^{2}$ was 0.53 . It appeared that the earplug fit-testing was able to predict the noise protection in normal work. The linear regression equation was:

$$
\mathrm{NRA}_{\text {work }}=4.85+0.68^{*} \mathrm{NRA}
$$

Where:

$$
\begin{aligned}
& \mathrm{NRA}_{\text {work }}=\text { noise reduction in decibels }(\mathrm{dB}) \text { from working } \\
& \mathrm{NRA}_{\text {fit-testing }}=\text { noise reduction in decibels }(\mathrm{dB}) \text { from fit-testing }
\end{aligned}
$$

However, the prediction relationship was only moderately strong because the $\mathrm{R}^{2}$ of 0.53 indicated $47 \%$ of the variability in NRA from work was not explained from the fittesting by the linear equation. However, Figure 7-2-1 and Table 7-1-1show that the NRA difference was less than $5 \mathrm{dBA}$ within each pair of fit-testing and work data, except for Subject 20. That subject had an observed NRA difference of $5.8 \mathrm{dBA}$. When Subject 20 was removed, the coefficient of determination $\mathrm{R}^{2}$ was 0.76 . However, there was no justification for removing the outlier other than its disagreement with other data.

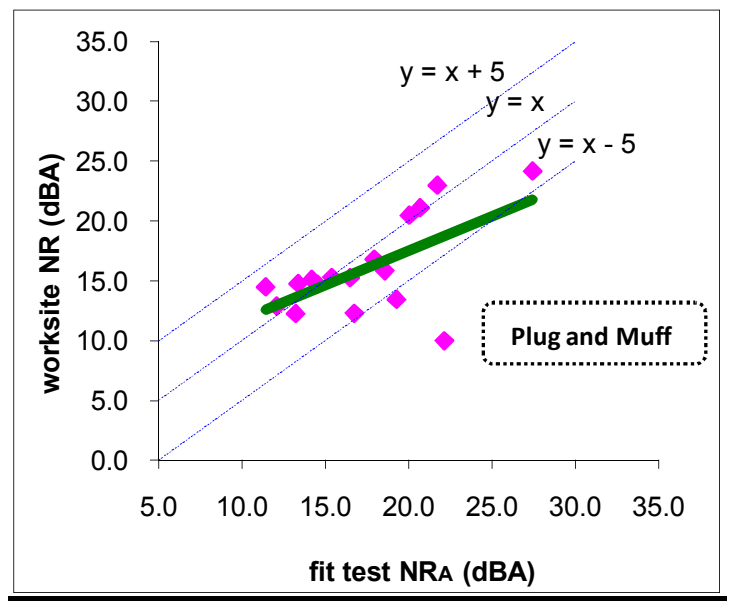

Figure 7-1- 3. Compare HPD (earmuff and earplug combined) NRA for multiple fit-tests and work 


\subsubsection{Result and discussion: $\mathrm{HPD}$ (earplug and earmuff combined) prediction relationship between the average of multiple fit-tests and work NRA}

The results of linear regression analysis between the average NRA of multiple fit-tests and work for the HPD (i.e., earmuff and earplug combined) are shown in Figure 7-1-3, Tables 7-1-1 and 7-1-2. The slope of the regression line was not significantly different from zero ( $p=0.37$ ), and the coefficient of determination $R^{2}$ was only 0.38 , indicating there was no predicting relationship between the fit-testing and the normal work NRA. When the data from Subject 9 was removed the linear regression analysis for the earmuff showed the slope of the regression line was significantly different $(\mathrm{p}=0.001)$ with a coefficient of determination $R^{2}$ of 0.69 , a strong prediction relationship between the fittesting and the normal work NRA. Again, however, there was no justification for removing the outlier other than its disagreement with other data.

The $95 \%$ confidence interval of fit-test NRA averaged across all the fit-test measurements of each subject's HPD was calculated. As shown in Table 7-1-1, twelve of seventeen subjects' confidence interval (71\%) does not include the average NRA value during work. That indicates that it is difficult to predict the NRA value during work from fit-test NRA measurements for an individual coal miner. This conclusion is similar to the prediction relationship for respirator performance between the protection factor achieved in fit-tests and that measured during a worker's actual work. Very few studies have found the prediction relationship for an individual respirator user. The actual work situation is complicated. Various unknown variables may be introduced during a worker's normal work such as environmental humidity, temperature, the worker's movements, refitting, and so on, which make it difficult to find a solid prediction relationship for a respirator user (Janssen and Bidwell, 2007).

However, the fit-test result of a HPD may be used to judge if a miner is able to achieve adequate noise protection of the HPD for him during his work, if we choose 10dBA noise reduction as the threshold of adequate protection. Berger (2000c) have found that $10-\mathrm{dBA}$ noise reduction is adequate for vast majority of noisy workplaces. In current study, every mine subject's fit-test NRA value exceeded $10 \mathrm{dBA}$. Correspondingly, the average NRA of each of mine subject's NRA during work also exceeded $10 \mathrm{dBA}$. It indicated that the fit-testing result of a HPD was still useful for a miner to choose an appropriate HPD for him to obtain adequate noise protection in his coal mining work.

\subsubsection{Result and discussion: comparing NRA variability for multiple fit-tests to work}

Each pair of standard deviations (SD) of fit-testing and work condition on each subject's NRA is shown in the Table 7-1-1. It may be useful to determine whether the $\mathrm{NR}_{A}$ from the work was more variable than the NRA from fit-testing. The average of SD 
in fit-test was $3.3 \mathrm{dBA}$, which was lower than that (average SD $=5.0 \mathrm{dBA}$ ) in work. Student's paired t-test analysis showed the SD in the work condition was significantly higher than that from fit-testing $(\mathrm{p}<0.0003)$, indicating the $\mathrm{NR}_{\mathrm{A}}$ in the work had more variability than that in the fit-testing.

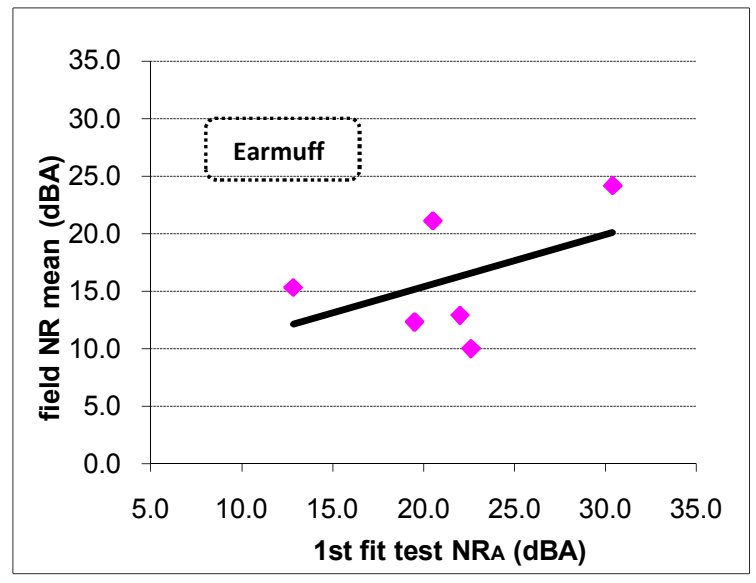

Figure 7-1-4. Compare earmuff NRA for $1^{\text {st }}$ fit-test and work

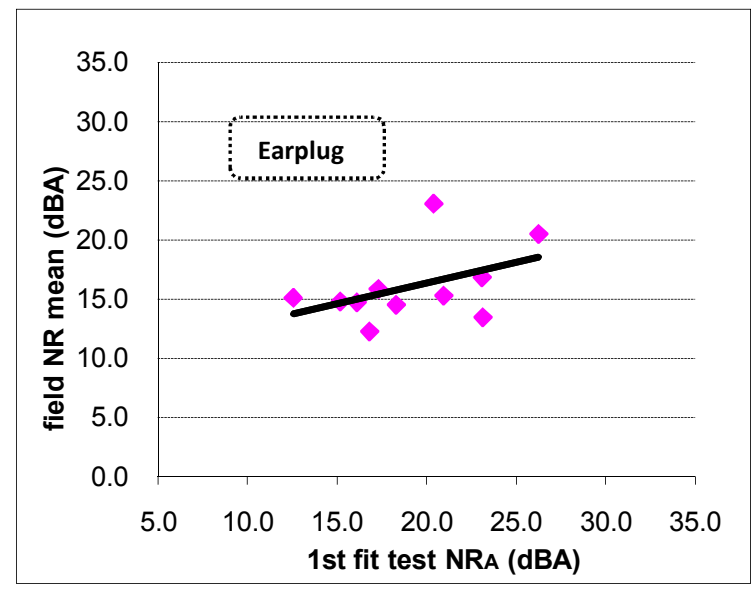

Figure 7-1- 5. Compare earplug NRA for $1^{\text {st }}$ fit-test and work

\subsubsection{Result and discussion: HPD (i.e., earplugs and earmuffs) prediction

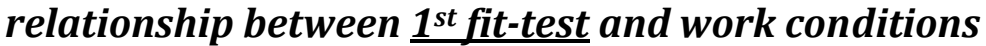

The results are shown in Figures 7-1-4 and 7-1-5 and Table 7-1-1. Linear regression analysis shows for both the earplug and the earmuff that the slope of the regression line was not significantly different from zero at the 5\% significance level, even after Subject 9 was removed. That indicates that there was no predicting relationship between the $1^{\text {st }}$ fittesting and the normal work.

\subsection{Conclusions}

For the earmuff alone, no prediction relationship was found between the multiple fittests and the normal work conditions. This conclusion was same as when the combination of the earmuff and the earplug were analyzed for the prediction relationship between multiple fit-tests and work. For the earplug alone, it appeared that the average NRA of multiple fit-testing was able to predict that from the normal work conditions with modest strength. Clearly, a higher fit-test NRA was suggestive of a high NRA during work.

The NRA in work condition ( $\mathrm{SD}_{\text {work average }}=5.0 \mathrm{dBA}$ ) has more variability than fittest $\left(\mathrm{SD}_{\text {fit-test average }}=3.3 \mathrm{dBA}\right)$. A single fit-test of the HPD is likely to be a highly unreliable indicator of actual noise protection for a coal miner during work. The mean of multiple fit-test measurements should be used to predict HPD protection during work. 


\section{BIBLIOGRAPHY}

Abel, S. M., and Rokas, D. (1986). The effect of wearing time on hearing protector attenuation. Journal of Otolaryngology, 15(5), 293-297.

American National Standards Institute (1974). American National Standard for the Measurement of Real-Ear Hearing Protectors and Physical Attenuation of Earmuffs. ANSIS3.19-1974, New York, NY.

American National Standards Institute (1995). Microphone-in-Real-Ear and Acoustic Test Fixture Methods for the Measurement of Insertion Loss of Circumaural Hearing Protection Devices. S12.42-1995, New York, NY.

Berger, E. H. (1980c). Hearing protector performance: How they work - and - what goes wrong in the real world. Sound and Vibration. 14(10), 14-17.

Berger, E. H. (1981b). Details of real world hearing protector performance as measured in the laboratory, Paper presented in Proceedings of Noise-Con 81, Poughkeepsie, NY.

Berger, E. H., and Kerivan, J. E. (1983). Influence of physiological noise and the occlusion effect on the measurement of real-ear attenuation at threshold. The Journal of the Acoustical Society of America, 74(1), 81-94.

Berger, E. H. (1986c). Review and tutorial: Methods of measuring the attenuation of hearing protection devices. The Journal of the Acoustical Society of America, 79(6), 175182.

Berger, E. H. (1993b). The naked truth about NRR. Aearo Corporation, Retrieved April 18, 2009 from http://www.e-a-r.com/hearingconservation/earlog_main.cfm.

Berger, E. H., Franks, JR., \& Lindgren, F. (1996). International review of field studies of hearing protector attenuation. Scientific basis of noise-induced hearing loss (pp. 361-77). New York, NY.

Berger, E. H. (1999a). EARLog \#21 - Hearing protector testing - Let's get real, Aearo Corporation, Retrieved March 18, 2009 from http://www.e-a-r.com/hearingconservation/earlog_main.cfm.

Berger, E. H. (2000c). Hearing protector devices. In E. H. Berger, L. H. Royster, J. D. Royster, D. P. Driscoll, and M. Layne (Eds.), Noise Manual, 5th Edition (pp. 379-455).

Fairfax, VA: American Hygiene Association.

Berger, E. H. (2005). Preferred methods for measuring hearing protector attenuation, Paper presented at the Proceedings of Inter-Noise 05, Noise Control Foundation, Poughkeepsie, NY. 
Berger, E. H. (2007a). Redefining the NRR: A change is coming. Aearo Corporation, Retrieved April 1, 2009 from

http://www.e-a-r.com/hearingconservation/earlog_main.cfm.

Berger, E. H. (2007). Introducing F-MIRE testing: Background and concepts. Retrieved February 3, 2009 from http://www.hearingreview.com/issues/articles/2007-03_08.asp.

Bobick, T. G., \& Giardino, D. A. (1994). The noise environment of the underground coal mine. Mine Safety and Health Administration. Retrieved March 14, 2009 from http://www.msha.gov/techsupp/pshtcweb/ptadirs/IR1034.pdf.

Burks, J. A. and Michael, K. L. (2003). A new best practice for hearing conservation: the Exposure Smart Protector (ESP), Paper presented at Proceedings of Noise-Con 2003, Washington, DC.

Casali, J. G., and Grenell, J. F. (1989). An exploratory study of moderate physical activity and selected design attribute effects on earmuff attenuation. American Industrial Hygiene Association Journal, 50 (9), 480-485.

Casali, J. G., and Park, M. Y. (1990). Attenuation of four hearing protectors under dynamic movement and different user fitting conditions. Human Factors, 32(1), 9-25.

Casali, J. G., Mauney, D. W., \& Burks, J. A. (1995). Physical versus psychophysical measurement of hearing protector attenuation - a.k.a. MIRE vs. REAT. Sound and Vibration, 29(7), 20-27.

Chung, D. Y., Hardie, R., and Gannon, R. P. (1983b). The Performance of circumaural hearing protectors by dosimetry. Journal of Occupational and Environmental Medicine, 15(9), 679-682.

Cluff, G. L. (1989). Insert-type hearing protector stability as a function of controlled jaw movement. American Industrial Hygiene Association Journal, 50(3), 147-151.

Durkt, G., Jr. (1993). Field evaluations of hearing protection devices at surface mining environments. Mine Safety and Health Administration. Retrieved April 8, 2009 from http://www.msha.gov/techsupp/pshtcweb/ptadirs/IR1213.pdf.

Earshen, J.J. (2000) Sound measurement: Instrumentation and noise descriptors. In E. H. Berger, L. H. Royster, J. D. Royster, D. P. Driscoll, and M. Layne (Eds.), Noise Manual, 5th Edition (pp. 41-100). Fairfax, VA: American Hygiene Association.

Environmental Protection Agency (1979). Noise labeling requirements for hearing Protectors, 40CFR, 44(190), Part 211, 56130- 56147.

Franks, J. R., \& Stephenson, M.R. (1996a), Preventing occupational hearing loss: A practical guide. National Institute for Occupational Safety and Health. Retrieved April 8, 2009 from http://www.cdc.gov/niosh/docs/96-110/. 
Franks, J. R. (1996b), Analysis of audiograms for a large cohort of noise-exposed miners. National Institute for Occupational Safety and Health. Retrieved April 8, 2009 from http://books.nap.edu/openbook.php?record_id=11721\&page=187.

Frank, T., Bise, C. J ., Michael, K. (2003). A hearing conservation program for coal miners. Occupational Health Safety, 72(6), 101-106.

Giardino, D. A., and Durkt, G., Jr. (1996). Evaluation of muff-type hearing protectors as used in a working environment. American Industrial Hygiene Association Journal, 57(3), 264-271.

Janssen, L., and Bidwell, J. (2007) Performance of a full facepiece, air-purifying respirator against lead aerosols in a workplace environment, Journal of Occupational and Environmental Hygiene, 4(2), 123 -128

Kasden, S. D., and D'Aniello, A. (1978). Changes in attenuation of hearing protectors during use, Paper presented in Proceedings of Noisexpo., Bay Village, OH.

Krutt, J., and Mazor, M. (1980). Attenuation changes during the use of mineral down and polymer foam insert-type hearing protectors. Audiology \& Hearing Education, 6(4), 1314.

Mauney, D. (1993), Psychophysical and physical techniques for measuring the attenuation of hearing protectors in the field, Paper presented at the Proceedings of the Human Factors and Ergonomics Society 37th Annual Meeting, New York, NY.

McBride, D. I. (2004). Noise-induced hearing loss and hearing conservation in mining. Occupational Medicine, 54(5), 290-296.

Mine Health and Safety Administration. (1999). Occupational Noise Exposure. 30 CFR PART 62.

Neitzel, R., \& Seixas, N. (2005). The effectiveness of hearing protection among construction workers. The Journal of Occupational and Environmental Hygiene, 2(4), 227-238.

Neitzel, R., Somers, S., \& Seixas, N. (2006). Variability of real-world hearing protector attenuation measurements. Annals of Occupational Hygiene, 2 (6), 1-13.

Occupational Safety and Health Administration. (1983). Occupational noise exposure: Hearing conservation amendment; final rule. 48 (46), 9738-9785.

Savich, M. U. (1982b). Practical problems of hearing protector use in Canadian mines, in Personal Hearing Protection in Industry, New York, NY, 403-425. 
Toivonen, M., Paakkonen, R., Savolainen, S., and Lehtomaki, K. (2002). Noise attenuation and proper insertion of earplugs into ear canals. The Journal of Occupational and Environmental Hygiene 46(6), 527-530.

Voix, J., and Laville, F. (2004). New method and device for customizing in situ a hearing protector. Canadian Acoustics. 32(3), 86-87. 